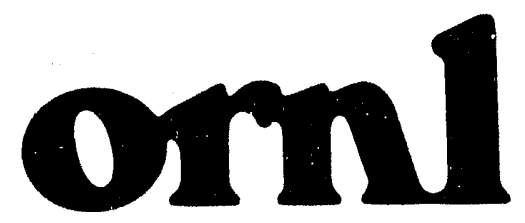

OAK RIDGE

NATIONAL

LABORATORY

MARTIN MARALETRA

\title{
Field Artillery Ammunition Processing System (FAAPS) Concept Evaluation Study
}

\author{
C. T. Kring \\ S. M. Babcock \\ D. C. Watkin \\ R. P. Oliver
}

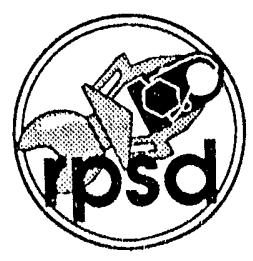


This report has ben reproduced directly from the best available copy.

Available to DOE and DOE contractors from the Office of Scientific and Techni. cal Information, P.O. Box 62, Oak Ridge. TN 37831 ; prices avallable from (615) 576-8401, FTS 626-8401.

This repont was prepared as an account of work sponsored by an agency of the United States Government. Neither the United States Government nor any agency thereof, nor any of their employees, makes any warranty, express or implied, or assumes any legal liability or responsibility for the accuracy. com. pleteness, or usefulness of any information, apparatus, product, or process dis. closed, or represents that its use would not tritringe privately owned rights. Reference herein to any specific commercial product. process, or service by trade name. trademark, manuiacturer, or otherwise, does not necessarily constitute or imply its endorsement, recommencation, or favoring by the United States Government or any agency inereot. The views and opinions of authors expressed herein do not necessarily state or reflect those of the United States Government or any agency thereot. 


\title{
Ammunition Logistics Program
}

\section{FIELD ARTILLERY AMMUNITION PROCESSING SYSTEM (FAAPS) CONCEPT EVALUATION STUDY}

\author{
C. T. Kring
}

S. M. Babcock

Robotics \& Process Systems Division

D. C. Watkin

R. P. Oliver

Engineering Division

Date Published-June 1992

\footnotetext{
Researsh sponsored by the
} Army's Project Manager-Ammunition Logistics under the Interagency Agreement 1892-A078-A1 between the Department of Energy and the Armament Research Development Engineering Center at the Picatinny Arsenal

Prepared by the OAK RIDGE NATIONAL LABORATORY

Oak Ridge, Tennessee 37831 managed by MARTIN MARIETTA ENERGY SYSTEMS, INC. for the DEPARTMENT OF ENERGY under contract DE-AC05-84OR21400 


\section{CONTENTS}

LIST OF FIGURES $\ldots \ldots \ldots \ldots \ldots \ldots \ldots \ldots \ldots \ldots \ldots \ldots \ldots$ vii

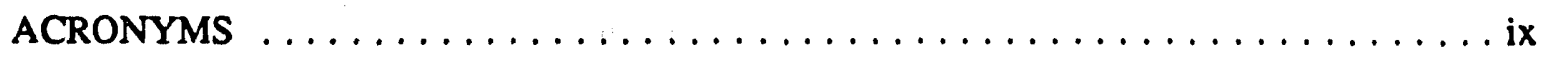

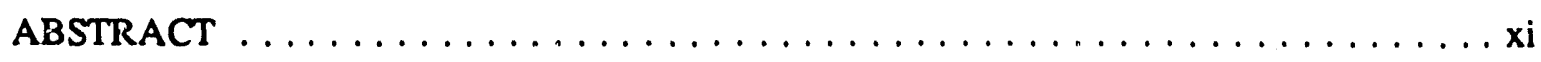

1. INTRODUCTION $\ldots \ldots \ldots \ldots \ldots \ldots \ldots \ldots \ldots \ldots \ldots \ldots \ldots \ldots \ldots$

2. PROJECT OBJECTIVE $\ldots \ldots \ldots \ldots \ldots \ldots \ldots \ldots \ldots \ldots \ldots \ldots$

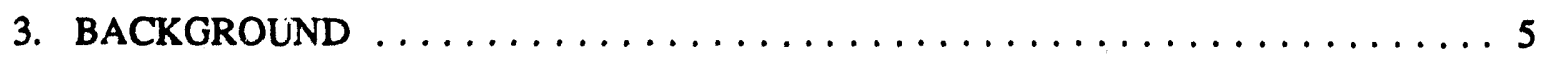

4. ASSUMPTIONS AND REQUIREMENTS $\ldots \ldots \ldots \ldots \ldots \ldots \ldots \ldots \ldots$

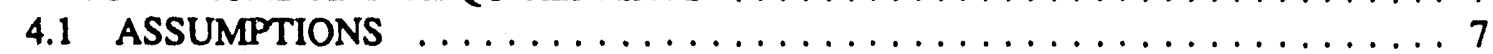

4.2 FUNCTIONAL REQUIREMENTS $\ldots \ldots \ldots \ldots \ldots \ldots \ldots \ldots \ldots \ldots$

4.3 DESIGN REQUIREMENTS $\ldots \ldots \ldots \ldots \ldots \ldots \ldots \ldots \ldots \ldots \ldots$

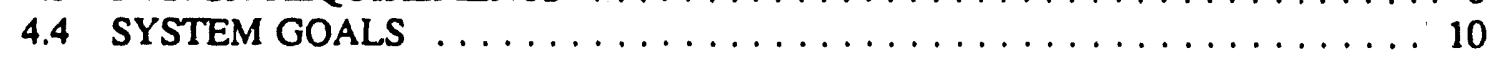

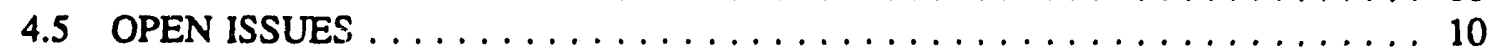

5. PROCESS DESCRIPTION $\ldots \ldots \ldots \ldots \ldots \ldots \ldots \ldots \ldots \ldots \ldots \ldots \ldots \ldots$

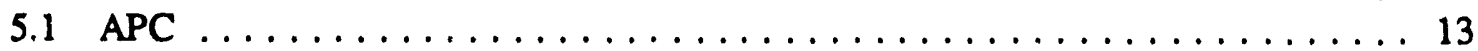

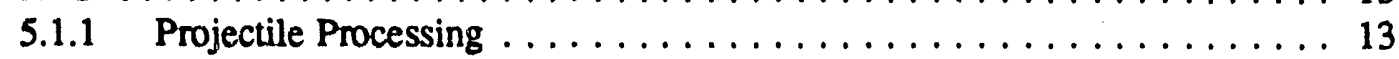

$5.1 .2 \quad$ Fuze Processing $\ldots \ldots \ldots \ldots \ldots \ldots \ldots \ldots \ldots \ldots \ldots \ldots$

5.1 .3 Propellent Processing $\ldots \ldots \ldots \ldots \ldots \ldots \ldots \ldots \ldots \ldots \ldots$

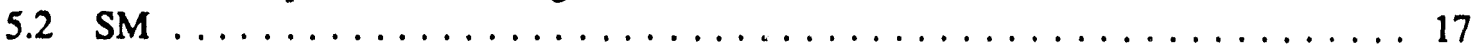

5.3 SYSTEM INTERFACES $\ldots \ldots \ldots \ldots \ldots \ldots \ldots \ldots \ldots \ldots \ldots \ldots$

6. TECHNOLOGY ASSESSMENT $\ldots \ldots \ldots \ldots \ldots \ldots \ldots \ldots \ldots \ldots \ldots \ldots \ldots \ldots$

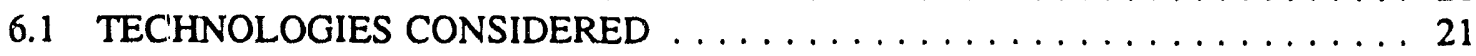

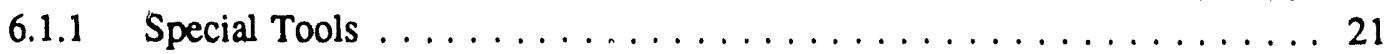

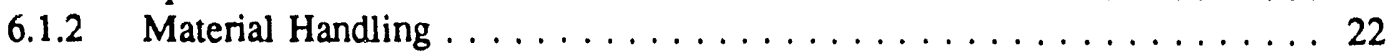

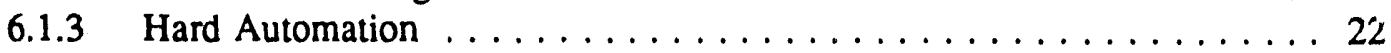

6.1 .4 Robotics ............................ 22

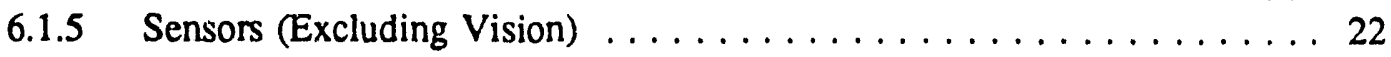

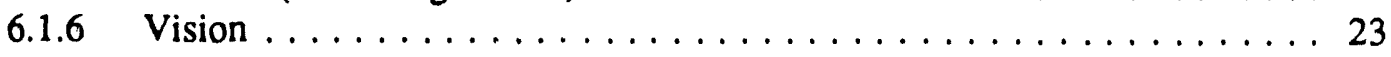

6.1 .7 Local Control Hardware $\ldots \ldots \ldots \ldots \ldots \ldots \ldots \ldots \ldots \ldots \ldots \ldots$

6.1 .8 Local Control Software . . . . . . . . . . . . . . . . 23

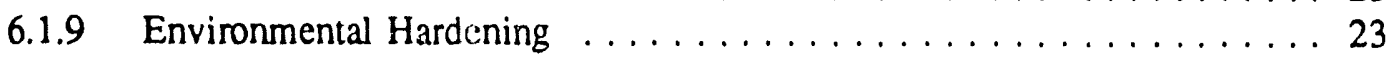


6.2 ASSESSMENT METHODOLOGY $\ldots \ldots \ldots \ldots \ldots \ldots \ldots \ldots \ldots$

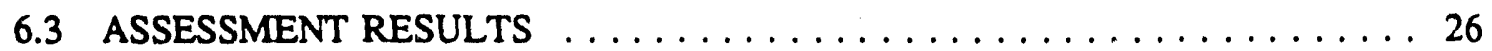

7. CONCEPT IDENTIFICATION ....................... 27

7.1 MANUAL OPERATIONS/MECHANICALLY ASSISTED MATERIAL

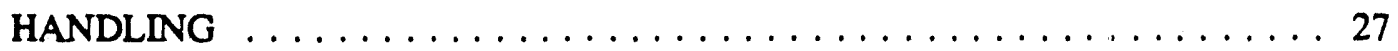

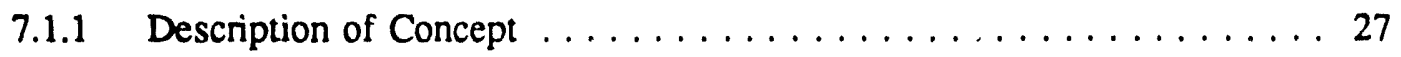

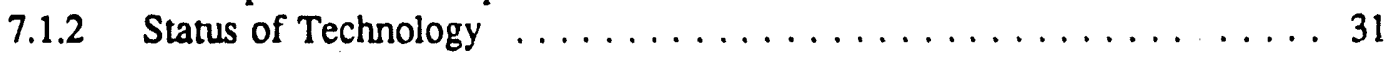

7.1 .3 Concept Costs .......................... 33

7.2 POWER-ASSISTED MANUAL OPERATIONS/POWERED MATERIAL

HANDLING $\ldots \ldots \ldots \ldots \ldots \ldots \ldots \ldots \ldots \ldots \ldots \ldots \ldots \ldots$

7.2.1 Description of Variations in the Concept ............... 33

7.2.2 Effect on Status of Technology $\ldots \ldots \ldots \ldots \ldots \ldots \ldots \ldots \ldots, \ldots \ldots$

7.2 .3 Concept Costs ........................... 34

7.3 MILAN AAP APPROACH-MINIMAL AUTOMATED OPERATIONS/

AUTOMATED MATERIAL HANDLING $\ldots \ldots \ldots \ldots \ldots \ldots \ldots, \ldots$

7.3.1 Description of Concept $\ldots \ldots \ldots \ldots \ldots \ldots \ldots \ldots \ldots \ldots \ldots \ldots \ldots$

7.3.2 Status of Technology $\ldots \ldots \ldots \ldots \ldots \ldots \ldots \ldots \ldots \ldots \ldots \ldots$

7.3.3 Concept Costs ........................... 40

7.4 FULLY AUTOMATED OPERATIONS/AUTOMATED MATERIAL

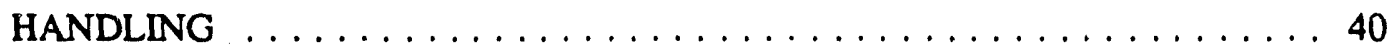

7.4.1 Description of Concept $\ldots \ldots \ldots \ldots \ldots \ldots \ldots \ldots \ldots \ldots, \ldots \ldots$

7.4.2 Status of Technology $\ldots \ldots \ldots \ldots \ldots \ldots \ldots \ldots \ldots, \ldots, \ldots$

7.4.3 Concept Costs ......................... 53

7.5 FULLY AUTOMATED OPERATIONS WITH SIMPLIFICATIONS DUE TO STANDARDIZATION OF PACKAGING $\ldots \ldots \ldots \ldots \ldots \ldots \ldots \ldots, 53$

7.5.1 Description of Variations in the Concept ................ 53

7.5.2 Effect on Status of Technology $\ldots \ldots \ldots \ldots \ldots \ldots \ldots \ldots \ldots . \ldots \ldots$

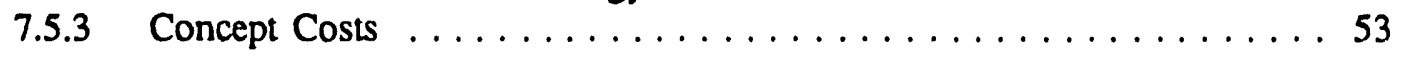

8. RECOMMENDED CONCEPT-AUTOMATED OPERATION WHERE

PRACTICAL/AUTOMATED MATERIAL HANDLING $\ldots \ldots \ldots \ldots \ldots \ldots, 55$

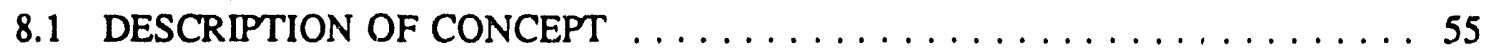

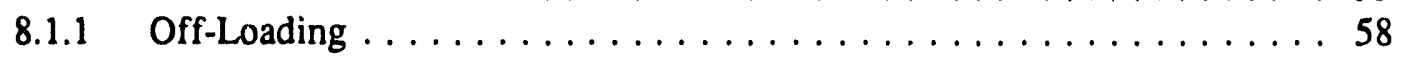

8.1.2 Projectile Removal from Pallet .................. 58

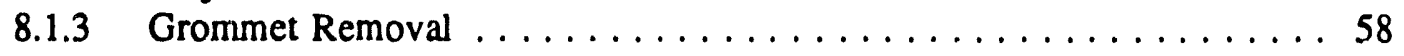

8.1 .4 Lifting Lug Removal $\ldots \ldots \ldots \ldots \ldots \ldots \ldots \ldots \ldots \ldots$

8.1.5 Supplemental Charge Removal . . . . . . . . . . . . . . 58

8.1 .6 Fuze Thread Chasing $\ldots \ldots \ldots \ldots \ldots \ldots \ldots \ldots \ldots \ldots \ldots \ldots$

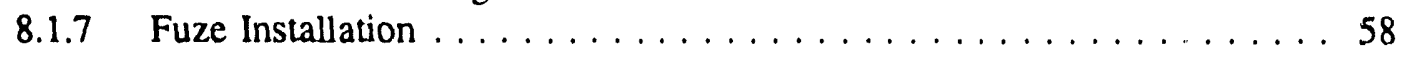

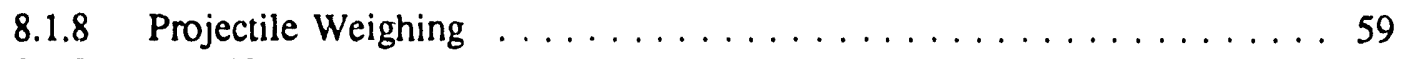

8.1 .9 Identification Marking $\ldots \ldots \ldots \ldots \ldots \ldots \ldots \ldots \ldots \ldots \ldots \ldots$

8.1 .10 Projectile Transfer to Storage $\ldots \ldots \ldots \ldots \ldots \ldots \ldots \ldots \ldots \ldots . \ldots \ldots 9$

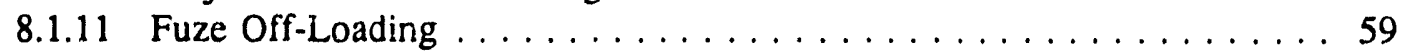

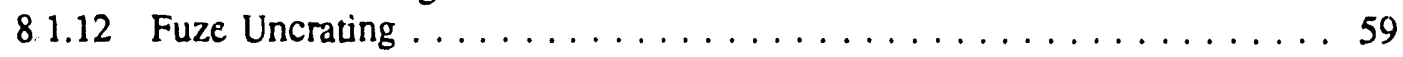

8.1 .13 Fuze Transfer and Sorting $\ldots \ldots \ldots \ldots \ldots \ldots \ldots \ldots \ldots \ldots$

8.1 .14 Projectile Primary Conveyor $\ldots \ldots \ldots \ldots \ldots \ldots \ldots \ldots \ldots \ldots$

8.1 .15 Inventory and Control System $\ldots \ldots \ldots \ldots \ldots \ldots \ldots \ldots \ldots \ldots$

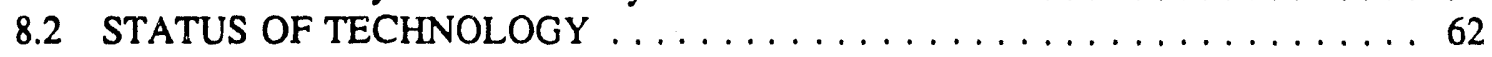

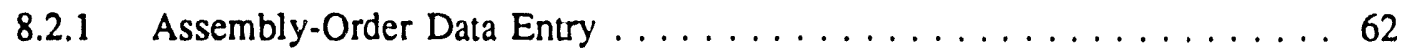


8.2.2 Projectile Transfer . . . . . . . . . . . . . . . . 62

8.2.3 Supplemental Charge Removal . . . . . . . . . . . . . 63

8.2.4 Thread Chasing . . . . . . . . . . . . . . . . . . . 63

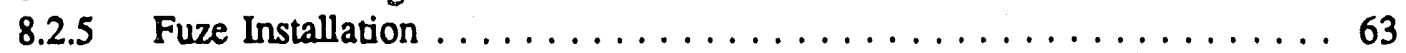

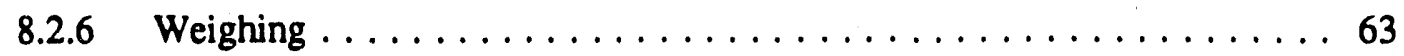

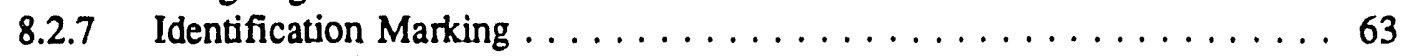

8.2.8 Conveyor Off-Loading Station $\ldots \ldots \ldots \ldots \ldots \ldots \ldots \ldots \ldots \ldots \ldots \ldots$

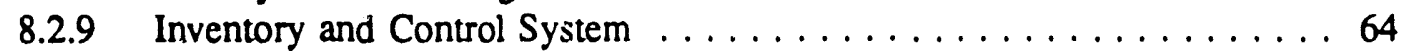

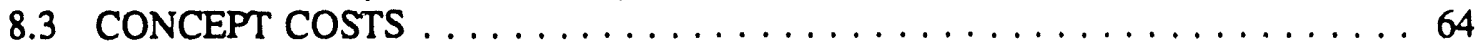

9. CONCLUSIONS AND FUTURE DIRECTION $\ldots \ldots \ldots \ldots \ldots \ldots \ldots \ldots \ldots \ldots$ APPENDIXES

APPENDIX A TECHNOLOGY ASSESSMENT WORKSHEETS . . . . . . . . . 69

APPENDIX B DETAILS OF POWER REQUIREMENT ESTIMATES . . . . . . 71

APPENDIX C DETAILS OF DEVELOPMENT AND CAPITAL COST

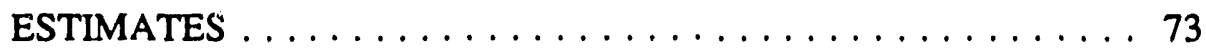

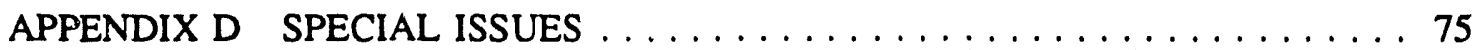




\section{LIST OF FIGURES}

Fig. 1. FAAPS concept evaluation project schedule $\ldots \ldots \ldots \ldots \ldots \ldots \ldots \ldots \ldots$

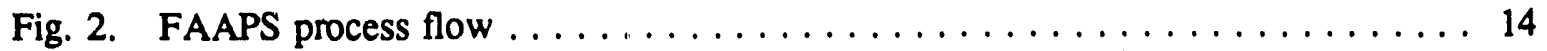

Fig. 3. FAAPS layout on the battlefield $\ldots \ldots \ldots \ldots \ldots \ldots \ldots \ldots \ldots \ldots$

Fig. 4. Possible $S M$ configuration $\ldots \ldots \ldots \ldots \ldots \ldots \ldots \ldots \ldots \ldots \ldots \ldots$

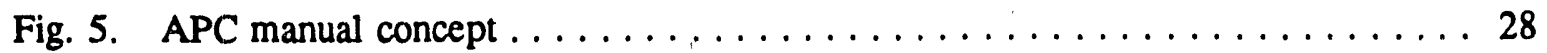

Fig. 6. APC manual concept control system block diagram $\ldots \ldots \ldots \ldots \ldots \ldots \ldots$

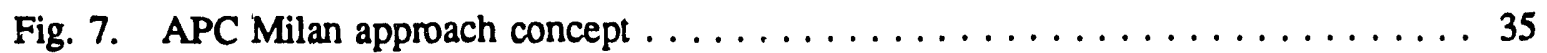

Fig. 8. APC Milan approach concept control system block diagram . . . . . . . . 39

Fig. 9. APC fully automated concept (existing packaging) $\ldots \ldots \ldots \ldots \ldots \ldots \ldots$

Fig. 10. APC fully automated concept control system block diagram $\ldots \ldots \ldots \ldots \ldots 47$

Fig. 11. APC fully automated concept (standardized packaging) $\ldots \ldots \ldots \ldots \ldots \ldots$

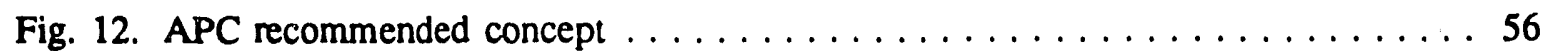

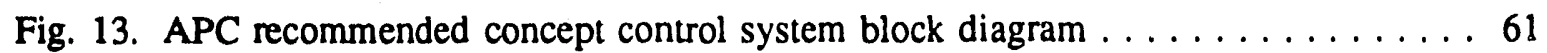

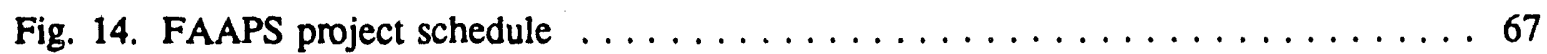

Fig. 15. APC prefuzed projectile processing concept $\ldots \ldots \ldots \ldots \ldots \ldots \ldots$ 


\section{ACRONYMS}

$\begin{array}{ll}\text { AAP } & \begin{array}{l}\text { Army Ammunition Plant } \\ \text { Advanced Field Artillery System } \\ \text { AFAS }\end{array} \\ \text { AFAS-C } & \text { Advanced Field Artillery System-Cannon } \\ \text { automatic identification technology } \\ \text { AIT } & \text { American National Standard Institute } \\ \text { ANSI } & \text { Ammunition Processing Center } \\ \text { APC } & \text { central processing unit } \\ \text { CPU } & \text { Field Artillery Ammunition Processing System } \\ \text { FAAPS } & \text { Future Armored Resupply Vehicle-Ammunition } \\ \text { FARV-A } & \text { International Standards Organization } \\ \text { ISO } & \text { liquid propellant } \\ \text { LP } & \text { material-handling equipment } \\ \text { MHE } & \text { nuclear, biological, and chemical } \\ \text { NBC } & \text { Oak Ridge National Laboratory } \\ \text { ORNL } & \text { programmable logic controller } \\ \text { PLC } & \text { palletized load system } \\ \text { PLS } & \text { Project Manager-Ammunition Logistics } \\ \text { PM-AMMOLOG } & \text { storage modules } \\ \text { SM } & \text { to be determined } \\ \text { TBD } & \end{array}$




\begin{abstract}
The Field Artillery Ammunition Processing System concept evaluation identifies and documents assumptions, requirements, and open issues associated with the project. A description of the process steps that must be completed is provided in this report. Technologies necessary to accomplish the required processing steps at varying degrees of automation are identified, and a systematic approach to assess their applicability was adopted. Altemative concepts representing the full range of the automation spectrum are presented and discussed along with projected processing rates, manpower requirements, developmental and capital costs, and electrical power requirements for each concept. An approach is recommended that represents the project team's evaluation of the most efficient utilization of technologies and resources to achieve identified requirements. It uses automatic processing of the ammunition except for off-loading and depalletizing of ammunition components and the removal of the grommet, where mechanized tools with manual interface are employed. This approach allows a phased implementation of technologies and resources that permits full automation of the system at a later date, if desired. A future direction is also identified that suggests a strategy which might be adopted for implementation of the selected approach.
\end{abstract}




\section{INTRODUCTION}

The Field Artillery Ammunition Processing System (FAAPS) concept evaluation study was prepared by the Oak Ridge National Laboratory's (ORNL) Robotics \& Process Systems Division at the request of the Project Manager-Ammunition Logistics (PM-AMMOLOG). The basis for the study was a review of existing Amy literature, visits to Army installations and commercial vendors, discussions and meetings with civilian and military subject matter experts, and attendance at industrial trade shows and exhibitions. A project team knowledgeable in the areas of mechanical design, instrumentation and controls, robotics, and automation used their expertise and this information to complete the study. The resulting concept evaluation study is intended to provide a basis from which the Project Manager can make informed decisions on future project direction. 


\section{PROJECT OBJECTIVE}

FAAPS is an initiative to introduce a palletized load system (PLS) that is transportable with an automated ammunition processing and storage system for use on the battlefield. System proponents have targeted a $20 \%$ increase in the ammunition processing rate over the current operation while simultaneously reducing the total number of assigned field artillery battalion personnel by 30 . The overall objective of the FAAPS Project is the development and demonstration of an improved process to accomplish these goals.

The initial phase of the FAAPS Project and the subject of this study is the FAAPS concept evaluation. The concept evaluation consists of (1) identifying assumptions and requirements, (2) documenting the process flow, (3) identifying and evaluating technologies available to accomplish the necessary ammunition processing and stcrage operations, and (4) presenting altemative concepts with associated costs, processing rates, and manpower requirements for accomplishing the operation. This study provides insight into the achievability of the desired objectives. Major project activities and the schedule for their accomplishments are shown in Fig. 1. 


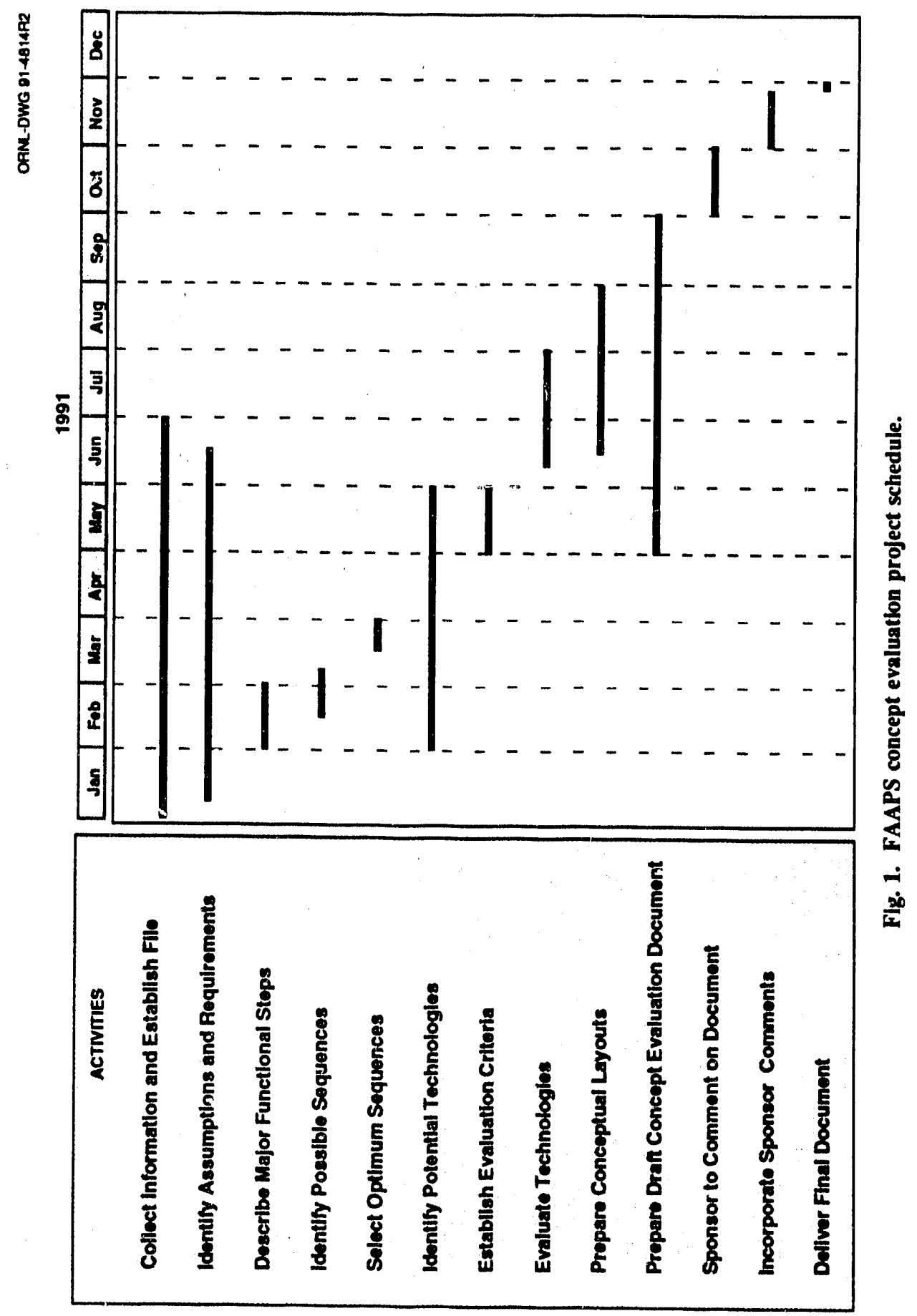




\section{BACKGROUND}

Corps-level logistics elements provide depot-packed munitions which must be manually broken down, properly configured, and loaded into the field artillery ammunition supply vehicle for delivery to the howitzer. This approach is time ccnsuining and manpower intensive. Field arillery units desire a more effective and efficient ammunition resupply system that can meet increased ammunition throughput requirements of the future howitzer.

The Adviancod Field Artillery System (AFAS) is the initiative to modemize the entire fire support system including the logistics system. The AFAS consists of the development of three interdependent subsystems: the future howitzer, known as the AFAS-Cannon (AFAS-C); the future resupply vehicle, known as the Future Amored Resupply Vehicle-Ammunition (FARV-A); and the transportable ammunition processing and sturage system (FAAPS). The development of the FARV-A is currently under way and will significantly strengthen the Army's capabilit;' to meet the desired rates. However, once the FARV-A is deployed, the ammunition logistics burden is moved rearward and is centered on the preparation of ammunition for uploading into the resupply vehicle. To enhance the total ammunition logistics chain, an automated method is required for preparation of ammunition for the uploading of the FARV-A. The ammunition components must be unpackaged, fuzed, weighed, identified, sorted, inventoried, retrieved, and delivered to the FARV-A. The overall objective of the FAAPS Project is the development and demonstration of an automated process to accomplish these operations. The system will consist of an Ammunition Processing Center (APC) and several storage modules (SMs) housed in transportable modules which are compatible with American Naticnal Standard Institute/Intemational Standards Organization (ANSI/ISO) container standards. These modules can be shipped by airplane and transported by PLS to locations near the field artillery units. 


\section{ASSUMPTIONS AND REQUIREMENTS}

To accomplish : useful and meaningful concept evaluation, it is imperative that assumptions utilized and requirements imposed be documented. It should be recognized that the assumptions and requirements are continually changing and that the information contained here represents a "snapshot in time" of collective opinions. As various Army organizations were solicited for input, each had slightly different-sometimes even significantly different-ideas of what FAAPS should or should not be like. Initially, a listing of all assumptions and requirements was made based on a review of available documentation. In a number of cases, conflicting information existed depending on the source. This information was provided to PM-AMMOLOG $\omega$ distribute to appropriate groups for comment. Although the discrepancies were gerierally resolved, the resulting information became very general in nature. Before proceeding beyond the concept evaluation stage, a more definitive and realistic set of requirements must be developed.

The assumptions listed in Sect. 4.1 represent those used for the concept evaluation study. The system requirements were divided into two groups-functional and design. Functional requirements represerit actual functions that the FAAPS must be capable of performing while design requirements represent attributes the system must possess. Functional and design requirements are listed in Sects. 4.2 and 4.3 respectively. Another group classified as system goals was also identified. System goals are considered desirable characteristics but are not mandatory for the success of the system. These are listed in Sect. 4.4. Lastly, an attempt was made to ir'entify issues that are currently unresolved but may have an impact on the final product. These issues are listed in Sect. 4.5.

It should be recognized that a valuable product of this exercise is the consolidation of the various assumptions, requirements, and goals that exist for the system because they, as a single source, will serve as the basis for any future work.

\subsection{ASSUMPTIONS}

1. The system transporting ammunition to FAAPS will be either PLS or M871/872 trailers. This will be determined after the location of FAAPS on the battlefield has been determined.

2. The ammunition transporting system will deliver the ammunition to within $10 \mathrm{ft}$ of the APC.

3. The ammunition transportation personnel will not assist in transferring the ammunition to FAAPS.

4. The FAAPS's crew chief will be provided orders specifying the projectile and fuze combination.

5. FAAPS will only handle either Unicharge or liquid propellant (LP). (No further consideration of propellant processing will be given until more definitive information is available.)

6. The projectiles can be handled and stored either vertically or horizontally. 
7. The APC will protect the processing equipment and workers from the weather but will not be sealed to protect from the nuclear, biological, and chemical (NBC) environment.

8. All projectiles within one pallet will be the same type. Pallets of similar projectiles will not necessarily be together on the ammunition transporting system.

9. The orientation of grommet latches on projectiles will be random.

10. Technology for the SM is conceptually similar to other automated artillery ammunition-handling technology currently under development by PM-AMMOLOG, and no further consideration will be given in the concept evaluation to its internal design. Interfaces for the APC to SM and the SM to EARV-A, AFAS-C, or another SM must be considered.

\subsection{FUNCTIONAL REQUIREMENTS}

In the following list of requirements, the term "system" is used in a general sense and does not imply that any particular operation must be performed by a machine.

1. The system will off-load munitions from all transport modes.

2. The system will remove projectiles from pallets and dispose of all dunnage. It must handle both wooden and metal projectile pallets.

3. The system will remove grommets from projectiles and dispose of the grommets. It must accommodate all existing grommet designs.

4. The system shall remove lifting lugs from projectiles and dispose of the lifting lugs.

5. The system will provide for the removal of supplemental charges and inspection of fuze wells. Provision to hold supplemental charges pending further processing or disposal must be made.

6. The system will unpackage and provide interim storage of fuzes.

7. The system will match/install fuzes to/in the projectiles.

8. The system will identify the weight of each fuzed projectile. This may be accomplished by weighing the fuzed projectile or weighing the unfuzed projectile and adding a known fuze weight to be determined (TBD).

9. The system will mark each projectile with a unique machine-readable code that identifies the projectile type and lot, fuze type and lot, and the weight of the fuzed projectile. The mark must be compatible with the AFAS-C and FARV-A ammunition identification system. Any of this information which is not already soldier readable on the projectile or fuze shall be marked in a soldier-readable format as well as machine-readable format.

\subsection{DESIGN REQUIREMENTS}

Each of the following requirements was established by the Army.

1. TBD thousand rounds/d are required for each artillery battalion.

2. The system will be set up and operational within $20 \mathrm{~min}$ of arrival at the desired location.

3. The system will be capable of ceasing operation and leaving the area in $15 \mathrm{~min}$.

4. The system will be capable of operating on a $10^{\circ}$ slope. 
5. All equipment will be housed in standard ANSI/ISO-compatible containers $(8 \times 8 \times 20 \mathrm{ft})$.

6. All modules (APC and SM) must meet all ANSI/ISO interface requirements unless other, more restrictive requirements exist.

7. The maximum weight of a fully loaded module is $33,000 \mathrm{lb}$ (without flatrack). If the flatrack is integrated into the module design, the weight is increased to $37,000 \mathrm{lb}$.

8. Projectiles will be weighed to an accuracy of $\pm 4 \mathrm{oz}$.

9. Projectile and fuze markings shall be machine readable, and those items not already marked in a soldier-readable format on the projectile and fuze shall be marked.

10. The system will be capable of operating from -46 to $49^{\circ} \mathrm{C}$.

11. The system will be capable of operation and repair by workers in Mission Oriented Protective Posture level 4 gear and arctic mittens.

12. The SM will be capable of uploading the FARV-A or AFAS-C at a rate of 12 rounds $/ \mathrm{min}$.

13. The system will operate from 0 to $100 \% \mathrm{RH}$ (environmental conditioning may be provided to accomplish this).

14. Both the APC and SM will be PLS transportable.

15. The FAAPS mist handle the following types of $155-\mathrm{mm}$ projectiles.

\begin{tabular}{lll}
\multicolumn{1}{c}{ Number } & \multicolumn{1}{c}{ Designator } & \multicolumn{1}{c}{ Type } \\
\hline M107 & HE & High-explosive \\
M110 & WP & Smoke, white phosphorous \\
M110A1 & WP & Smoke, white phosphorous \\
M110A2 & WP & Smoke, white phosphorous \\
M116A1 & Smoke, HC & Smoke \\
M116B1 & Smoke, HC & Smoke \\
M118A2 & Illuminating & Illumination \\
M485A2 & Illuminating & Illumination \\
M449A1 & HE & High-explosive, antipersonnel \\
submunition
\end{tabular}




\begin{tabular}{|c|c|c|}
\hline Number & Designator & Type \\
\hline M718/M741 & HE & $\begin{array}{l}\text { High-explosive projectile with } \\
\text { submunitioned antitank mines }\end{array}$ \\
\hline M718A1/M741A1 & HE & $\begin{array}{l}\text { High-explosive projectile with } \\
\text { submunitioned antitank mines }\end{array}$ \\
\hline M795 & HE & High-explosive \\
\hline M864 & HE, ER-DPICM & $\begin{array}{l}\text { High-explosive, dual-purpose } \\
\text { submunitioned }\end{array}$ \\
\hline XM898 SADARM & HE & $\begin{array}{l}\text { High-explosive, } \\
\text { submunitioned, base ejection }\end{array}$ \\
\hline M825A1 & Smoke, WP & Smoke, white phosphorous \\
\hline
\end{tabular}

\subsection{SYSTEM GOALS}

Each of the following system goals is followed by an $\mathbf{A}$ (Amy) or an $\mathbf{O}$ (ORNL) to indicate the origin.

1. All semiautomated or automated operations will be provided with at least one backup method of operation; $\mathbf{0}$.

2. The interfaces between modules will accommodate misalignment of TBD between adjacent modules; $\mathbf{0}$.

3. The changeout time for the SM will be less than $10 \mathrm{~min} ; \mathrm{A}$.

4. The changeout time for the ammunition supply vehicle will be less than $10 \mathrm{~min} ; \mathrm{A}$.

5. The APC will be capable of uploading the SM at a rate of 12 rounds $/ \mathrm{min} ; \mathbf{0}$.

6. The FAAPS will have a system reliability of $95 \%$ or greater, an operational availability of $85 \%$ or greater, and a mean time to repair of $1 \mathrm{~h}$ or less; $A$.

\subsection{OPEN ISSUES}

The following is a listing of open issues conceming FAAPS. These are issues that must be resolved prior to system design.

1. Propellant pallet/container configuration-design of the containers and pallets for the propellant should be finalized. For studying the PLS flatrack off-loading options, we have assumed the use of the 6- by 6-ft Unicharge pallet. This level of detail is adequate for studying the unloading options, but much more detail is needed for evaluating the propellant processing operations.

2. Propellant processing operations-most of this may fall out when the design of the containers is defined.

3. Misalignment between adjacent modules-since the different modules will be towed into position, it is reasonable to assume less than perfect alignmerit-but how much less? 
4. Buffer capacity - how much buffer capacity must be incorporated into the APC design? For example, must the system continue to operate while the SM is being changed out? Is this something that should be considered?

5. Dunnage-how should dunnage be disposed of?

6. Supplemental charges-jetailed storage and disposal requirements for supplemental charges should be identified.

7. Control system-the control system must address the sequencing of operations within FAAPS and maintain an associated data base of projectiles, fuzes, and propellant. FAAPS location on the battlefield will impact requirements for the control system. Should the control system aid in optimizing the production schedule?

8. Environmental control-are modules environmentally controlled? 


\section{PROCESS DESCRIPTION}

This section provides a description of the process steps that must be completed in FAAPS. No attempt is made to describe how the step is accomplished or whether it is a manual or automated operation. The FAAPS process flow is shown in Fig. 2. The process is separated into two major systems which are of primary concern in the FAAPS Project-the APC and the SM. The interfaces with the supply system, the disposal system, and the FARV-A will also be addressed. Figure 3 is a simplified rendering of FAAPS, indicating the modularity and utilization of the PLS.

\subsection{APC}

The APC will accomplish projectile, propellent, and fuze processing; it will interface with the ammunition supply vehicle, the SM, and a module for collecting and returning reusable pallets and disposing of dunnage. System modularity will be emphasized to facilitate rapid maintenance and operation in a confined space. The following section gives a brief description of the individual operations that will occur in the APC.

\subsubsection{Projectile Processing}

Projectile processing begins with off-loading the projectiles from the supply vehicle. The projectiles are then depalletized and, if on a wooden pallet, the pallets and bands are disposed of. If a metal pallet is used, the pallets are removed and stored. The protective grommet (three different variations) and the lifting lug are then removed and disposed of. Fuze installation is accomplished and consists of inspecting the threads in the fuze well, removing the supplemental charge (if required), and inserting and torquing the fuze. The projectile is then weighed; marked (to identify the type, lot, fuze type and lot, and weight; and transferred to the SM. Consideration is given to having projectiles already fuzed upon arrival at the APC; this study will also consider the impact to the overall system should this be done. The following paragraphs give a more detailed description of each of the projectile processing steps:

1. Off-loading of ammunition-ammunition will arrive in various configurations on the transporting system. A combat-configured load on a PLS flatrack is desirable but is TBD at this point. The exact form and quantity of propellant is unknown at this time since the selection of the type (Unicharge or LP) has not been made and no final packaging design exists for either. The projectile pallets weigh $\sim 875 \mathrm{lb}$ each, and the fuzes weigh an average of $60 \mathrm{lb} / \mathrm{box}$. The projectile pallets are designed for handling by fork-lift truck, hoist, or crane. The fuze wooden crates are equipped with two rope handles for manual lifting.

There will probably be different types of projectiles and fuzes in an ammunition load. Orders will specify what types of projectiles and fuzes to match. It is assumed that all projectiles 


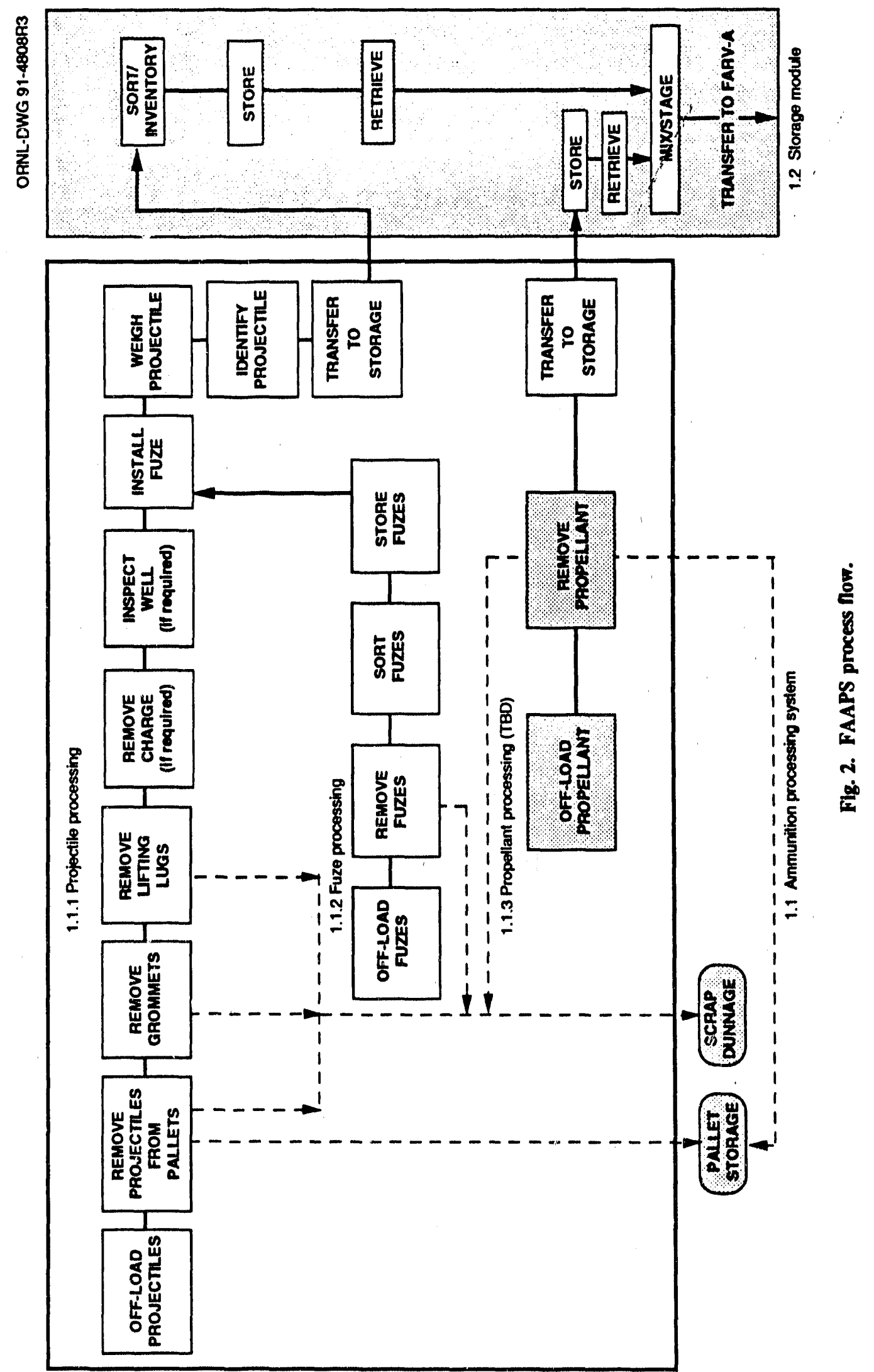


5
7
8
0
0
8
8
8
8

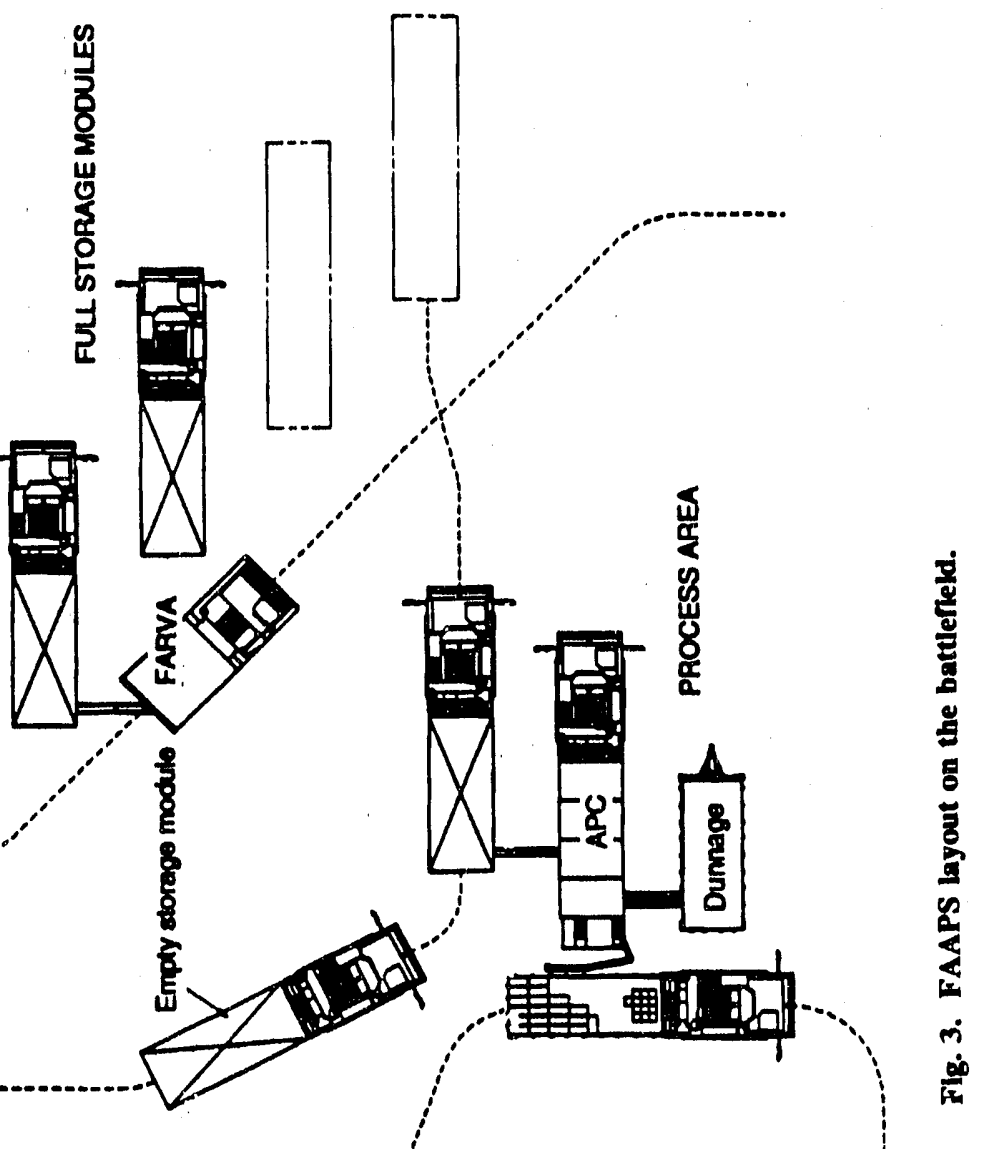

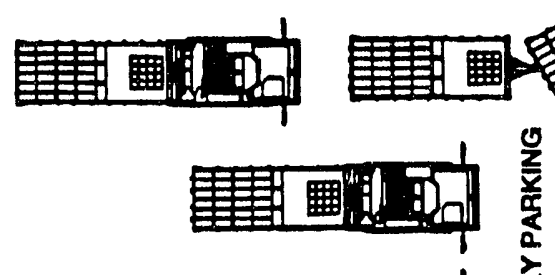

霜回霜正的的 
within one pallet will be of one type and that all the pallets of one projectile type may not be located together on the PLS flatrack (the same applies for fuzes). Basically, this means that off-loading the different types of fuzes and projectiles in an optimum order will not be possible.

It is also assumed that the different modules (each APC/SM is considered a module) constituting FAAPS will be leveled when initially set up. However, leveling of the ammunition transporting system does not appear practical. It should be assumed that the four comers of the flatrack are within TBD in. of the ideal position in all three directions. The material-handling equipment (MHE), used to off-load the ammunition, should accommodate these positional variances.

2. Removal of projectiles from pallets-the pallets to be used in the field will consist of a wooden base and top that are connected by three steel bands. To depalletize the projectiles, the three bands are cut and the top is removed in a vertical motion. The majority of the steel band is removed with the top (assuming the bands are cut near the bottom). After the top is removed, the projectiles can be removed individually or in multiples.

A new pallet design consists of a metal top and bottom connected by two vertical steel tierods nested between the projectiles. A latching mechanism in the top is released to remove the top for access to the projectiles. FAAPS must be capable of removing projectiles from either pallet design.

The most likely option for removing projectiles is by lifting them individually or in multiples using the lifting lugs on the upper end of each projectile or by gripping the projectiles on the sides. This latter option is complicated by the small clearance $(<1 \mathrm{in}$.) between adjacent projectiles. In addition, the projectiles must be gripped on their cylindrical sides and not on the ogive (the conical portion of projectile) to avoid damage to thin-wall sections.

3. Renioval of grommets-each projectile has a protective grommet about the rotating band -4 in. above the base of the projectile. These grommets will be removed during the processing operation. Two types of grommets are used on the majority of projectiles. Older projectiles (pre-1974) have grommets that are stretched over the rotating band so that the elasticity of the grommet holds it in place. This type can be removed by stretching and then moving the grommet axially over the projectile or by applying a force in the direction parallel to the axis of the shell that forces the rrommet over the rotating band. The newer grommets have a quick-release latch that must : opened to remove it. The orientation of the latch relative to the projectile must be assumed to be random. A third grommet design exists on the older projectiles that must also be handled.

4. Removal of lifting lug - each projectile has a lifting lug (eyebolt) located in the fuze well at the tip of the projectile. This lug must be removed prior to fuzing. The lugs will be removed by a simple unscrewing operation and discarded as waste. The projectiles may require securing to unscrew the lifting lug.

5. Removal of supplemental charge-removal of the supplemental charge in the fuze well is optional and will only be required when deep intrusion fuzes are used in certain types of projectiles. Removal requires gripping a short lanyard (recessed $\sim 2$ in. into the fuze well) and pulling out the charge.

6. Inspection of well-an inspection of the fuze well may be required to determine acceptability of the threads. 
7. Fuze installation-installation of the fuze requires selecting the appropriate fuze, aligning the threads, screwing in the fuze, and applying the proper torque.

8. Projectile weighing - after fuzing the projectile, the assembly will be weighed and must meet the tolerance requirements of $\pm 4 \mathrm{oz}$.

9. Projectile identification-the projectile will be marked in a location or locations TBD to identify the iype and lot of the projectile, the type and lot of the fuze, and its weight. The marking codes should be either soldier- or machine-readable.

10. Transfer to storage-the final step of projectile processing involves transferring the completed round to the SM. The projectile will be transferred horizontally, nose first.

\subsubsection{Fuze Processing}

Fuze processing consists of off-loading the boxes of fuzes from the supply vehicle, removing the fuzes from the boxes and ammunition cans, and sorting by type to match an apps sp:iaie projectile. The fuzes are packed in metal cans (eight fuzes in a can) with two cans placed in a single wooden box. The boxes, which are bound by wire, can be opened by bending three wire loops. The metal cans are the standard military, hinged M2A1 ammunition cans. The fuzes can be either nose up or nose down when the can is opened, depending on the fuze type. The wooden boxes and metal cans will be discarded as dunnage when the fuzes are removed.

\subsubsection{Propellent Processing}

The exact form of propellent is unknown at this time. Both Unicharge and LP are being considered, but the final selection has not been made and no final packaging design exists for either. The impacts of Unicharge and LP on the system design are also being considered. Should Unicharge be selected, it will have the greatest impact on the design of the APC since it must be unpackaged and processed through the system. LP should have little impact on the APC since it will probably interface directly from the ammunition supply trailer to the SM.

\section{$5.2 \mathrm{SM}$}

The SM will be a transportable module which can take fully prepared artillery ammunition to a forward staging area for transfer to the FARV-A. It will have the capability to maintain inventory control of all stored components and to retrieve ammunition as required to support field artillery units. Technology for the SM is conceptually similar to other technology currently under development; therefore, no further consideration will be given to its internal design. Figure 4 illustrates a possible configuration for the SM.

\subsection{SYSTEM INTERFACES}

System interfaces include both mechanical interfaces and communications between the elements of AFAS. System interface refers primarily to the means by which the APC interfaces to the SM, the ammunition supply trailers, and the dunnage trailers. The SM interface to the FARV-A will also be considered. The mechanical interface of the APC with the ammunition supply trailer is discussed in detail in the various approaches presented. The mechanical interface with the dunnage trailers uses standard commercial conveyors and is generally uncomplicated; it 


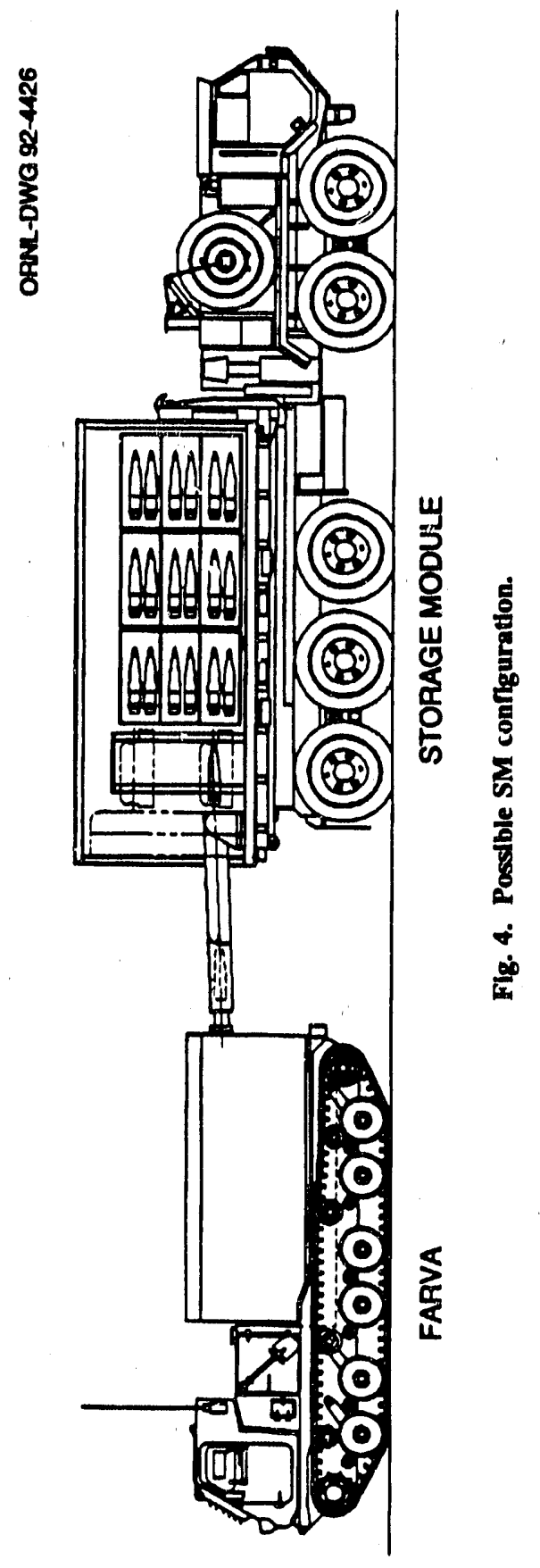


will not be considered further in this report. Since the SM must be capable of uploading both the FAKV-A or the AFAS-C, it can be assumed that the SM must have a transfer mechanism similar to the FARV-A and the technology can be considered generally the same. Because this system is being developed as part of another PM-AMMOLOG project, the SM transfer system will not be given any further consideration in the concept evaluation. Communication interfaces are required between the ammunition supply trailers and the APC (paper orders, possibly with associated machine-readable, two-dimensional, bar-coded data), between the APC and SMs, and between the FARV-A and the APC or SMs. Communication interfaces are briefly addressed in the discussions for the various concepts presented. 


\section{TECHNOLOGY ASSESSMENT}

The intent of the technology assessment is to look at the full spectrum of technologies either emerging or in development and assess their applicability to the automation of the various process steps just described. A systematic approach was adopted for the assessment because it tended to encourage participants to consider the technology assessment task more comprehensively. It highlights problem areas that might easily be overlooked by more traditional approaches. The approach also allowed the collective judgment of the participants in such a manner that the most logical and sound decisions evolved. The goal of the assessment was to identify the status of applicable technology and where the application of this technology provides the greatest payoff possible for the least investment of resources, whether in terms of personnel, money, or hardware. The first step of the assessment process was to select a project team consisting of individuals familiar with the various technologies associated with the automation of process equipment. Once established, the project team conducted a brainstorming session to generate a list of potential technologies. Team members then conducted literature surveys, attended industrial trade shows and exhibitions, and contacted commercial vendors to select the most applicable technologies to be considered. The selected technologies are described in Sect. 6.1, the assessment methodology is described in Sect. 6.2, and assessment results are described in Sect. 6.3.

\subsection{TECHNOLOGIES CONSIDERED}

The following technologies were considered in the assessment: (1) special tools, (2) material handling, (3) hard automation, (4) robotics, (5) sensors (except vision), (6) vision, and (7) local control hardware and software. In addition, environmental hardening was considered as a technology that covers the effect of the environmental extremes on each of the other technology areas. These areas are defined in the following sections.

\subsubsection{Special Tools}

Special tools refer to standand or custom hand- and machine-held tools or special end-effectors that provide the interface between the operator or machine and the part being made or modified (e.g., a specially designed gripper for picking up a part or inserting a part). Special tools also includes special fixtures used to hold parts in place accurately while they are being modified. For the APC, specific examples of special tools include (1) rigging for off-loading pallets, (2) specially designed assemblies for removing pallet tops, (3) specially designed hoist or impact wrench combinations for removing lifting lugs, (4) specially designed end-effectors for grasping supplemental charges to be removed, (5) specially designed end-effectors for grasping and torquing fuzes, (6) specially designed end-effectors for lifting projectile or fuze combinations for weighing, (7) specially designed label applicator fixtures, and (8) specially designed fixtures for picking up assembled projectiles for transfer to storage. 


\subsubsection{Miterial Handling}

Material handling refers to standard or custom mechanisms for moving parts from one location to another. From the standpoint of the individual steps of the process, the general conveyance system that moves parts from one process step module to the next is not considered except at the beginning, where pallets are unloaded and jib hoists are used to unload projectiles from pallets, and at the end of the processing line where "special" MHE transfers projectiles to the SM. Conveyors needed to remove scrap material (such as pallet tops, bands, bottoms, fuze boxes, and packing material) are included. Also included in this class are the conveyors which may be required to transfer unpacked fuzes to the fuze installation station.

\subsubsection{Hard Automation}

Hard automation refers to machines which are custom designed for a specific purpose and, generally, are not reprogrammable. This should not be confused with whether or not the machine has a custom interface to the part being processed; that area is covered in Sect. 6.1.1. Hard automation includes such devices as mechanisms for applying bar codes and man-readable text, even though these devices must be reprogrammable. (Label printers and applicators are assumed to fall in the class of hard automation unless otherwise specified.) Other examples of hard automation may include machines for automatic band cutting and pallet top and bottom removal, automatic fuze insertion, automatic weighing, and automatic transfer of projectiles from a main conveyor to an SM conveyor. Hard automation is typically controlled by limit switches and is minimally adaptable to variations in the material being processed.

\subsubsection{Robotics}

Robotics refers to reprogrammable, general-purpose machines which are intended for multiple applications or for flexibility and adaptability in a specific application. As in the case of hard automation, this should not be confused with whether or not the machine has a custom interface to the part being processed. The differences between hard automation and robotics are not well defined; this is emphasized by the fact that many pieces of equipment considered to be hard automation in the United States are considered to be robotics in Japan. For this assessment, robotics will be limited to devices which resemble common industrial robots or are pmogrammed in a manner similar to industrial robots. Although equipment used for automatic band cutting and pallet top and bottom removal, automatic fuze insertion, automatic weighing, and automatic transfer of projectiles from a main conveyor to an SM conveyor may be designed as hard automation, the use of robotic devices may be more practical due to the variations in the projectiles and fuzes. Selection of the proper fuze from a series of storage locations for automatic installation may be most effectively accomplished using robotics.

\subsubsection{Sensors (Excluding Vision)}

Sensors (excluding vision) refer to sensing devices such as position, velocity, and force transducers or load cells. They also include the devices commonly used in automation such as electromechanical limit switches and optoelectronic switches. Devices such as bar-code readers are also included. For this assessment, sensors typically included in commercial equipment or modified commercial equipment are not included. 


\subsubsection{Vision}

Vision refers to optical sensing in which image information is captured and interpreted to provide data (e.g., positioning information in the simplest form and character recognition in a more complex application). It is highly dependent on the specific task required. One example of an application within FAAPS that might utilize vision is locating the pallet bands for cutting and identifying the types of projectiles from information painted on the projectiles. Piujectile information may also be implied by the size and shape of the projectile that could be captured with a vision system. Another possible application is locating pallets on flatracks for automatic off-loading in a fully automated system. Vision can also be used to search for supplemental charges. In this assessment, vision includes that software which $\mathrm{m}$.st be developed for the specific application as well as the required hardware.

\subsubsection{Local Control Hardware}

Local control hardware refers to electronic and electrical hardware associated with a specific assembly module or step. It includes input and output electronics for computer-controlled equipment, power supplies, power amplifiers, and computer-based equipment which may be dedicated to a specific assembly module or step. Operator input devices such as simple and push-buttons switches and more complex, general-purpose display and input devices such as touch panels are included.

\subsubsection{Local Control Software}

Local control software refers to control system software which must be developed and is associated with a specific assembly module or step. While multiple steps may be controlled by a single computer-based controller [i.e., a programmable logic controller (PLC) or general-purpose microcomputer] software must be developed that is specific to individual steps and allows communication of information between control software for various steps or groups of steps. For the purpose of this assessment, local control software does not include vision software that is commercially available and generally designed to operate on specific electronic boards, modules, or custom software required to perform a specific vision task. While the general problem of inventory control is not considered as local control software, an interface between a general inventory control data base and the individual stations such as fuze installation, weighing, and identification may be required.

\subsubsection{Environmental Hardening}

Environmental hardening refers to efforts required to extend the storage and operating condition ranges of the equipment in general to include those conditions required for the FAAPS. Specific elements include temperature ranges, humidity ranges, and shock and vibration loading. It also includes efforts needed to improve reliability and maintainability, such as modularization, and efforts to accommodate NBC warfare conditions. In addition, battlefield electromagnetic interference conditions must be considered.

An open issue is the degree in which the FAAPS module(s) will be environmentally conditioned. Maintaining the environment within the module in a much narrower temperature range would allow a reasonable working environment for the soldiers operating or supervising operation of the equipment; however, it would be necessary to allow storage of the equipment in the full extreme conditions generally specified. 


\subsection{ASSESSMENT METHODOLOGY}

Having identified the required process steps and potentially applicable technologies, a systematic approach quantifying the technology required to accomplish each of the processing steps was desired. The methodology selected is described below.

First, an attempt was made to define the incremental steps representing increasing levels of automation. Each of the defined levels of automation (1 through 5) are described in Table 1. The levels of automation apply to the processing steps and the material handling aspects of the projectile processing. Level 1 represents a totally manual approach, levels 2 through 4 represent the application of incrementally increasing degrees of automation, and level 5 represents a totally automaied approach.

Table 1. Definition of levels of automation for ammunition processing concepts

\begin{tabular}{cl}
\hline Level & \multicolumn{1}{c}{ Description } \\
\hline 1 & $\begin{array}{l}\text { Manually accomplished processing step with the operator utilizing unpowered } \\
\text { tools }\end{array}$ \\
2 & Manually accomplished processing step using powered or special tools \\
3 & Semiautomated processing step with operator interaction required \\
4 & Automated processing step with operator oversight required \\
5 & Automated processing step with no operator required \\
\hline
\end{tabular}

Next, a worksheet was developed for each of the process steps. Table 2 represents a sample worksheet. The process step is identified at the top of the sheet, the technologies are listed down the left column, and the level of automation is listed across the top. A matrix then results for each process step that allows an indication of the status of a specific technology to achieve a particular level of automation.

Next, it was necessary to define the status of the technology. A numerical value was assigned from 0 to 16 to annotate the status of the technology required to achieve a specified level of automation. A brief definition of each of the values is given in Table 3. Zero indicates that the technology is not required, and 16 indicates that a significant development is necessary. A prugram-length column was added as a further description to provide an indication of the extensiveness of the effort. The time indicated is the time required to demonstrate an operational prototype to accomplish a particular step. It should be noted that the progression of assigned values $(0,1,2,4,8$, and 16$)$, from one step to the next, doubles each time since this closely corresponds to the effort; thus, costs are increased to achieve the next step.

Each project team member completed the worksheet matrix using subjective judgments of the appropriate tecinology status based on the descriptions given in this section. Each assessment participant also estimated processing rates and the number of personnel required for the specific step being considered for each automation level. 


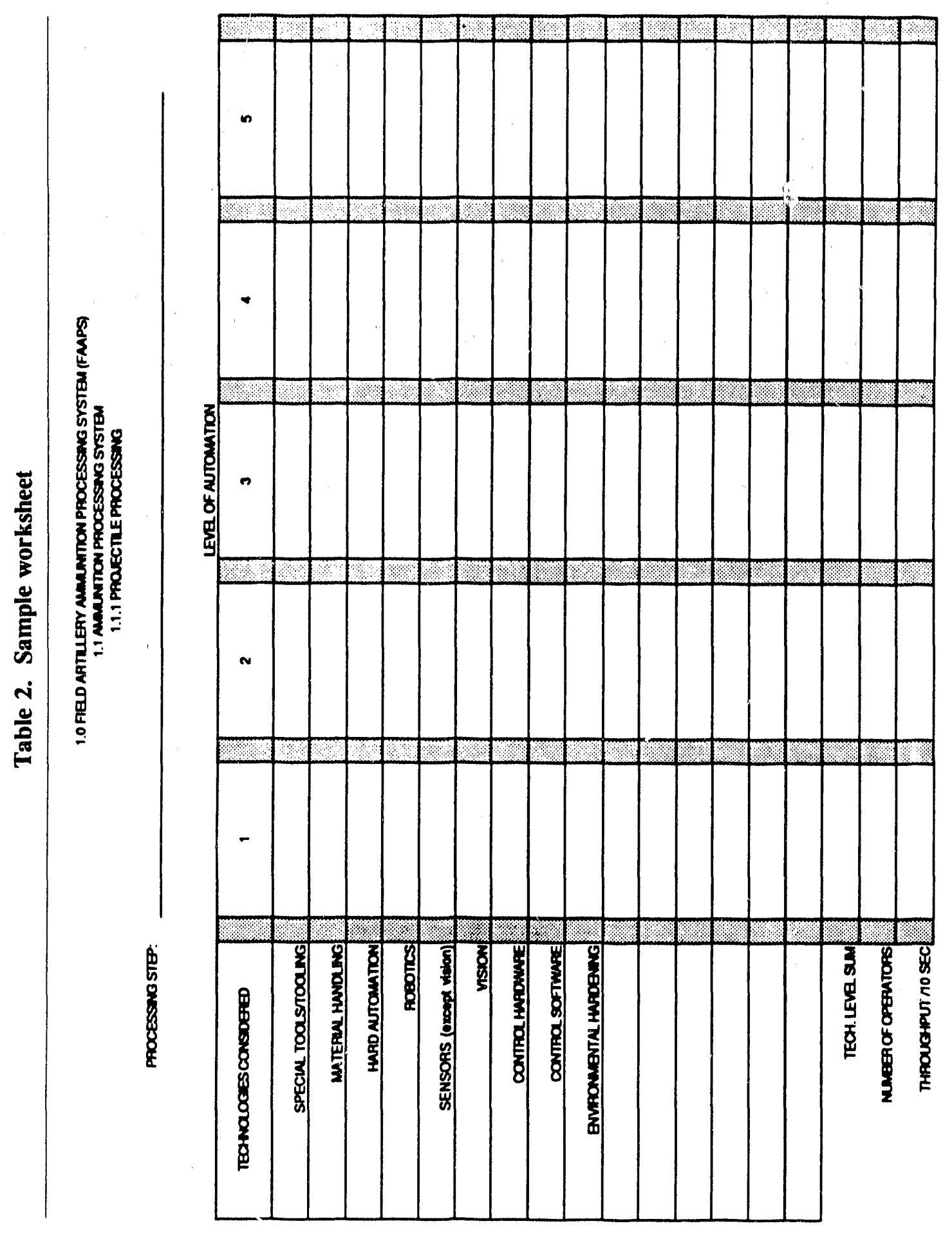


Table 3. Definition of technology status

\begin{tabular}{cll}
\hline Value & \multicolumn{1}{c}{ Description } & $\begin{array}{c}\text { Program length } \\
\text { (operational prototype } \\
\text { available) }\end{array}$ \\
\hline 0 & $\begin{array}{l}\text { Technology not applicable/required } \\
\text { Technology readily available } \\
\text { Commercial hardware suitable } \\
\text { System checkout testing only } \\
\text { Technology readily available } \\
\text { Commercial hardware could be modified } \\
\text { System checkout and verification testing }\end{array}$ & 0 \\
\hline 8 & $\begin{array}{l}\text { Technology readily available } \\
\text { Custom design required } \\
\text { Prototype testing required } \\
\text { Some development required } \\
\text { Custom design required } \\
\text { Limited proof-of-principle testing } \\
\text { Prototype testing } \\
\text { Significant development required } \\
\text { Custom design required } \\
\text { Proof-of-principle testing } \\
\text { Prototype testing }\end{array}$ & 6 to 12 months \\
\hline
\end{tabular}

\subsection{ASSESSMENT RESULTS}

The individual assessments completed by each team member wern table representing the collective opinion of the group. Appendix A worksheets. This information subsequently served as the basis $\mathrm{fc}$ technology integrated into the recommended concept. The technolo for each technology area, for the varying levels of automation desirer of the technology step from one level to the next. Processing rates cost estimates (presented later in this report) for each of the conc degree, based on information extracted from these tables. 


\section{CONCEPT IDENTIFICATION}

Five concepts have been identified for initial investigation. The first concept provides a lower boundary on the degree of automation and represents an unpowered, manual approach. A variation of this approach is considered next, which includes power assistance as appropriate. The third concept represents essentially the level of automation currently used at the Milan Army Ammunition Plant (AAP), which includes manual, semiautomated, and automated process steps. The fourth concept provides an upper boundary on the degree of automation-a fully automated system. A variation of this approach is considered last and is a simplification of the fully automated approach based on the standardization of ammunition packaging. Automatic identification technology (AIT) was considered in varying degrees of sophistication which corresponded to the degree of automation. It should be noted that it would be possible to use AIT to a much greater extent in the less automated concepts with some (possibly significant) improvement in throughput and elimination of possible errors occurring with manual entry of data. Each of these approaches will be described in detail in the following section. A concept summary listing each approach, along with the number of personnel required, projected processing rates, power required, and projected costs, is included in Table 4 (see Sect. 9).

\subsection{MANUAL OPERATIONS/MECHANICALLY ASSISTED MATERIAL HANDLING}

The first concept represents manual performance of the basic steps of the assembly process; however, it incorporates mechanically assisted material handling. The following paragraphs describe the concept and the status of the technology. A plan view of the concept is shown in Fig. 5.

\subsubsection{Description of Concept}

The APC manager will receive projectile and fuze assembly orders with each shipment. These orders will specify the combinations of projectiles and fuzes that are to be produced. The simplest approach to accomplishing the assembly requirements is for the APC manager to transfer the paper order to the supplemental charge remover and the fuze installer.

The system will use a custom-designed, three-link, manually operated jib hoist to remove pallets with projectiles and crates of fuzes from the ammunition transporting system to the tailgate of the APC. If not on pallets, crates of fuzes will be manually moved to the APC. A conveyor will transfer the pallets from the set-down point on the tailgate of the APC and provide some surge capacity. The bands will be manually cut and the pallet top manually removed. A manual monorail hoist will be used to transfer the projectiles, one at a time, from the pallet to the carousel. During the transfer of the projectile from the pallet to the carousel, the projectile will be rotated so that the identification markings are visible for future reference. The operator will use an unpowered conveyor with gravity assist to remove the pallet top and bottom from the APC to a dunnage bin or truck. 

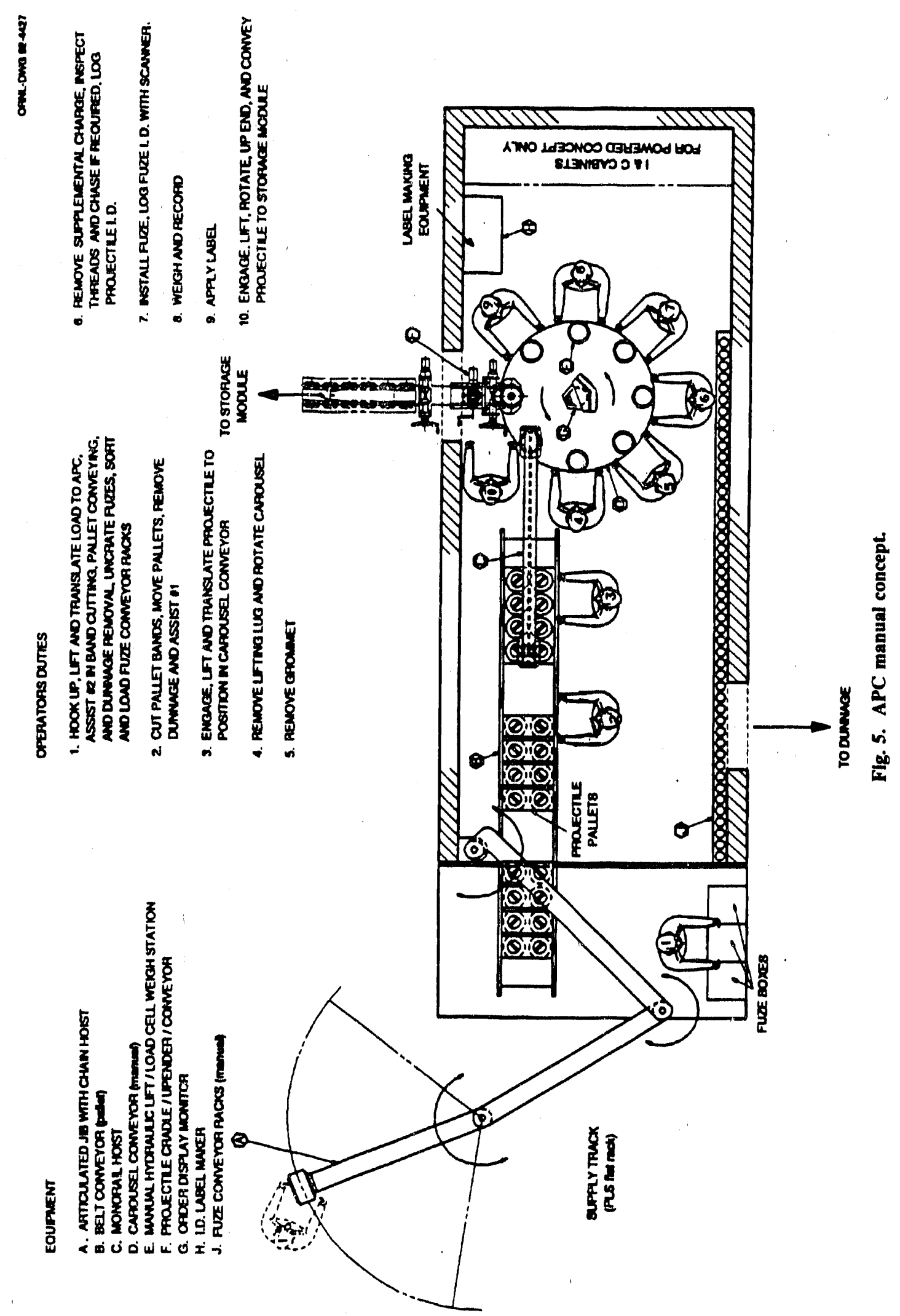
Crates of fuzes will be manually moved along a conveyor to the point where the fuze crate top is manually removed and the metal fuze boxes will be removed from the crate. The metal fuze boxes will be manually opened and the fuzes removed. The operator will place the fuzes on one of several conveyors, based on fuze type, and dispose of the dunnage using the same conveyor system as used for the projectile pallets.

The carousel is manually indexed, moving the projectile from station to station for performance of the various process steps. The first step performed on the carousel will be the manual removal of the lifting lug. At the next carousel station, the grommet will be manually removed by releasing the latch in the case of plastic grommets or by cutting in the other cases. Lifting lugs and grommets will be placed in boxes for periodic removal from the APC to a dunnage bin or truck.

The sequence of assembly of projectiles and fuzes will be constrained by the order in which the projectiles are off-loaded. The supplemental charge remover will read the identification on the projectile and, from the assembly orders, determine if a supplemental charge must be removed. The remover will also enter the carousel position, the type of projectile, the projectile lot number, and the type of fuze to be instilled into a computer terminal or custom operator interface and check off the projectile and fuze assembly on the paper order. The fuze installer will enter the carousel position, install a particular fuze type for the projectile type and lot (as prompted by the inventory and control system), install the appropriate fuze type, check off the projectile and fuze assembly on his copy of the paper order, and record the fuze lot. This provides a degree of redundancy in the assembly and identification process; however, this method could be improved by automatic identification of the carousel position by a bar code, radio frequency tag, or some other method. Given the limited number of carousel positions, a simple through-beam optical sensor approach may be suitable.

The weigh station operator will enter the carousel position into a custom operator interface (or it will be read automatically), thus allowing the weight of the projectile to be automatically added to the appropriate data set. A bar code and soldier-readable label is automatically printed and presented to the carousel off-loading and labeling operator, who manually applies the label to the projectile.

At the last position on the carousel, a custom-designed mechanical device will lower the projectile to a horizontal conveyor for transfer to the SM.

In addition to maintaining the data for marking, the computer system will maintain a data base of the production for comparison with the paper order. Adding the SM number to the data associated with a particular projectile and fuze allows a centralized data base of the contents of the various SMs for use in directing the FARV-As to the appropriate SMs to acquire the desired loads. This information is retrievable from the APC manager's operator interface.

Based on the assessment results, this concept requires 10 people to process 400 rounds of ammunition per shift of operation. The total power requirement is estimated to be $2 \mathrm{~kW}$. Details of power requirement estimates are included in Appendix B.

The following paragraphs describe in more detail the mechanical aspects of the various process steps and the inventory and control system necessary to conduct operations already discussed.

\subsubsection{Off-loading}

A custom-designed jib hoist with three articu'ating horizontal arms, similar to a "Conco" articulated crane industrial manipulator is required ine this operation. This 3000 -lb-capacity jib hoist (chain-operated) will cover an 18-ft radius including the area inside the APC. This feature will also allow the jib hoist to be stored inside and to service equipment within the APC. 


\subsubsection{Projectile removal from pallet}

An unpowered standard belt conveyor running from the APC tailgate to near the carousel conveyor will provide assistance and guidance in manually positioning three to four pallets. Hand cutters similar to sheet metal shears, will be used to cut the metal pallet bands, and a hand wrench or bar will be used to release the metal pallet top from its bottom. Cut bands will be coiled and crimped using a custom hand tool, and dunnage will be placed on an unpowered standard conveyor. A standard monorail hoist (chain-operated) will transfer projectiles from the pallet bottom to the carousel conveyor.

\subsubsection{Grommet removal}

Standard hand tools will be used to cut the grommet or to release the latch.

\subsubsection{Lifting lug removal}

A standard hand wrench or bar with, perhaps, the aid of a mallet will be sufficient to remove the lifting lugs.

\subsubsection{Supplemental charge removal and fuze thread inspection}

The supplemental charges will be removed manually. Visual inspection of the fuze threads will suffice, but a manual tap wrench will be used if necessary. The paper assembly orders will dictate whether or not the supplemental charge should be removed.

\subsubsection{Fuze installation}

A standard fuze wrench will be used to tighten the fuze after starting the process by hand. An order display monitor will indicate the type fuze to install.

\subsubsection{Projectile weighing}

A standard, manually operated hydraulic jack located directly under the weigh station with a load cell will lift the projectile with its holder cup $\sim 1 / 4$ in. The projectile holder cup handle will be mounted in the carousel conveyor floor in a ball bushing extending $-1 / 2$ in. below the conveyor floor. A foot-operated pump will be required to operate the jack.

\subsubsection{Identification marking}

An automatic label maker will print the identification labels based on information received from previous operations, and the station operator will apply the label directly to the projectile.

\subsubsection{Projectile transfer to storage}

A custom projectile mechanism designed to lift, upend, and convey the projectile to the SM will be operated manually with hand controls. The mechanism consists of (1) a cradie with two rows of rubber-tired rollers to first contact the projectile when rotated to its upright position, (2) a vise-like pair of jaws to grip and lift the projectile out of its holder cup, and (3) a pivoting frame to upend or rotate the projectile from vertical to horizontal or slightly beyond to allow it to roll by gravity on the cradle rollers out to the SM. 


\subsubsection{Projectile primary conveyor}

This conveyor consists of a manually operated carousel with eight equally spaced receptacles for projectile holder cups.

\subsubsection{Inventory and control system}

The inventory and control system consists of a single computer system, a minimum number of sensors, and several operator interfaces. The inventory and control system will assemble the data (based on manual data entry) necessary for labeling the projectile and fuze combination and interface directly with the label printer. The fuze installer will be prompted by the inventory and control system to select the correct fuze type based on input from the supplemental charge remover. A data base of projectile and fuze combinations for each SM will be maintained for communication with the FARV-As that are arriving for reloading. A block diagram of the inventory and control system for this concept is shown in Fig. 6.

\subsubsection{Status of Technology}

The technology required for this concept is essentially available commercially, and very little development is required. Material handling will be accomplished by commercial- or customdesigned, manual conveying and lifting systems utilizing commercially available components such as chain hoists and hydraulic lifts. Areas requiring special consideration are weighing, identification, and the inventory and control system.

\subsubsection{Weighing}

The concept includes the use of a load cell incorporated in a lifting mechanism at the weigh station. While the required accuracy of the load cell is commercially available for industrial temperature ranges, custom load cells may be necessary for the extended military temperature ranges required if the APC is not environmentally controlled. Provisions will be required for calibration of the load cells, possibly by utilizing known standard projectiles.

\subsubsection{Identification marking}

Several types of label printing methods are used in industry including thermal transfer printing, thermal printing, ink-jet printing, and laser printing. In addition, radio frequency identification and laser engraving methods are used in specific applications. Thermal transfer printing is the highest quality approach used in industry today. While laser engraving and ink-jet printing would eliminate the need for handling labels, significant development efforts are expected to allow fielding such systems. Military-hardened printers are available which would likely be suitable for producing labels. Development would probably not be required to identify a suitable label material and adhesive. Altemate marking approaches, such as laser engraving, are being investigated.

A second question related to labeling is whether or not a compressed data symbology is required. It appears that with the minimal amount of information required for this specific application, a stacked bar code such as Code 49 or $16 \mathrm{~K}$, could be acceptable. One disadvantage of such an approach is the lack of redundancy incorporated in the newer two-dimensional bar codes. Two-dimensional bar codes are becoming commercially available; it is assumed that a decision to use this technology would not significantly affect the concept. 


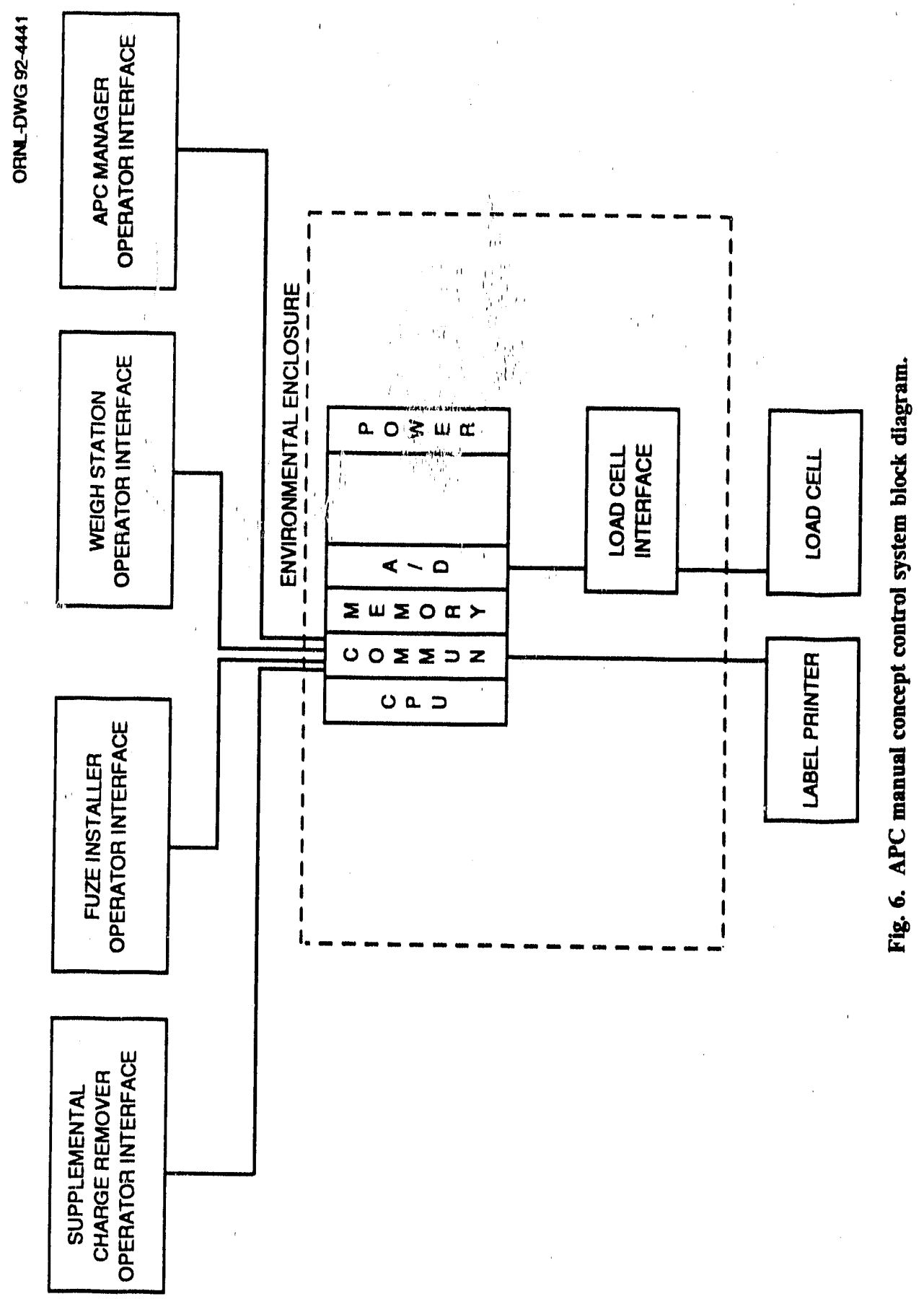


A third question related to identification is whether or not there would be a significant advantage to providing data symbols that can be read without rotating the projectile. Multiple symbols may satisfy the need. Altemately, a continuous bar code applied around the projectile may satisfy such a need. For the purpose of this assessment, it is assumed that multiple labels may be used if required.

\subsubsection{Inventory and control system}

Two approaches are available for selection of the computer system to be used for inventory control and marking. Military-hardened computer systems are available. One alternative may be to use industrially hardened computer systerns mounted in environmental enclosures that would maintain the required operating temperature ranges and vibration isolation. Extended storage temperature ranges may be a problem for industrial computer systems. Military-hardened, touch-panel displays are available, if required, for data entry; however, simpler hard-wired, operator interfaces will be considered where appropriate. Improvements to the inventory and control system could be made in the manual concept by entering the assembly requirements as discussed in the more automated concepts.

\subsubsection{Concept Costs}

The development costs for this concept are estimated to be $\$ 1,925,000$, and the capital costs of this concept are TBD (capital costs will be estimated after concept selection). A discussion of the basis for the cost estimates for each of the concepts is presented in Appendix C.

\subsection{POWER-ASSISTED MANUAL OPERATIONS/POWERED MATERIAL HANDLING}

A second concept presented is essentially the same as that described in Sect. 7.1, except that power assistance is provided to increase the processing rate and/or relieve the operator of the need to repetitively manually handle heavy objects.

\subsubsection{Description of Variations in the Concept}

All material-handling operations are powered; however, they are manually controlled in this variation of the concept described in Sect. 7.1. These include an off-loading jib hoist, a projectile pallet conveyor, a jib hoist for transfer of the projectile to the carousel, a carousel for indexing, a carousel off-loading mechanism, and a conveyor for transfer of the projectile to the SM.

In addition to powering the MHE, power tools will be added for band cutting, lifting eye removal, grommet removal, and fuze torquing. A powered lifting mechanism will be included in the weigh station.

It is not anticipated that these changes from the manual concept, described in Sect. 7.1, will significantly impact the equipment layout, as shown in Fig. 5, or the inventory and control system, as shown in Fig. 6.

Based on the assessment results, it is estimated that the concept will require 9 people to process 700 rounds of ammunition per shift of operation. The total power requirement is estimated to be $8 \mathrm{~kW}$. Details of power requirement estimates are included in Appendix B. 


\subsubsection{Effect on Status of Technology}

In general, the addition of power to material hardiling and the addition of power tools will have very little effect on the status of the technolog, in each case, the technology is available; however, in some cases, custom design will be required.

\subsubsection{Concept Costs}

The development costs for this concept are estimated to be $\$ 2,220,000$, and the capital costs are TBD (capital costs will be estimated after concept selection). A discussion of the basis for the cost estimates for each of the concepts is presented in Appendix C.

\subsection{MILAN AAP APPROACH-MINIMAL AUTOMATED OPERATIONS/AUTOMATED MATERIAL HANDLING}

The third approach is one similar to that witnessed on a project team visit to Milan AAP. The $155-\mathrm{mm}$ projectile assembly line has been in operation for many years and appears to be very efficient. The Milan AAP approach described in the following paragraphs includes minimal automated operations but automated material handling. This approach (essentially the reverse of the end of the Milan AAP $155-\mathrm{mm}$ assembly line) involves a combination of various levels of automation for the different assembly steps-from manual to fully automated. A plan view of the concept is shown in Fig. 7.

\subsubsection{Description of Concept}

The APC manager will receive the projectile and fuze assembly orders with each shipment. These orders will specify the combinations of projectiles and fuzes to be produced. The fuze and projectile orders will be entered into the inventory and control system.

The off-loading operation will utilize a powered monorail hoist, which is pendant operated and not connected to the inventory and control system, to move the pallets from the ammunition transportation system to the tailgate of the APC. Transfer of the pallets along the first powered conveyor will be initiated by the operator who cuts the bands and removes the pallets. The conveyor will be stopped by mechanical or optical limit switches. Bands on wooden pallets will be cut using a powered hand tool, and the top will be manually removed. For metal pallets, latches will be manually released or retaining nuts will be removed with an impact wrench, allowing manual top removal. This step in the operation will be locally controlled and not connected to the inventory and control system.

Pallets of crates of fuzes will also be unloaded using the off-loading jib hoist, bands will be cut, and crates will be removed from the pallets. If not on pallets, the crates of fuzes will be manually off-loaded. The crates will move along a powered conveyor to the point at which the fuze crate top is manually removed and the metal fuze boxes are removed from the crate. The metal fuze boxes will be manually opened and the fuzes removed. The operator will place the fuzes on one of several conveyors, based on fuze type, and dispose of the dunnage using the same conveyor system as used for the projectile pallets.

A manually operated, powered jib hoist will be utilized to lift the projectile out of the pallet and transfer the projectile to the conveyor system. The projectile label will be oriented outward.

At the first station, the lifting lug will be automatically removed. If cutting is required, the grommet will be manually removed at the next station using powered tools.

Supplemental charge removal and thread inspection are manual operations. The supplemental charge remover will manually enter the projectile type and lot number into the inventory and 


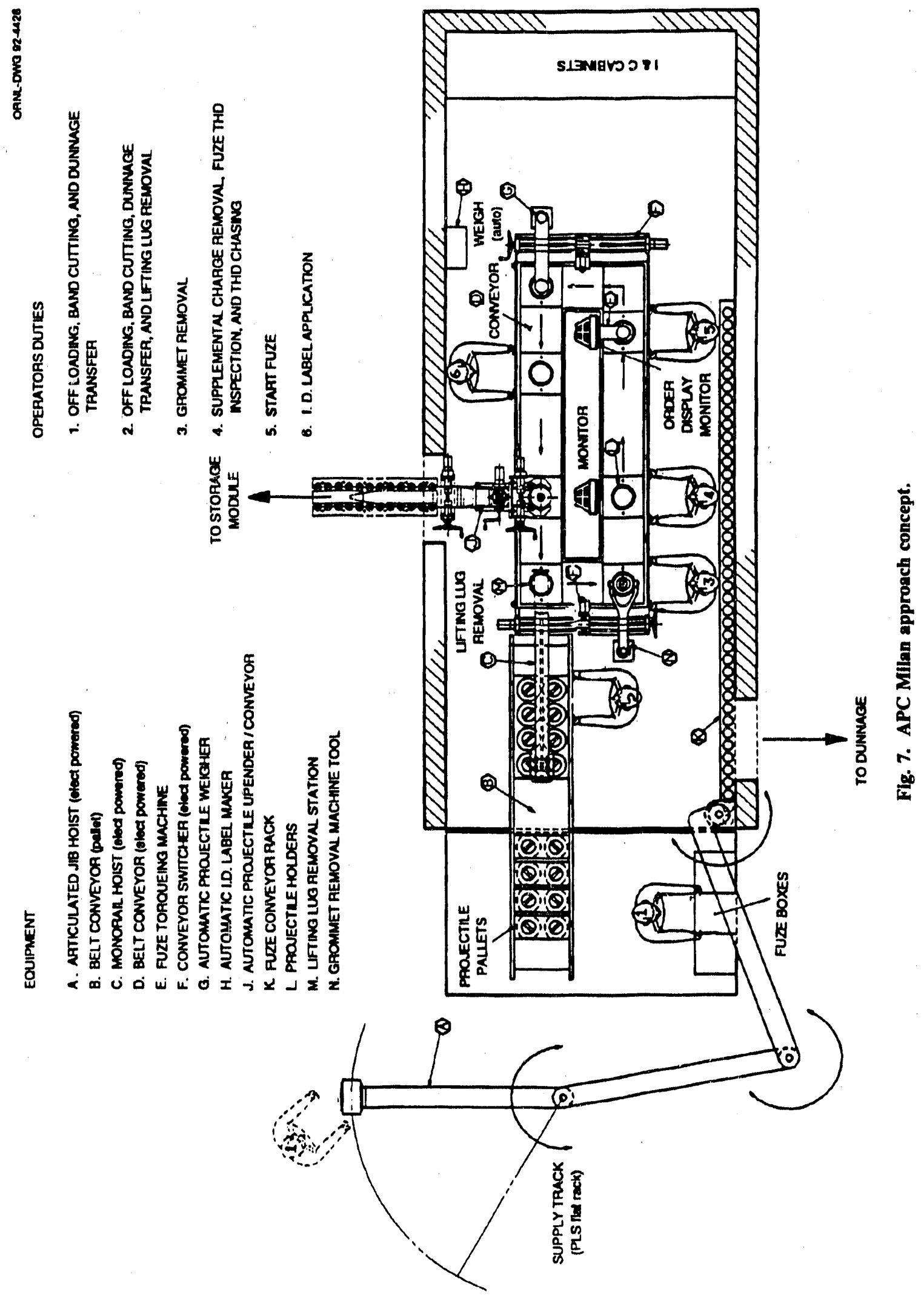


control system, which will automatically read the conveyor position. A repeat function eliminates repetitively entering common projectile types and lot numbers. The inventory and control system will prompt the supplemental charge remover if removal is required. If removal is required during development, then the threads will be manually chased.

The fuze installer will be prompted by the inventory and control system for a fuze type for the particular projectile type. The fuze installer will manually select the fuze, start the fuze thread, and enter the fuze lot number into the inventory and control system. An automated station will apply the proper torque to the fuze.

An automated system controlled by the inventory and control system will perform the weighing operation sequence. Data from the weighing system will automatically be associated with the projectile and fuze data for the particular conveyor position and transferred to the identification station for printing a bar code and soldier-readable label. The label will be manually applied to the projectile.

When released by the identification station operator, the conveyor will automatically move the projectile to th off-loading station. The off-loading station will be completely automatic, as it employs a custom upender to transfer the projectile from the main conveyor to a horizontal position on the SM transfer conveyor. Optical sensors will be used to initiate transfer when the SM transfer conveyor is engaged and cleared to accept another projectile.

When SMs are changed, a communication link between the APC inventory and control system and the SM will be connected to allow electronic transfer of the current SM inventory to the APC and allow automatic shutdown of the transfer sequence when the SM is full. Data bases of the current APC inventory and the SM inventories will be maintained. The data bases of the contents of the various SMs will direct the FARV-As to the appropriate SMs to acquire the desired loads.

Based on the assessment results, it is estimated that the concept will require 6 people and will process 1000 rounds of ammunition per shift of operation. The iotal power requirement is estimated to be $14 \mathrm{~kW}$. Details of power requirement estimates are inciuded in Appendix B.

The following paragraphs describe in more detail the mechanical aspects of the various process steps and the inventory and control system necessary to conduct operations as previously discussed.

\subsubsection{Off-loading}

A custom-designed jib hoist, as described in Sect. 7.1.1.1, will be used except that the hoist and articulating arms will be powered and pendant controlled.

\subsubsection{Projectile removal from pallet}

The equipment described in Sect. 7.1.1.2 will be used except that it is powered by electric motors with local controls and an impact wrench is integrated with the hoist pickup.

\subsubsection{Grommet removal}

Power-assisted custom tools for cutting, unlatching, and lifting the grommet will be provided to assist the station operator.

\subsubsection{Linting lug removal}

A powered robot with a standard impact wrench and custom lifting-lug, engagement-release mecharism will be used to remove the lifting lugs. 


\subsubsection{Supplemental charge and thread inspection}

No tools will be required to remove the charge. The equipment at this station is the same as that described in Sect. 7.1.1.5

\subsubsection{Fuze installation}

An automatic fuze torquing device will be manually initiated after the fuze is manually started.

\subsubsection{Projectile weighing}

An automatic weighing station consisting of a custom-designed mechanism will engage the projectile holder, lift it $1 / 2$ in. off the conveyor, and record the weight using a load cell.

\subsubsection{Identification marking}

This station will consist of an automatic label maker that will print identification labels based on information received from previous operations. The station operator will manually apply the label to the projectile.

\subsubsection{Projectile transfer to storage}

This equipment, which transfers the projectile to storage, is similar to that described in Sect. 7.1.1.9, except that it is motor powered and automatically actuated.

\subsubsection{Projectile primary conveyor}

The Milan AAP ammunition assembly line utilizes a continuous belt-type conveyor on which projectiles in holders are conveyed and stopped at work stations while a specific assembly operation is performed. This Milan AAP concept will use two continuously operating belt conveyors, running in opposite directions, that are coupled at each end by switching mechanisms which shuttle projectile holders from one belt conveyor to another, thus creating a continuous loop in a minimum amount of space. Automatic equipment will be mounted in the narrow space between the two belt conveyors.

\subsubsection{Inventory and control system}

The inventory and control system will consist of a single computer rack with two or more central processing units (CPUs), sensor and actuator interfaces required for the automated stations, and several operator interfaces. The system may also include PLC boards to handle logic associated with machine sequencing. As with the manual approach, the inventory and control system will assemble the data necessary for labeling the projectile and fuze combination based on manual data entry and interface directly with the label printer. Given the assembly orders and the type and lot number of the projectile being processed, the inventory and control system will automatically determine the supplemental charge and fuze requirements. In addition, consideration may be given to the particular SM being loaded when determining the projectile and fuze combination to be assembled. The supplemental charge remover will be prompted by the inventory and control system if removal of a supplemental charge is necessary, and the fuze installer will be prompted to select the correct fuze type for insertion. The system will also maintain a data base of projectile and fuze combinations for each SM, allowing central communication with the 
FARV-As arriving for reloading. A block diagram of the inventory and control system for this concept is shown in Fig. 8.

\subsubsection{Status of Technology}

This technology is generally available to implement an APC with a level of automation similar to that employed at the Milan AAP. Material handling will be accomplished by commercial or custom designed, powered conveying and lifting systems using commercially available components such as powered hoists. Other areas which will require special consideration are lifting lug removal, thread chasing, fuze torquing, weighing, identification, conveyor off-loading, and the inventory and control system.

\subsubsection{Lifting lug removal}

The automatic lifting lug removal station will utilize a robot with a custom-designed end-effector. The robot used may require modification of commercial equipment or custom design to meet environmental requirements.

\subsubsection{Thread chasing}

The thread chasing (if necessary) will be accomplished with a robot designed to accommodate the various projectiles. The thread chasing will utilize existing technology but require custom design. Torque sensing may require special design to accommodate the extreme variation in temperature if the APC is not environmentally controlled.

\subsubsection{Fuze torquing}

The concept includes an automatic fuze torquing station. Adequate torque cells will be available for industrial environments; however, a custom design may be required to satisfy the extended, military temperature ranges if the APC is not environmentally controlled. Provisions will be required for calibration of the torque cell.

\subsubsection{Weighing}

The concept also includes the use of a load cell incorporated in an automated weigh station. In general, automation of the weigh station can be accomplished with available technology and custom design. While the required accuracy of the load cell is commercially available for industrial temperature ranges, like the torque cell mentioned above, custom load cells may be necessary for the extended, military temperature ranges required if the APC is not environmentally controlled. Provisions will be required for calibration of the load cells, possibly by using known standard projectiles.

\subsubsection{Identification marking}

For the purpose of this assessment, it is assumed that the most practical identification marking approach is thermal transfer marking or laser printing of stick-on labels. Military-hardened priniers are available which may be suitable for producing the labels. Development will probably not be required to identify a suitable label material and adhesive. Alternate marking approaches, such as laser engraving, are being investigated. See Sect. 7.1.2.2 for a more extensive discussion of labeling. 


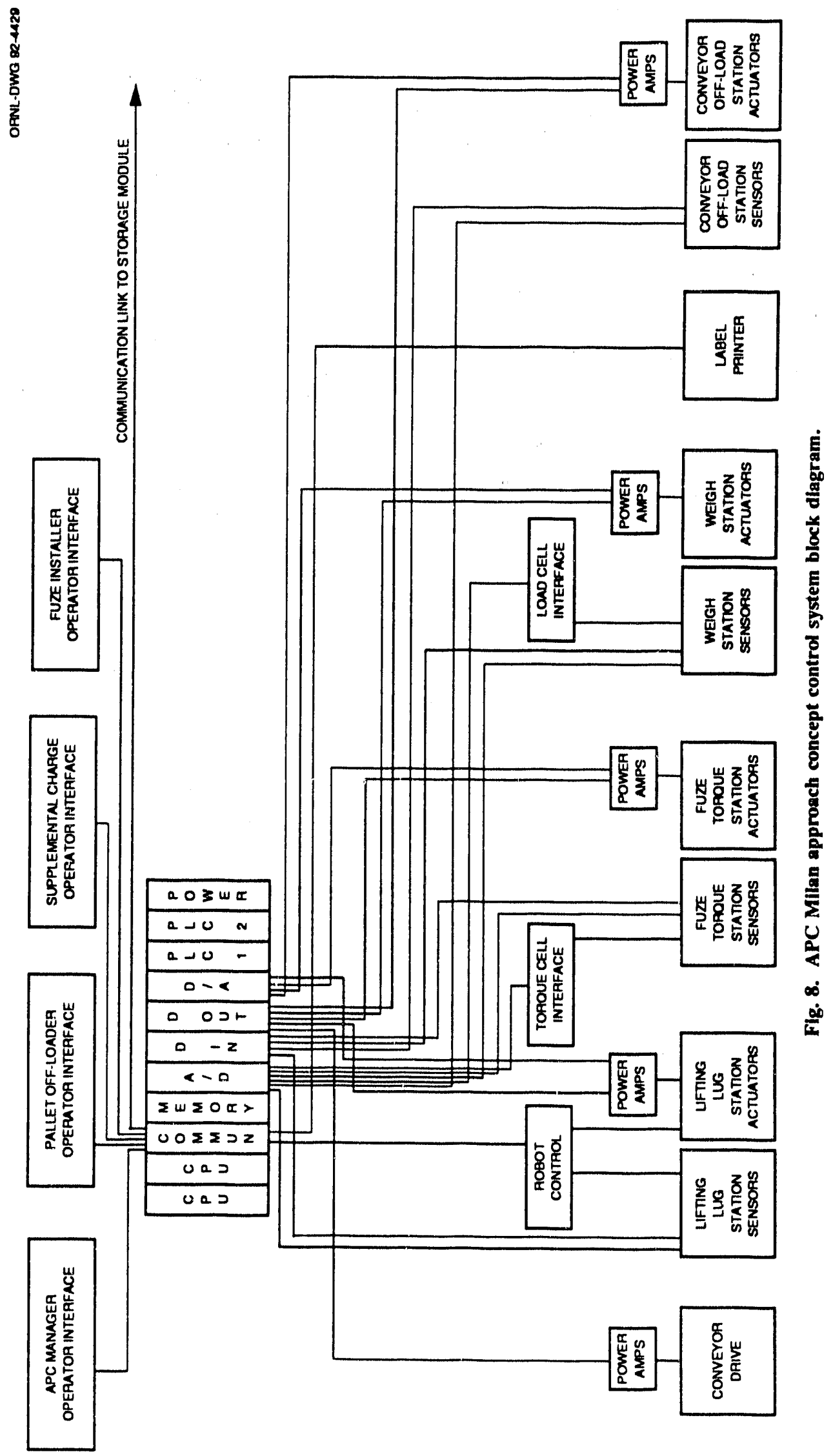




\subsubsection{Conveyor off-loading station}

The technology is available for off-loading the fuzed projectile from the main conveyor onto a conveyor to the SM in a horizontal position. The concept chosen incorporates a custom mechanism designed to lay the projectile down into a horizontal position. Sensors may be required to confirm the projectile identification during transfer to the SM.

\subsubsection{Inventory and control system}

Two approaches are available for selection of the computer system to be used for the inventory and control system. Military-hardened computer systems are available; however, an alternate may be to utilize industrially hardened computer systems mounted in environmental enclosures that would maintain the required operating temperature ranges and vibration isolation. Extended storage temperature ranges may be a problem for industrial computer systems. Military-hardened, touch-panel displays are available if required for data entry; however, simpler, hard-wired operator interfaces will be considered where appropriate.

The main computer system for the inventory and control system will include general-purpose CPU modules and, possibly, PLC modules. The PLCs will be used for sequencing operations associated with the automated stations. The control system for the Milan AAP approach also will include several industrial robot controllers. An alternate would be to control the robot directly from the main computer system. Basically, the technology needed for the inventory and control system is available; however, a significant software development effort is involved.

\subsubsection{Concept Costs}

The development costs for this concept are estimated to be $\$ 5,155,000$, and the capital costs are TBD (capital costs will be estimated after concept selection). A discussion of the basis for the cost estimates for each of the concepts is presented in Appendix C.

\subsection{FULLY AUTOMATED OPERATIONS/AUTOMATED MATERIAL HANDLING}

The fourth concept represents a fully automated system. In each step of the process, an attempt has been made to identify automation approaches that will eliminate attendance by an operator. Because of the additional equipment required, this concept requires at least two modules for the APC. A plan view of the concept is shown in Fig. 9.

\subsubsection{Description of Concept}

The APC manager will receive projectile and fuze assembly orders with each shipment. These orders will specify the combinations of projectiles and fuzes which are to be produced. The APC manager will enter the projectile and fuze orders into the inventory and control system. To more fully automate this process, projectile and fuze assembly orders and shipment contents will be transferred using some type of electronic storage media or, possibly, a two-dimensional bar code on the paper orders.

Automated off-loading is one of the more complex of the steps. A combination of optical or proximity sensors could be used to identify the location of the ammunition transporting system relative to the APC. One or more fixed vision systems combined with ultrasonic proximity sensing, which would te suspended above the ammunition transporting system, could be used to locate the projectile pallets, fuze boxes or pallets, and propellent pallets (if used). 

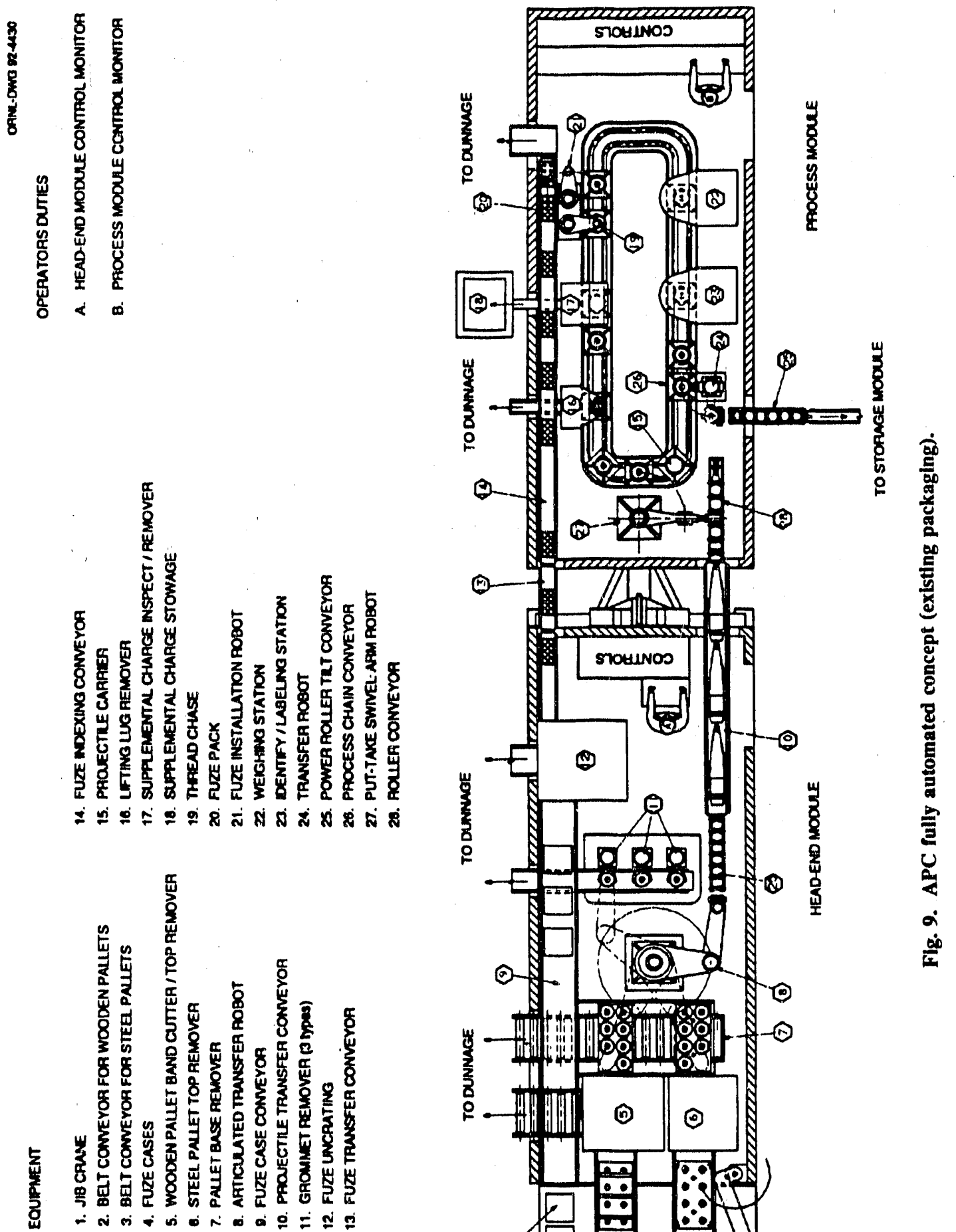
Consider first the projectile off-loading and the main assembly sequence. Fuze handling will be covered following the main projectile assembly sequence. Given the rough location and orientation of the pallets relative to the APC, the pallet off-loading robot could be programmed to follow a desired sequence in locating, grasping, lifting, moving, lowering, and unhooking pallets using additional sensors (possibly vision) to locate the pallets with sufficient accuracy. It is presumed that the pallets will be lifted by grasping two or more projectile lifting lugs and that a custom-designed end-effector tool will be required. In addition, a mechanism for orienting the pallet must be either incorporated into the lifting robot or into a conveyor system upon which the pallet is placed. Sensors, such as a load sensor, will provide feedback to the inventory and control system to indicate the successful placement of the pallet and to identify unintentional disengagement or loss of the pallet during the transfer for sequence interruption and operator notification. The vision system will determine if the pallet is wooden or metal to allow placement of the pallet on the appropriate receiving conveyor.

A powered conveyor controlled by optical limit switches will move the single pallet into the band-cutting and top-removal position. A top-removal mechanism will be moved to grasp the top, including the portion of the bands to be removed with the top. In the case of wooden pallets, the individual bands will be cut automatically, either sequentially or simultaneously. Proximity detection could be used to confirm location and cutting of the bands. This would allow the top removal mechanism to lift a wooden top and place it on a continuously operating conveyor to be transferred out of the APC to the scrap truck or bin. In the case of metal pallets, the top removal mechanism will require additional tools that will automatically disengage the top latches or remove the retaining nuts, allowing removal of the top.

The projectiles will then be removed by a robot equipped with a special end-effector tool to grasp the projectile lifting lug for transfer to an intermediate point for grommet removal. Automatic sequencing of the projectile-removal robot will allow removal of all of the projectiles from a given pallet. Sensors will identify empty projectile positions. After removal of all of the projectiles in a given pallet is confirmed using through-beam optical switches, the pallet bottom (with any remaining band sections) will be automatically pushed onto a continuously operating conveyor for transfer out of the APC to the scrap truck or bin. Once optical sensors confirm removal of the empty pallet bottom, the conveyor will index the next pallet into position for band cutting (if wooden) and top removal.

Vision will be used to identify the type of grommet, and hard automation will be used to remove the grommet. The projectile is transferred to the specific station for the removal of the particular type of grommet identified. If the grommet is elastic, it will be stretched and cut; if it is plastic, the projectile or grommet will be rotated to a position which allows a mechanism to release the grommet latch; if it is the old style, it will simply be cut. In all cases, the grommet will be placed on, or fall onto, an exit conveyor that will carry it to a scrap bin or truck. Optical sensors (or vision) will confirm removal of the grommet.

In the second module, the projectile will be transferred from the module-to-module conveyor to the main conveyor utilizing a robot with a lifting lug end-effector. At an intermediate point between the pallet and the main conveyor, a vision system will identify the projectile type and lot number. A rotating mechanism in the end-effector will be required to rotate the projectile to locate the lettering. A load cell in the pickup end-effector could be used to confirm, to some extent, the projectile type. At this point, the projectile type and lot number will be automatically read by the inventory and control system. The data associated with the projectile will be correlated with the main conveyor position automatically. 
The conveyor system will use a continuously moving track and transfer carriers which are indexed through the various stations, the first of which is the lifting lug removal station. The projectile-lifting lug will be automatically removed using an impact wrench built into the end-effector of a robot. The robot will place the lifting lug on a conveyor that carries it to a scrap bin or truck.

The supplemental charge will be removed and inspected at the second station. The inventory and control system will determine if the projectile type and the fuze type to be later installed require that a supplemental charge be removed. A vision system will confirm the presence of a supplemental charge and determine the type. Several concepts for supplemental charge removal have been identified. If possible, a vacuum system may be the simplest system and the most generally applicable. In this concept, a vacuum head would be placed over the projectile using a robotic system and the supplemental charge would be vacuumed out of the projectile into a holding device for transfer to safe storage. Another concept would involve several custom end-effectors, each designed to grasp a particular type of supplemental charge. The different types of end-effectors are either changed using a standard tool changer or selected by rotating a carousel located at the end-effector of the robot. The third approach might involve grasping the projectile and turning it upside down to dump the supplemental charge. In all of these cases, removal of the supplemental charge would be confirmed using either vision or a probe system. Once removal of the supplemental charge is confirmed, the inventory and control system would release the conveyor transfer carrier to move to the next station.

At the next station, the projectile threads will be chased (if necessary during development). The station will use a robot with an end-effector with the spindle drive for thread chasing. Torque sensing will protect against overload in the thread-chasing operation.

At the fuze installation station, a robot with an appropriate gripper will pick up and install the fuze. The robot will automatically select the proper fuze for a given projectile according to the inventory requirements. Fuzes will be retrieved from a multiple conveyor system which will allow separation of fuzes by type. A vision system will read the fuze lot number for addition to the inventory data base and confirm the fuze type. Torque and position sensing will ensure complete installation of the fuze and proper torquing. Once the fuze is installed and the required data are read from the fuze, the conveyor transfer carrier will be released by the inventory and control system for movement to the next station.

The assembled projectile and fuze will be weighed at the next station. Two concepts for weigh stations have been considered. The Milan approach utilizes a vertical lifting mechanism and load cell. An altemate approach would be to utilize an in-line conveyor weighing system. The first approach is likely to be the simpler to implement. The projectile and fuze data will be correlated with the weight by identifying the specific conveyor transfer carrier. This information will be transferred automatically to the label station, and the projectile and fuze will be released.

The label station will receive projectile type and lot, fuze type and lot, and weight based on identification of the conveyor transfer carrier. Although altemate methodologies are being investigated, it is assumed that the label station will use either thermal transfer printing or laser printing to create a bar code and soldier-readable label. A custom label applicator will be required that is flexible enough to place the lajel automatically in the appropriate position according to the type of projectile and fuze. Multiple labels may be required to simplify reading in downstream process steps in the SM, FARV-A, or AFAS-C.

A robot will transfer the projectile from the main conveyor to a tilting mechanism and powered roller conveyor for transfer to the SM. As the projectile is transfer ad, the bar code will be read to confirm the data presumed and update the APC and SM data bases. 
A communication link between the APC inventory and control system and the SM will allow (1) electronic transfer of the current SM inventory to the APC and (2) automatic shutdown of the transfer sequence when the SM is full. A data base of the current APC inventory as well as data bases of the projectile and fuze assemblies transferred to each SM are maintained.

The centralized data base of the contents of the various SMs will direct the FARV-As to the appropriate SMs to acquire the appropriate loads. This information would be retrievable from the APC manager's operator interface.

Retuming to the initial step of off-loading, consider now the handling of fuzes. The fuzes are packed eight in a metal ammunition box and two boxes in a wooden crate. Several wooden crates may be loaded on a pallet. Special lifting end-effectors will be required to unload the fuzes; it is not likely that a common end-effector could be designed to off-load both fuze boxes and projectile pallets. Given the location and orientation of the fuze boxes (or pallets of boxes), the off-loading robot will automatically change end-effectors and proceed to off-load fuze boxes or pallets of boxes essentially the same way that the projectile pallets are off-loaded.

If multiple fuze crates are assembled on a pallet, the next step is band cutting. This process will be handled with automated band location and cutting equipment. Once separated, the fuze crates will be separately opened by locating and cutting the wire retainers holding the top on the fuze crate. An alternate approach would be to bend the wire retainers, using a robot to save the crates for reuse without replacement of the wire retainers.

A robot will remove the metal fuze boxes from the crates and to transfer them to a fuze box conveyor. Once the fuze crates are emptied, the crates and pallet, if present, will be automatically moved to a waste conveyor for transfer to a scrap bin or truck.

The next step is opening the fuze boxes and removing the packing. With the fuze box clamped in place, an automated system will unlatch and open the top. A robot will remove the upper formed packing and place it on a scrap removal conveyor. Another robot will remove the fuzes one or more at a time and transfer them to a vision station for identification. (Altemately, the fuzes may be identified by marking on the fuze box.) Once identified, the robot will place the fuzes on the appropriate conveyor for transfer to the projectile and fuze assembly station and update the inventory and control system. When all of the fuzes have been removed from a given metal box, the box will be transferred to a scrap-removal conveyor. This approach assumes that fuzes are packed in formed packing without additional stuffing which may be difficult to deal with automatically, particularly if each fuze is individually wrapped. An altemate approach would be to transfer the metal boxes of fuzes directly to the appropriate conveyor after packing removal.

Based on the assessment results, it is estimated that the concept will require 2 people to process 1800 rounds of ammunition per shift of operation. The total power requirement is estimated to be $40 \mathrm{~kW}$. Details of power requirement estimates are included in Appendix B.

The following paragraphs describe in more detail the mechanical design of the various process steps and the inventory and control system.

\subsubsection{Off-loading}

A motorized, custom-designed jib hoist with three articulating arms (described in Sect. 7.1.1.1) would also be used for this automatic operation. However, this jib hoist must function in this automatic concept as a robot complete with custom end-effectors, load sensors, position sensors, and an intelligent vision system. 


\subsubsection{Projectile removal from pallet}

Two motorized belt conveyors, one for wooden pallets and one for metal pallets, would be required to feed the pallets into the pallet top removal machines. Two automatic pallet top removal machines, one for wooden pallets and one for metal pallets, would be required. The wooden pallet top removal machine would consist of a head with four grippers and six cutters with a vertical and horizontal travel for gripping the pallet top, cutting the bands, removing the top with the cut bands, and depositing it on the dunnage conveyor. 'The metal pallet removal machine would also consist of a traveling head with grippers and end-effectors for tie-rod disengagement for removing the pallet top and depositing it on the dunnage conveyor. A pallet top dunnage conveyor for both metal and wooden tops would run normal to the incoming pallet belt conveyors. An industrial robot, such as a Cincinnati Milicron, would consist of an articulated arm and an end-effector for engaging and lifting each projectile out of its pallet and transferring it to one of three grommet removal stations. The projectile will then travel to an upender/con'eyor which lays the projectile down for transfer from the first module into the second by belt conveyor.

\subsubsection{Grommet removal}

Three grommet removal stat ns will be required to accommodate the three types of grommets. The first station will consist of a projectile holder and a custom mechanism for rotating, unlatching, and stripping the grommet from the projectile. The second station will consist of a projectile holder and custom-designed grommet cutter and stripper, and the third station will consist of a projectile holder and a custom-designed wire cutter and stripper.

\subsubsection{Lifting lug removal}

This automatic machine will consist of a robot with end-effectors (for engaging and disengaging the lifting lug) and an impact wrench for lug removal. After removal, the lugs will be deposited onto a dunnage conveyor by the robot.

\subsubsection{Supplemental charge removal}

A robot for a vacuum pickup probe is recommended for removing and transferring supplemental charges to storage. A backup design will require a custom-designed carriage with end-effectors and an intelligent vision system to identify the type of charge, locate and engage its attachment, and remove it from the projectile.

\subsubsection{Fuze thread chasing}

A robot with a compliant tool head for precise centering and starting of tapping tool will be required for chasing each projectile.

\subsubsection{Fuze installation}

A robot-like swing arm with a pickup head which has vertical travel will retrieve a fuze from the conveyor, read its identification data, and install it in the projectile at a specified torque. 


\subsubsection{Projectile weighing}

A custom-designed mechanism will automatically engage and lift the projectile on its holder slightly off the conveyor, allowing the built-in load cell to sense and relay the weight to the auto labeling station.

\subsubsection{Identification marking}

A commercially available label maker or applicator (modified for the environment) will be employed in concert with a custom-designed mechanism for rotating the projectile about its axis.

\subsubsection{Projectile transfer to storage}

A swing-arm-type robot with gripping jaws and short vertical travel will transfer the projectile from its holder in the conveyor to an upender and conveyor. The upender and conveyor will consist of a cradle-like frame with two rows of powered rubber rollers which becomes a conveyor when rotated $90^{\circ}$ to lay the projectile down in a horizontal attitude.

\subsubsection{Fuze off-loading}

The jib hoist system, described in Sect. 7.4.1.1, will also off-load fuze boxes automatically.

\subsubsection{Fuze removal}

This station will use a series of robots to uncrate fuze boxes, open the boxes, and remove upper packing. A commercially available robot with custom-designed end-effectors will load fuzes in the appropriate fuze conveyor.

\subsubsection{Fuze conveying}

A fuze conveyor will be provided for each type fuze. These conveyors will span from the rear APC module to the front APC and terminate at the fuze installation station.

\subsubsection{Inventory and control system}

The complexity of the inventory and control system for the fully automated concept warrants several communicating racks. The concept involves the integration of several robot controllers as well as controllers for hard automation stations. In addition, this concept involves the use of vision in several situations to provide information to the inventory and control system which would otherwise be read and input by an operator.

It is envisioned that control software will be written in modules, one for each of the following: (1) off-loading the projectiles and fuzes, (2) uncrating the projectiles, (3) transferring the projectiles, (4) removing the grommets, (5) removing the supplemental charges, (6) chasing the threads, (7) installing the fuzes, (8) weighing the projectiles and identifying the labeling, (9) transferring the projectiles to storage, (10) uncrating the fuzes, (11) transferring and sorting the fuzes, and (12) inventorying and processing step coordination. A block diagram of the inventory and control system for this concept is shown in Fig. 10. The five computer racks shown each have multiple processors. Controllers are shown for the steps using robots. 


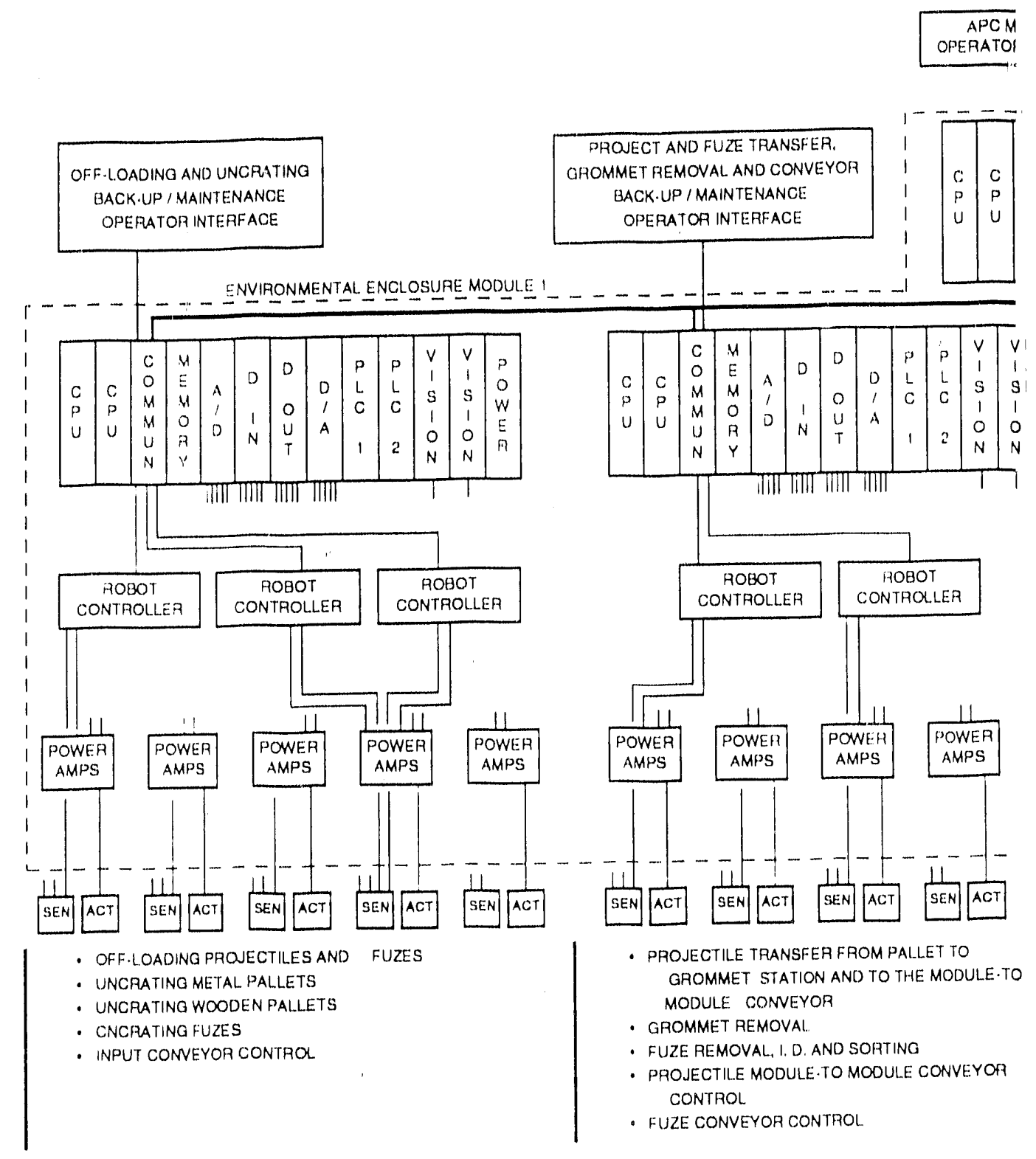

Fig. 10. APC fully aut 


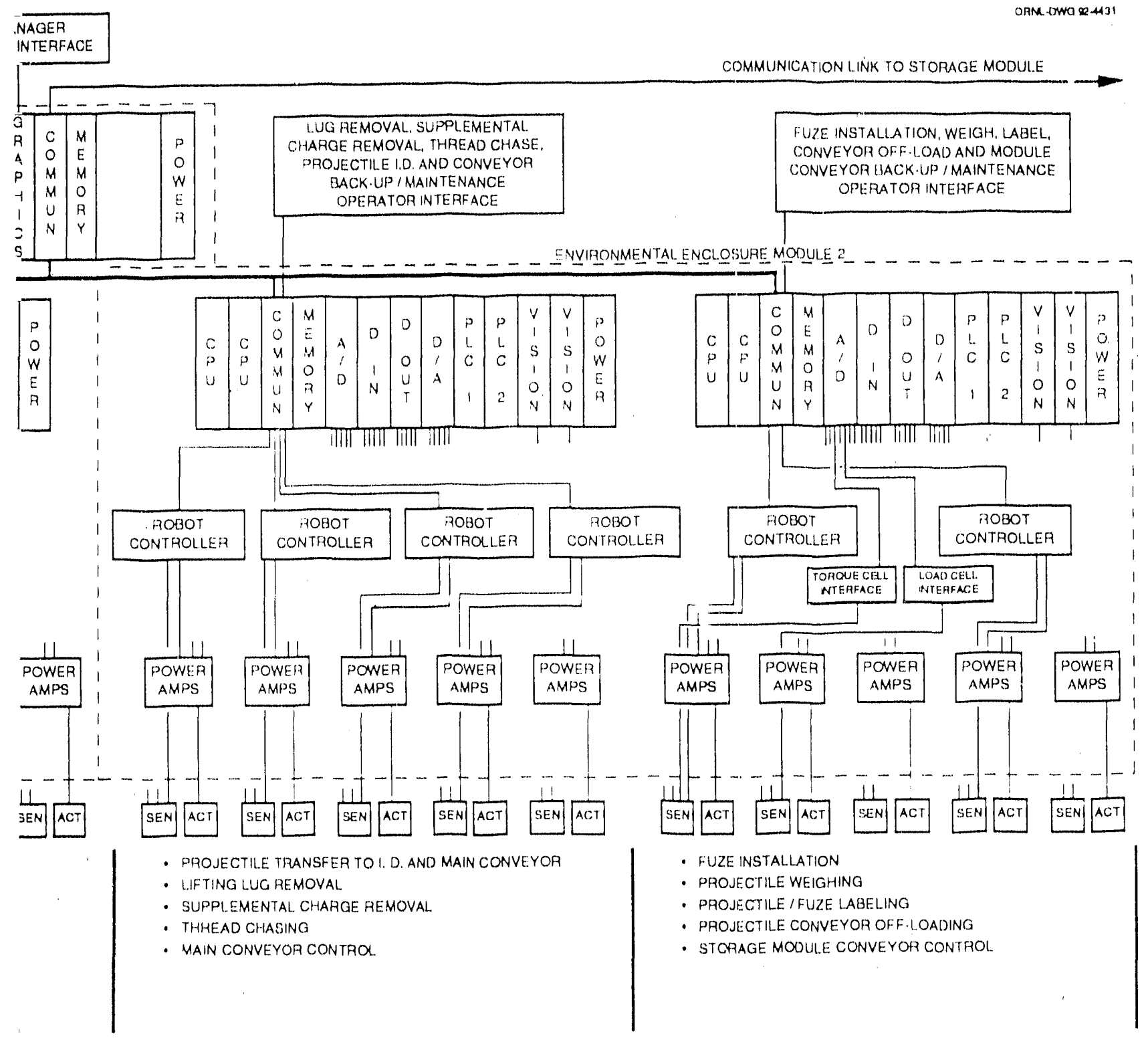

nated concept control system block diagram. 
The inventory and control system will assemble the data necessary for labeling the projectile and fuze combination using automated, vision-based data input and interfaces directly with the label printer. Given the assembly orders, entered possibly by two-dimensional bar code, and the type and lot number of the projectile being processed, the inventory and control system will automatically determine supplemental charge and fuze requirements. In addition, consideration may be given to the particular SM being loaded when determining the projectile and fuze combination to be assembled. The supplemental charge removal station will be prompted by the inventory and control system if removal of a supplemental charge is necessary and fuze installation station is prompted to select the correct type fuze for insertion. A data base of projectile and fuze combinations for each SM will be maintained for communication with the FARV-As arriving for reloading.

\subsubsection{Status of Technology}

The technology required for this concept is essentially available; however, significant development and innovative application of technology is required. Material handling will be accomplished by commercial or by custom-designed automated conveying and lifting systems or by robots using commercially available components, where possible. Each of the major steps in the process will require special development to some extent.

\subsubsection{Off-loading}

Automated off-loading of projectiles and fuzes from an ammunition transporting system presents several technical challenges. The first is the relatively accurate location of the ammunition transporting system with respect to the APC. It is likely that this can be accomplished with a combination of optical and proximity sensors. The second is the location of projectile pallets, fuze crates or pallets of crates, and propellent pallets. (Propellent has not been specifically addressed in this study.) One approach to locating the pallets on the ammunition-transporting system would be to suspend one or more cameras and range sensors above the ammunition-transporting system and use a vision system to identify the pallet and crate types and locations. In addition, it will be necessary to identify groups of pallets or crates which are banded together. This identification and location problem can be solved with standard vision software, neglecting the effects of weather. Possible solutions might include the use of a tarp to protect the system from inclement weather to highlight the edges of the pallets and crates. It is assumed that tarps would be used to cover the ammunition transporting systems in snow. Some development may be required to combine the views from several cameras into a composite view of the ammunition transporting system.

The use of the same robotic device for off-loading projectile pallets and crates or pallets of fuzes may require end-effector changing, although this would be undesirable. Because of limited storage space at the front end of the assembly line, an automated system may be alternately used to unload projectiles and fuzes. The design of the robot itself involves the application of available technology, but requires custom design for the application. The design of a special end-effector for automatically grasping the appropriate number of projectile lugs for a single pallet would be required. In addition, an end-effector which would be capable of picking up a crate of fuzes would be required. Two approaches will be considered. The first is a device which would grasp the crate on two sides, although this may be difficult to apply if crates are loaded side by side, as expected. The second approach would be to automatically grasp the manual lifting ropes, possibly in a sequential fashion, which would likely be done by personnel to provide space between crates.

A special sensing requirement will determine whether the projectile pallet is wooden or metal, which can be solved with the custom application of existing vision technology. This will allow determination of the appropriate placement location for the pallet, given two separate projectile pallet processing lines. 
The robotic transfer system will orient the pallet or crate for placement, or the conveyor system will provide automatic orientation. Either approach would involve innovative application of currently available technology and custom design.

Automatic release of the load will be included in the control system and end-effector design. Identification of unwanted release of the load could be accomplished by a combination of sensors including both load and optical proximity sensors or through-beam swiltches.

\subsubsection{Projectile removal from pallet}

Two separate projectile pallet processing lines will allow separate handling of wooden and metal pallets. In the case of wooden pallets, removal of the projectiles from the pallets will involve (1) band cutting, (2) top removal, (3) projectile removal, and (4) bottom disposal. In the case of metal pallets, removal of the projectiles from the pallets will involve (1) top release, (2) top removal, (3) projectile removal, and (4) bottom disposal. In each case, the technology for these steps is generally available; however, an innovative application of the technology and custom design will be required. In the case of the metal pallets, special attention will be required for releasing the latches and removing the top if the retaining nuts on the support rods are not removed. In addition, a mechanism for folding down the support rods will be required to minimize the storage space required for the metal pallets.

\subsubsection{Grommet removal}

Grommet removal will require automatic identification of the grornmet type. A vision system may be able to distinguish between the three types of grommets; however, development and testing will be required. Custom end-effector design and testing will the required for each type of grommet. The grommets could be removed in either a single, multipurpose station or in three stations, each dedicated to a particular type of grommet. In the case of the plastic grommets, the mechanism must either rotate the projectile or the grommet around the projectile to position the latch for release. Although release of the latch is a relatively complex procedure, robotic technology is available to accomplish the task, but development will be required. Currently available vision technology could be used to confirm removal of the grommet.

\subsubsection{Lifting lug removal}

The lifting lug removal station could incorporate the use of an industrial robot and end-cffector equipped with an automatically engaging and latching clevice similar to that used in the off-loading step and an impact wrench. No significant developrnent is required, but custom design is required. The robotic features will allow for variations in projectiles and transfer of the lifting lug to a scrap conveyor system. Sensors could easily confinm removal of the lifting lug prior to release of the conveyor transfer carrier.

\subsubsection{Supplemental charge removal}

Supplemental charge removal may be another of the more complex steps to perform automatically. Three approaches are described in Sect. 7.4.1. Current vision technology could be used to confirm the presence and absence of the supplemental charge. In the approach that uses multiple end-effectors for grasping the various types of supplemental charges, the vision system may also be required to identify the type of supplemental charge. This task is likely to be more 
difficult and require development. The end-effectors themselves will require significant development and testing. All of the approaches could use current robotic technology, with the possible exception of the grasping approach, in which significant development may be required to consistently acquire the supplemental charge. Development will be required to safely handle and pack the supplemental charges for removal from the APC.

\subsubsection{Thread chasing}

The thread chasing (if necessary) will be accomplished with a robot designed to accommodate the various projectiles. The thread chasing uses existing technology but requires custom design. Torque sensing may require special design to accommodate the extreme variation in temperature if the APC is not environmentally controlled.

\subsubsection{Fuze installation}

Fuze installation will be accomplished with a robot designed to perform the pick-and-place operation. Fuze selection and installation use existing technology, but require custom design. A dual end-effector with one position for location only and the second position for fuze handling will assist in the precision location required because of the current fuze thread design. Custom design will be required for grasping the fuze. Torque sensing may require special design to accommodate the extreme variation in temperature if the APC is not environmentally controlled.

\subsubsection{Projectile weighing}

The concept includes the use of a load cell incorporated in an automated weigh station. In general, automation of the weigh station can be accomplished with available technology and custom design. While the required accuracy of the load cell is commercially available for industrial temperature ranges like the torque cell mentioned above, custom load cells may be necessary for the extended, military temperature ranges required if the APC is not environmentally controlled. Provisions will be required for calibration of the load cells, possibly by utilizing known standard projectiles.

\subsubsection{Identification marking}

For the purpose of this assessment, it is assumed that the most practical identification marking approach is thermal transfer marking or laser printing of stick-on labels. Military-hardened printers are available that may be suitable for producing the labels. Development would probably not be required to identify a suitable label material and adhesive. Altemate marking approaches such as laser engraving are being investigated. See Sect. 7.1.2.2 for a more extensive discussion of labeling.

In addition to printing labels, the system will be required to apply the labels automatically. While this is commonly done in industrial applications, custom design is required and special consideration must be given to the variations in projectile and fuze profiles. This may significantly complicate the application of one or more labels.

\subsubsection{Projectile transfer to storage}

The technology is available for off-loading the fuzed projectile from the main conveyor onto a conveyor to the SM in a horizontal position. The concept chosen includes a combination of a 
pick-and-place robot and a custom mechanism designed to lay the projectile down into a horizontal position. A modified commercial robot may be available for the application; however, a custom end-effector will be required. Also, a custom-designed mechanism for laying the projectile down will be required. Sensors may be required to confirm the projectile identification during transfer to the SM.

\subsubsection{Fuze off-loading}

Fuze off-loading is covered in Sect. 7.4.2.1, along with projectile off-loading.

\subsubsection{Fuze removal from crate and metal box}

Fuze removal requires the following steps: (1) band cutting, if multiple crates are banded together to a pallet; (2) crate top removal; (3) removal of metal fuze boxes; (4) opening metal fuze boxes; (5) packing removal; and (6) fuze removal. An altemate approach, emphasizing that the metal fuze containers are loaded with a single type of fuze, would be to transfer the metal containers of fuzes directly to conveyors after removal of packing. This would eliminate the need to individually handle fuzes at this point in the process. These operations can be accomplished using existing technology but would require custom design and extensive testing. Band cutting can be accomplished, as described for the projectile pallets, utilizing existing vision technology to locate the bands. Vision may also be required to locate the wire ties for crate top removal. Unwrapping the wire ties would probably be more complicated than cutting them, but would save the crates for recycling. Custom robot end-effectors would be required to remove the metal boxes from the crates, open the boxes, and remove the packing. A robot with a custom end-effector would be required to grasp the box or individual fuzes for transfer, depending on the approach.

\subsubsection{Fuze identification, sorting, and transfer}

Fuze identification may be possible by optical character recognition of printing on the metal fuze box or on individual fuzes. This would likely involve the custom application of commercially available optical character recognition software. The fuzes would be transferred automatically, using the previously mentioned robot, to the proper conveyor according to the information obtained from the identification process.

\subsubsection{Inventory and control system}

Two approaches are available for selection of the computer system to be used for the inventory and control system. Military-hardened computer systems are available. An alternate approach may be to use industrially hardened computer systems mounted in environmental enclosures, which would maintain the required operating temperature ranges and vibration isolation. Extended storage temperature ranges may be a problem for industrial computer systems. Military-hardened touch-panel displays are available if required for data entry; however, simpler hard-wired operator interfaces will be considered where appropriate.

The inventory and control system will consist of a central computer system which coordinates operation of individual local control systems for one or more of the stations. An APC inventory data base and a data base for each SM will be maintained for planning purposes. In addition, special-purpose robot controllers may be integrated into the system, as well as PLC boards integrated into local control systems for sequencing operations. The technology needed for the inventory and control system is basically available; however, a very significant software development and integration effort is involved. 
Among the more difficult steps from an automation point of view are off-loading, depalletizing and removing the grommet. While the fuze insertion step is complicated by the design of the fuze thread and the lack of thread lead-in, the task can be accomplished with a reasonable amount of developmental effort and testing.

\subsubsection{Concept Costs}

The development costs for this concept are estimated to be $\$ 25,000,000$, and the capital costs are TBD (capital costs will be estimated after concept selection). A discussion of the basis for the cost estimates for each of the concepts is presented in Appendix C.

\subsection{FULLY AUTOMATED OPERATIONS WITH SIMPLIFICATIONS DUE TO STANDARDIZATION OF PACKAGING}

This concept is essentially the same as that described in Sect. 7.4 except that a number of simplifications to the required operations have been made by assuming the use of standardized packaging. As a result of the standardization, the duplication of stations to handle variations is no longer necessary. A plan view of the concept is shown in Fig. 11.

\subsubsection{Description of Variations in the Concept}

As a result of standardization of the projectile pallet, off-loading is simplified and only a single process line is needed, whereas in the previous concept, two separate lines allow handling of the wooden and metal pallets separately.

In this concept it is assumed that a single type of grommet is used, thus eliminating the need for separate grommet removal stations for the three types of grommets in the current inventory.

The inventory and control system is essentially the same as that described in Sect. 7.4, with the elimination of elements associated with eliminated equipment.

Based on the assessment results, it is estimated that the concept will require 2 people to process 1800 rounds of ammunition per shift of operation. The total power requirement is estimated to be $34 \mathrm{~kW}$. Details of power requirement estimates are included in Appendix B.

\subsubsection{Effect on Status of Technology}

Standardization of the pallets and grommets will significantly simplify the FAAPS automation problem. Specific areas affected will involve the elimination of $50 \%$ of the development effort associated with depalletizing from custom hard automation and the vision system application to the problem of determining if the pallet is wooden or metal.

In the grommet removal area, nearly $66 \%$ of the development effort will be eradicated by eliminating two of the three types of grommets. Hard-automation development, as well as vision system applications, would be eliminated.

Automated removal of the supplemental charge using custom end-effectors will likely be one of the more difficult tasks if the vacuum approach to removal is not feasible for some reason.

\subsubsection{Concept Costs}

The development costs for this concept are estimated to be $\$ 20,000,000$, and the capital costs are TBD (capital costs will be estimated after concept selection). A discussion of the basis for the cost estimates for each of the concepts is presented in Appendix $C$. 

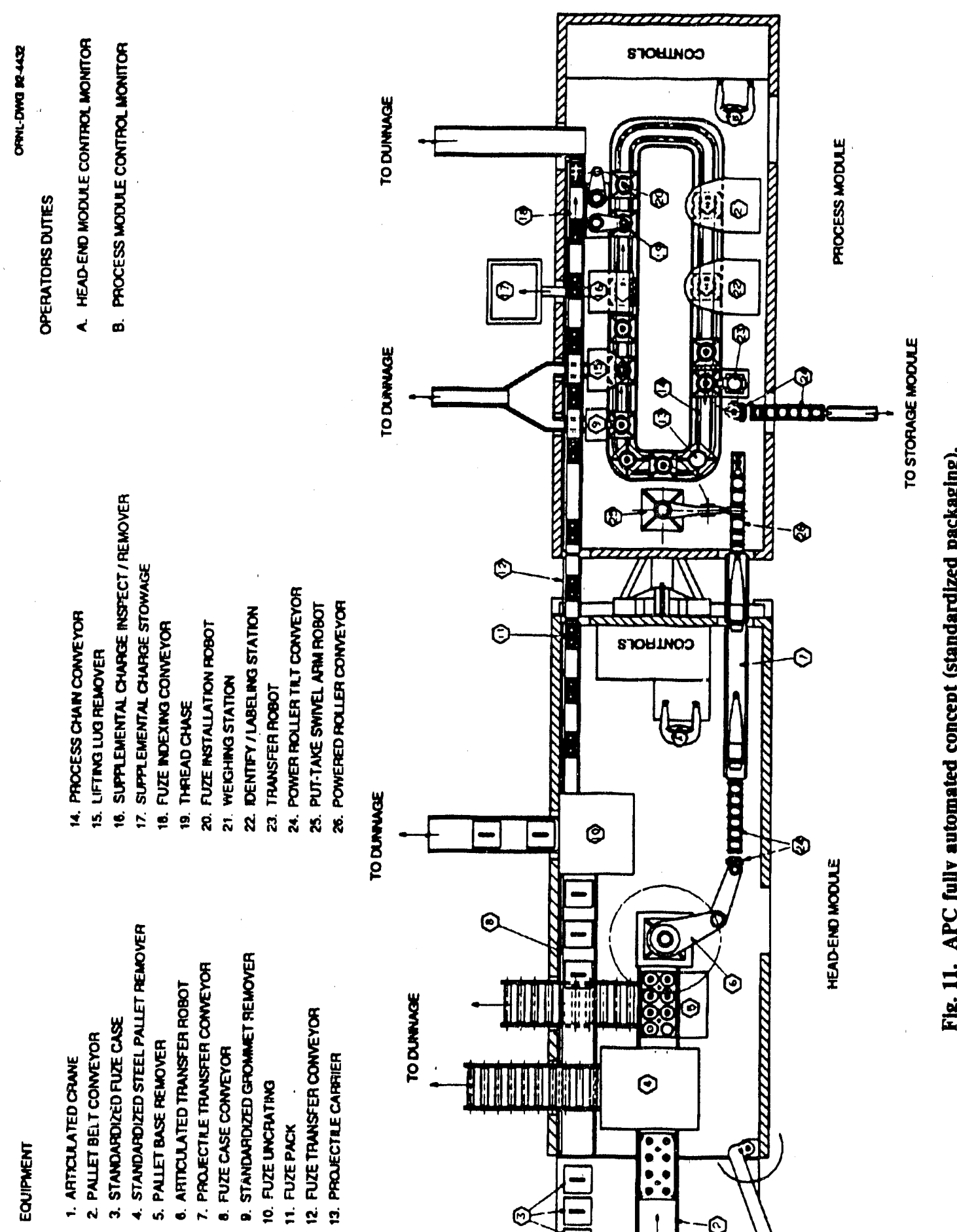


\section{RECOMMENDED CONCEPT-AUTOMATED OPERATIONS WHERE PRACTICAL/AUTOMATED MATERIAL HANDLING}

By comparison with the five concepts considered previously, the recommended concept is most similar to the Milan approach. Additional automated operations and automated material handling are included. This concept involves a combination of various levels of automation for the different assembly steps, varying from manual to fully automated. Automation is used where justified based on the technology assessment performed to improve throughput or to minimize personnel required for operation and where the development and capital costs are estimated to be reasonable. The steps tend to be either manual or automated with little or no use of semi-automation. Since the off-loading and depalletizing steps appear to require significant development and involve high capital costs, manual steps aided by power tools where needed are proposed. This approach allows phased implementation of technologies and resources which permits full automation of the system at a later date. A plan view of the concept is shown in Fig. 12.

\subsection{DESCRIPTION OF CONCEPT}

The APC manager will receive projectile and fuze assembly orders with each shipment that specify the combinations to be produced. The fuze and projectile orders will be entered into the inventory and control system utilizing a two-dimensional bar code system or another automated data transfer method to minimize the time and errors likely to occur in manual data entry.

The off-loading operation will use a pendant-operated, powered jib hoist. The mechanical redundancy of the powered jib hoist will be resolved through mechanical linkages or software. Pallet orientation will be assisted by either a rotational degree of freedom on the jib hoist or by the conveyor system. Transfer of the pallets along the first powered conveyor will be initiated by the band cutting and pallet removal operator and stopped by mechanical or optical limit switches. Bands will be cut using a powered hand tool in the case of wooden pallets, and the top will be manually removed. In the case of metal pallets, latches will be manually released or retaining nuts will be removed with an impact wrench allowing manual top removal. This step will be locally controlled and connected to the inventory and control system only for maintenance support.

Pallets of fuzes will also be unloaded using the powered jib hoist, bands will be cut, and crates will be removed from the pallets. If not on pallets, the crates of fuzes will be manually off-loaded. The crates will move along a powered conveyor to the point where the fuze crate top is manually removed and the metal fuze boxes are removed from the crate. The metal boxes will be manually opened, and the fuzes will be removed. The operator will place the fuzes on one of several conveyors (based on fuze type) and dispose of the dunnage using the same conveyor system as used for the projectile pallets.

A monorail gantry robot will automatically lift the projectile out of the pallet and transfer it to the conveyor system. A vision system will allow placement of the projectile so that the labeling is oriented outward. A robot with an impact wrench integral to the end-effector will automatically 


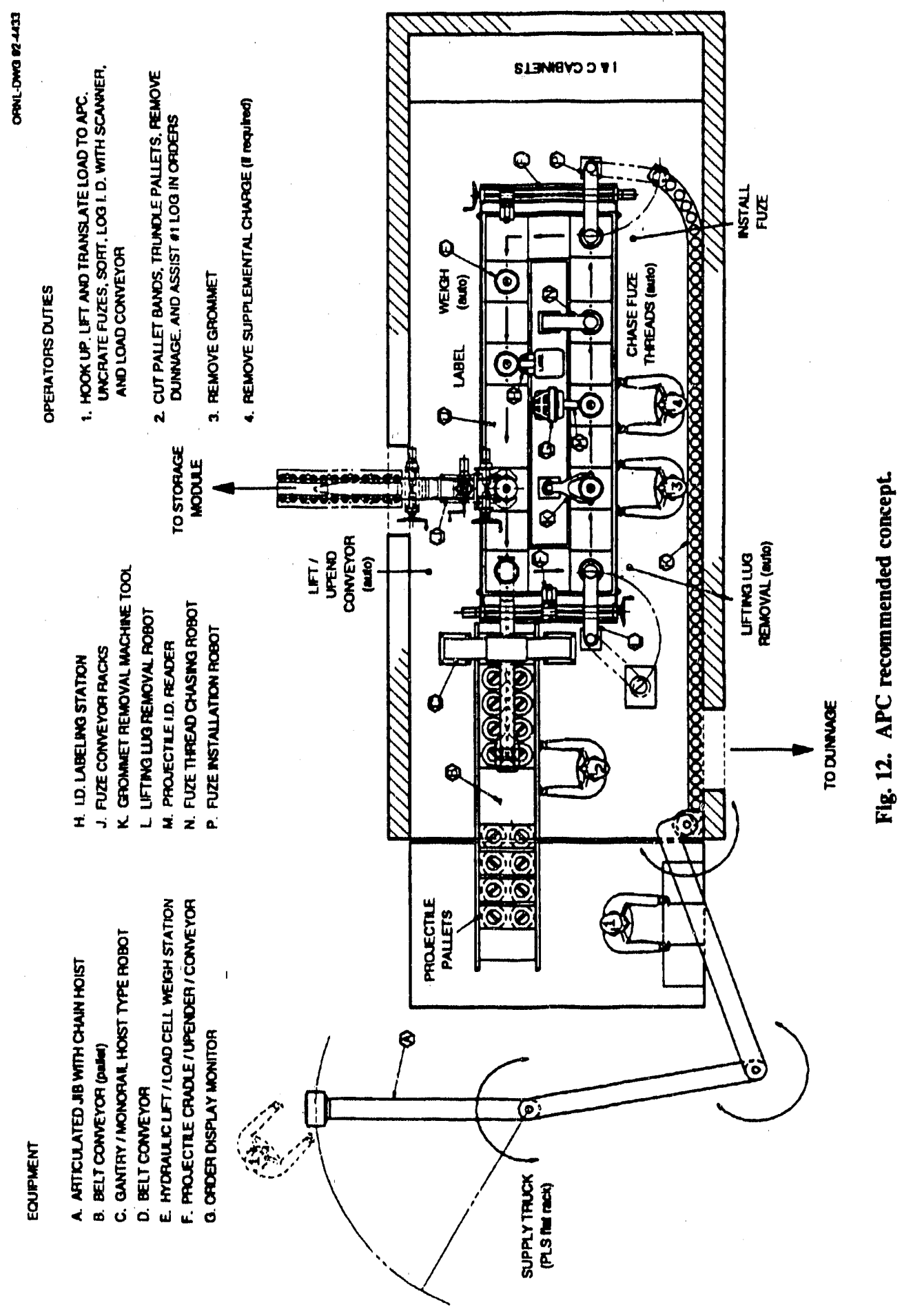


remove the lifting lug and deposit it in a box for removal from the APC. The gr; mmet will be manually removed at the next station using power tools.

Supplemental charge removal will be a manual operation, although the vacuum-based approach discussed previously should be investigated because it may allow automation. The projectile type and lot number will be automatically recorded by a vision system and are entered into the inventory and control system, which automatically records the conveyor position. As a backup, the supplemental charge remover may manually enter the data. A repeat function will eliminate repetitively entering common projectile types and lot numbers. The inventory and control system will prompt the supplemental charge remover if removal of a supplemental charge is required. If removal is required, release of the projectile carrier will require a manual input from the operator, otherwise the projectile will automatically move to the next station. Special provision will be made for storage of the removed supplemental charges until they can be properly disposed of.

If required during development, an automatic thread chasing station will ensure satisfactory threads for fuze insertion. The station will use a robot with an end-effector with the spindle drive for thread chasing. Torque sensing will be used to protect against overload in the thread chasing operation.

Fuze installation will be performed automatically. The inventory and control system will determine the appropriate fuze and instruct the insertion robot to pick the fuze from one of several conveyors of different types of fuzes. A vision system will read the fuze lot number for addition to the inventory data base and confirm the fuze type. Torque and position sensing will ensure complete installation of the fuze. Once the fuze is installed and the required data is read from the fuze, the conveyor transfer carrier will be released by the inventory and control system for movement to the next station.

An automated system controlled by the inventory and control system will perform the weighing operation sequence. Data from the weighing system will be automatically associated with the projectile and fuze data for the particular conveyor position and transferred to the identification station for printing a bar code and soldier-readable label. The label will be automatically applied to the projectile.

When released by the identification station control system, the conveyor will automatically move the projectile to the automatic off-loading station. A custom up-ender will transfer the projectile from the main conveyor to a horizontal position on the SM transfer conveyor. Optical sensors will initiate transfer when the SM transfer conveyor is engaged and clear to accept another projectile.

When SMs are changed, a communication link will connect the APC inventory and control system to the SM, and the current SM inventory will be electronically transferred to the APC. Automatic shutdown of the transfer sequence will be permitted when the SM is full. The inventory and control system will maintain a data base of the current APC inventory, as well as data bases of the projectile and fuze assemblies transferred to each SM.

The centralized data base of the contents of the various SMs will allow direction of the FARV-As to the appropriate SMs to acquire the appropriate loads. This information would be retrievable from the APC manager's operator interface.

Based on the assessment results, it is estimated that the concept will require four people to process 1500 rounds of ammunition per shift of operation. The total power requirement is estimated to be $30 \mathrm{~kW}$. Details of the power requirement are included in Appendix B.

The following paragraphs describe in more detail the mechanical design of the various process steps and the inventory and control system. 


\subsubsection{Ofr-Loading}

This operation will be handled with an articulated arm (three links), electrically powered, pendant-controlled jib hoist as described in Sect. 7.3.1.1.

\subsubsection{Projectile Removal from Pallet}

A standard, powered belt conveyor, described in Sect. 7.1.1.2, will be used for handling pallets. Portable, powered metal shears (commercially available) will be used to cut the bands, and a standard impact wrench will be used to disengage the metal pallets.

A motori $2 d$, custom-designed, monorail-type hoist robot will automatically transfer the projectiles from their pallet to the primary conveyor. A gantry support frame for the monorail will provide movement normal to the hoist travel for the robot to position the hoist over any of the eight projectiles on the pallet. Because of its restrictive travel, this type robotic system will not present a safety hazard to personnel.

Other equipment used in this operation is described in Sects. 7.1.1.2 and 7.3.1.2.

\subsubsection{Grommet Removal}

Custom power tools will assist the station operator in cutting, unlatching, and lifting the grommet.

\subsubsection{Lifting Lug Removal}

A vertical-travel robot equipped with a modified commercial impact wrench that has an engagement or release head will automatically remove the lifting lugs and deposit them in a dunnage container.

\subsubsection{Supplemental Charge Removal}

An identification reader and an order display monitor will be provided for the station operator. No tools will be required; however, this operation could possibly be automated if a suction-type probe proves reliable for removing the supplemental charge.

\subsubsection{Fuze Thread Chasing}

A robot with vertical drive, compliant tool head with precise centering and thread tap will automatically chase the threads on every projectile.

\subsubsection{Fuze Installation}

A robot with pickup head and vertical travel will automatically select the proper fuze conveyor level, grasp the fuze, record its identification, and install the fuze on the projectile at the specified torque. 


\subsubsection{Projectile Weighing}

A custom-designed mechanism will automatically engage and lift the projectile and its holder slightly off the conveyor, allowing the built-in load cell to sense and relay the weight to the auto labeling station. The weight tolerance of the projectile holders will be held to $\pm 0.10 \mathrm{oz}$.

\subsubsection{Identification Marking}

A commercially available label maker or applicator (modified for the environment) will be employed in concert with a custom-designed mechanism for rotating the projectile about its axis.

A variation of the concept will use a custom label maker or applicator designed to accommodate the shape and size of the projectile. The projectile will be rotationally indexed to allow the application of multiple copies of the label.

If the parts of the projectile and fuze are to be individually labeled, then multiple printer applicators may be required.

\subsubsection{Projectile Transfer to Storage}

An automatic motor-powered projectile cradle/upended conveyor, described in Sect. 7.1.1.9, will be used for this operation.

\subsubsection{Fuze Off-Loading}

The articulated arm jib hoist, described in Sect. 7.3.1.1, will be used in handling fuze boxes (especially multiple boxes).

\subsubsection{Fuze Uncrating}

Standard commercial powered hand tools will be used to uncrate the fuzes.

\subsubsection{Fuze Transfer and Sorting}

An automatic fuze conveyor consisting of several belt or chain conveyors mounted to the APC wall for each type fuze will be provided. The conveyors will be manually loaded, and an automatic fuze installation robot will retrieve fuzes from the appropriate fuze conveyor.

\subsubsection{Projectile Primary Conveyor}

A Milan-type conveyor system, described in Sect. 7.3.1.10, will be employed in this concept.

\subsubsection{Inventory and Control System}

In the proposed concept, the inventory and control system will consist of multiple computer racks (each with one or more CPUs), the sensor and actuator interfaces required for the automated stations, and operator interfaces. The individual control racks may also include PLC boards to handle logic associated with machine sequencing. A block diagram of the inventory and control system for this concept is shown in Fig. 13.

The inventory and control system will (1) assemble the data necessary for labeling the projectile and fuze combination according to automated data entry and (2) interface directly with the label printer and automatic applicator. Given the assembly orders and the type and lot number 

OPERATOR INTERFACE

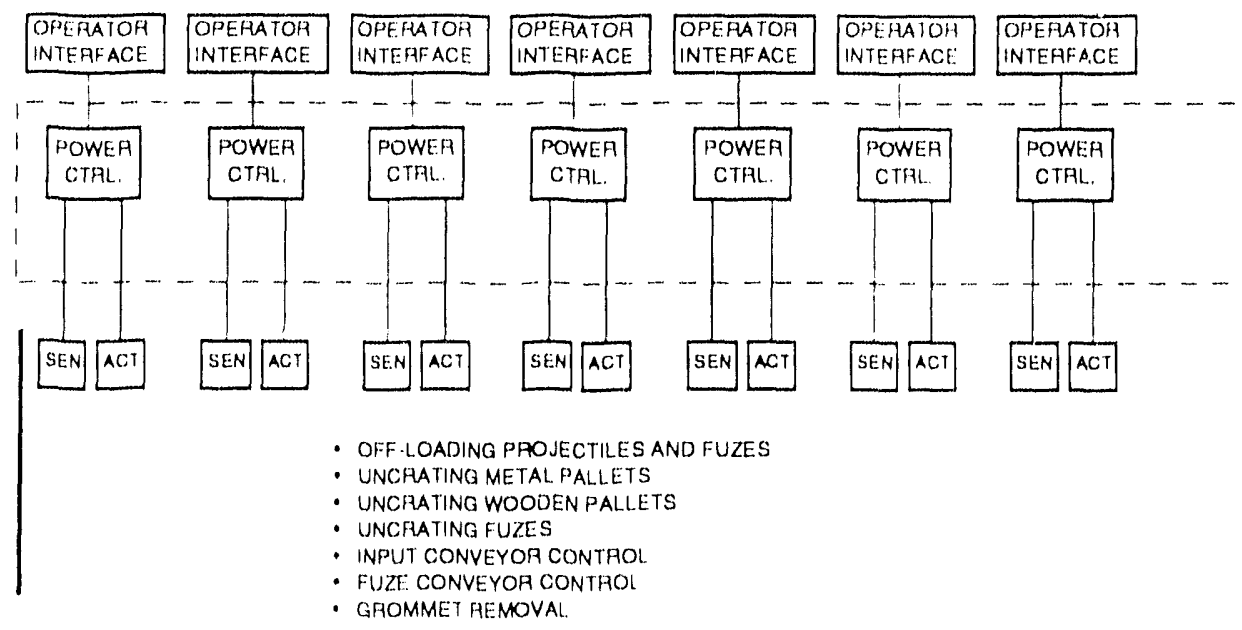

Fig. 13. $A P C$ 


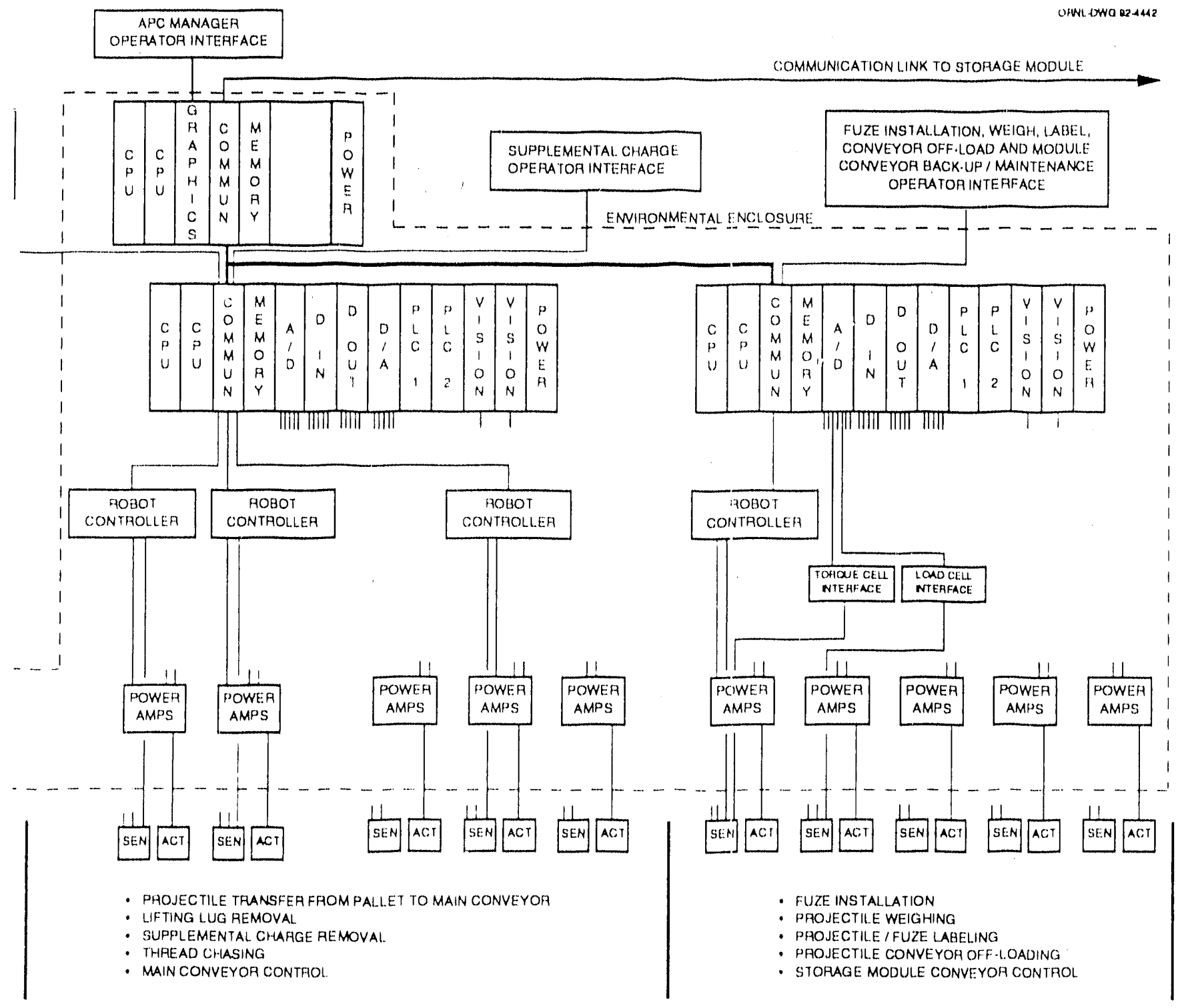

commended concept control system block dlagram. 
of the projectile being processed, the inventory and control system will automatically determine supplemental charge and fuze requirements. In addition, consideration may be given to the particular SM being loaded when determining the projectile and fuze combination to be assembled.

The supplemental charge remover (or removal station, if automated) will be prompted by the inventory and control system if removal of a supplemental charge is necessary, and the fuze installation robot will be commanded to select the correct luze type for insertion.

Data bases of projectile and fuze combinations for each SM will be maintained, allowing communication with the FARV-As arriving for reloading.

\subsection{STATUS OF TECHNOLO(;Y}

The technology is generally available 10 implement an $\mathrm{APC}$ with the automation described. An innovative application of this technology, with some development and custom design, will be required. Material handling in off-loading is accomplished by commercial-or custom-designed powered conveying and lifting systems using commercially available components such as powered hoists. The robots used in various locations along the assembly line maly require modification of commercial equipment or custom design to meet environmental requirements.

The proposed approach includes automation in several areas beyond that employed in the Milan approach, but it does not involve complete automation. The projectile transfer, lifting lug removal, thread chasing, fuze insertion, weighing, labeling, and projectile off-loading from the main conveyor are automated in this concept. Olf-loading and depalletizing as well as supplemental charge removal and label application remain essentially manual, with power equipment for assistance. This concept includes the use of both two-dimensional, bar-coded assembly order entry and several vision systems for automilted data entry.

\subsubsection{Assembly-Order Data Entry}

Several approaches will be considered for elimination of manual data entry of the projectile and fuze assembly order information. Two-dimensional, bar-eode technology is nearly commercially available and provides one practical approach for eliminating the time required and errors involved in manual dati entry. Given the assembly refpirements, the inventory and control system can, to some extent, optimize the assembly sequencing given knowledge of the conditions of the various SMS and the anticipated needs of the FARV-As.

\subsubsection{Projectile Transfer}

A robotic system will be utilized to transfer the projectiles from the pallets to the main conveyor system. Although the technology for the application of robotics is clearly available, the application may require modification or custom design to satisty the environmental requirements. In addition, a custom end-effector design will be required. A special consideration will be the application of a vision system to assure that the projectile labeling is positioned outward for later process steps. This would require the custom applicition of existing vision hardware and soltware algorithms as well as careful application of lighting. Optical character recognition of the data may be considered at this step rather than later in the process. The governing consideration would be processing time, which would be impacted by the number of fonts and other variables such as location of the information. 


\subsubsection{Supplemental Charge Removal}

If not performed in the transfer step, optical character recognition of the projectile type and lot number will be accomplished at the supplemental charge removal station. This will require custom application of existing vision hardware and software algorithms as well as careful application of lighting. If developmental testing of a vacuum concept for supplemental charge removal is successful, it may be used in automating this station. Special care is required in handling the charge.

\subsubsection{Thread Chasing}

If necessary for development, automatic thread chasing will be implemented. Special considerations include the environmental hardening of the robot and the torque sensing needed to protect against overload.

\subsubsection{Fuze Installation}

The concept will include an automatic fuze installation station. The robot may require special consideration in the area of environmental hardening. The vision system used to read the fuze lot number will employ standard optical character recognition software modified for the specific application. One approach is to utilize a line-scan camera while rotating the fuze to avoid the distortion of the information if viewed from a single location. Software correction of the distortion may also be possible but would require additional development. Appropriate lighting would be required. Adequate torque cells are available for industrial environments; however, a custom design may be required to satisfy the extended military temperature ranges if the APC is not environmentally controlled. Provisions will be required for calibrating the torque cell.

\subsubsection{Weighing}

The concept also includes the use of a load cell incorporated in an automated weigh station. In general, automation of the weigh station can be accomplished with available technology and custom design. While the required accuracy of the load cell is commercially available for industrial temperature ranges (like the torque cell previously mentioned), custom load cells may be necessary for the extended military temperature ranges required if the APC is not environmentally controlled. Provisions will be required for calibration of the load cells, possibly by using known standard projectiles.

\subsubsection{Identification Marking}

For the purpose of this assessment, it is assumed that the most practical identification marking approach is thermal transfer marking or laser printing of stick-on labels. Military-hardened printers are available that may be suitable for producing the lahels. Development would probably not be required to identify a suitable label material and adhesive. Alternate marking approaches such as laser engraving are being investigated. See Sect. 7.1.2.2 for a more extensive discussion of labeling.

In addition to printing labels, the system will be required to apply the labels automatically. While this is commonly done in industrial applications, custom design will likely be required and special consideration must be given to the variations in projectile and fuze profiles. This may significantly complicate the application of one or more labels. 


\subsubsection{Conveyor Off-Loading Station}

The technology is available for off-loading the fuzed projectile from the main conveyor onto a conveyor to the SM in a horizontal position. The concept chosen will use a custom mechanism designed to lay the projectile in a horizontal position. Sensors may be required to confirm the projectile identification during transfer to the SM.

\subsubsection{Inventory and Control System}

Two approaches are available for selection of the computer system to be used for the inventory and control system. Military-hardened computer systems are available, and an alternate approach may be to use industrially hardened computer systems mounted in environmental enclosures that would maintain the required operating temperature ranges and vibration isolation. Extended storage temperature ranges may be a problem for industrial computer systems. Military-hardened touch-panel displays will be available, if required, for data entry; however, simpler hard-wired operator interfaces will be considered where appropriate.

The inventory and control system will consist of muitiple computer racks (each with one or more CPUs), the sensor and actuator interfaces required for the automated stations, and operator interfaces. The individual control racks may also include PLC boards to handle the logic associated with machine sequencing. The system may also include industrial robot controllers for control of the pallet to conveyor station robot, as well as others. An altemate approach would be to control the robots directly from the local computer system associated with the particular process step. The technology needed for the inventory and control system is basically available; however, a significant software development effort is involved. Integration of the total control system (including actuators, sensors, and supervisory functions) is probably the most technically challenging aspect of this entire effort.

\subsection{CONCEPT COSTS}

The development costs for this concept are estimated to be $\$ 11,400,000$, and the capital costs of this concept are TBD (capital costs will be estimated after concept selection). A discussion of the basic for the cost estimates for each of the concepts is presented in Appendix C. 


\section{CONCLUSIONS AND FUTURE DIRECTION}

A concept summary listing each of the concepts discussed throughout the report is shown in Table 4. It includes the number of personnel required, projected processing rates, power required, development costs, and capital costs, according to APC, for each of the concepts identified. The recommended concept is the product of the project team's best effort to achieve the proper balance of system parameters based on the collective understanding of global objectives and preliminary system requirements. The limited availability of information or firm requirements is probably commensurate with the maturity level of the FAAPS project and the differences of opinion within the military. It is recognized that a quantitative decision on a specific concept is impractical until realistic and definitive requirements are established. Once these requirements are established, it is recommended that a cost/benefit analysis be conducted to reevaluate the appropriate level of automation to be incorporated based on more of a quantitative analysis than was possible here. Information collected as part of this concept study should serve as the basis for any further analysis.

The recommended concept uses automatic processing of the ainmunition, except for off-loading and depalletizing of ammunition components and removal of the grommet where mechanized tools with manual interface are employed. All automatic operations are accomplished without personnel interaction except during maintenance or repair. Manual mode operation of any or all steps are provided in case of equipment failure. The recommended concept, by emphasizing the automation of the processing steps associated with operations on individual projectiles, lends itself to a second phase of automation, if desired, at a later date. Once the proposed operations are successfully demonstrated, projectile off-loading and depalletizing, grommet removal, and fuze off-loading and uncrating could be automated, thus allowing a phased implementation of technology and resources.

Several issues which could have a significant impact on the concept selected include standardization of ammunition component packaging, prefuzing of projectiles, and selection of the propellant type. Some of the special issues are addressed in Appendix D.

Once an appropriate concept option is selected, whether it be the one recommended or another, a program plan should be developed that defines the specific tasks to be accomplished, the products to be delivered, and the desired scheduled. Should the decision be made to proceed with the concept approach recommended in this document, the process operations identified below represent a prioritized listing of automated operations which require the most development (based on the technology required). Those that have the greatest level of uncertainty as determined from the technology assessment (high delta technology) are given a higher priority. Operations not listed are accomplished manually.

Depending on the availability of facilities and experimental hardware, some preliminary developmental testing should be conducted, and the overali conceptual design of the selected approach should be initiated. This testing should produce results early enough to influence the conceptual design. During the conceptual design phase, there will be other areas of uncertainty identified which require further development and/or testing to answer design questions. These 


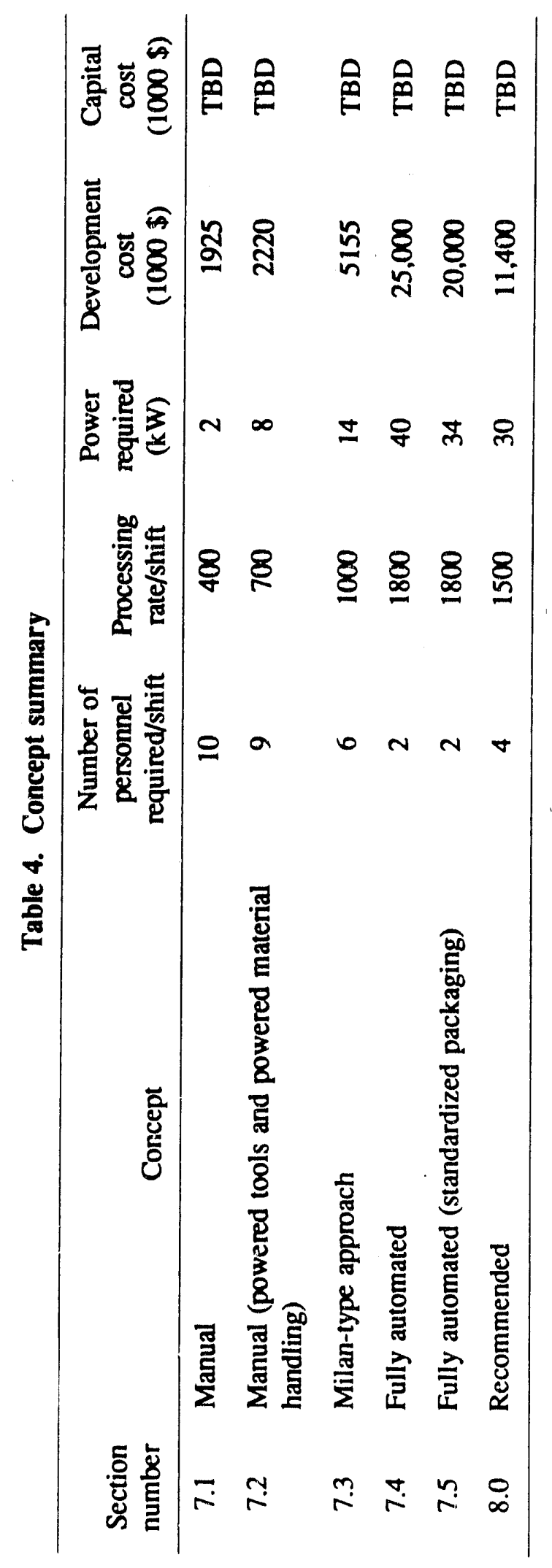




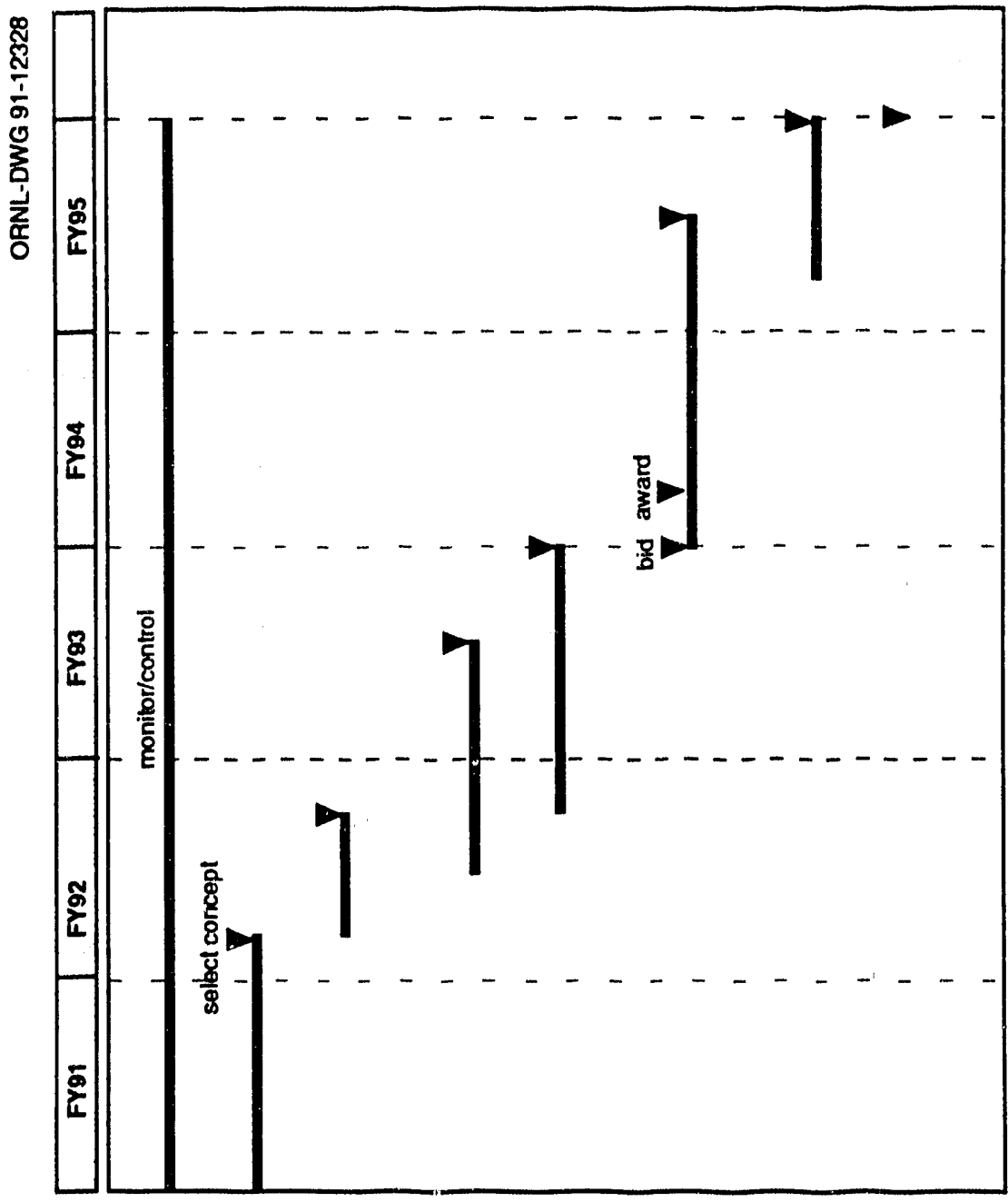

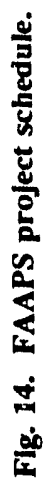

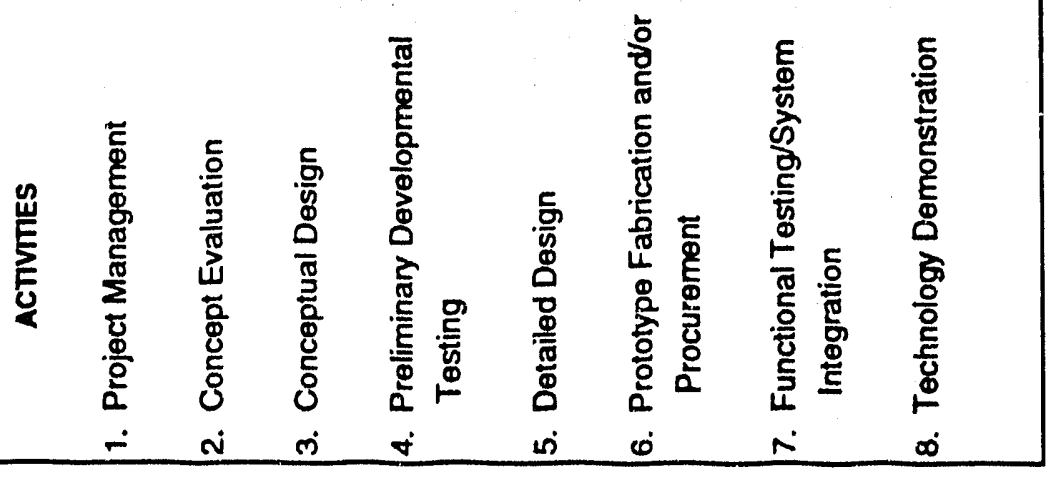


engineering tests will be planned and executed so that the design information will be generated or the process performance will be evaluated.

\begin{tabular}{clc} 
Priority & \multicolumn{1}{c}{ Process operation } & $\begin{array}{c}\text { Delta } \\
\text { technology }\end{array}$ \\
\hline 1 & Projectile identification & 33 \\
2 & Fuze installation & 33 \\
3 & Material handling & 32 \\
4 & Supplemental charge removal & 27 \\
5 & Projectile weighing & 25 \\
6 & Projectile removal & 24 \\
7 & Lifting lug removal & 23 \\
8 & Projectile transfer & 22 \\
9 & Thread chasing & 20 \\
\hline
\end{tabular}

Value extracted from technology assessment worksheets.

The testing and concept design should allow evaluation of the process performance and adequate information should result to proceed with the detailed design. Design reviews should be conducted during the design effort with formal reviews at predetermined intervals.

Fabrication and procurement should be initiated after construction drawings are approved. Also, a cost estimate should be generated and approved. As each subsystem is fabricated and made available for testing, it should be functionally tested for conformance with the design requirements. A technology demonstration could be conducted for each subsystem. System integration should begin as subsystems are installed in a mock-up module. Each subsystem and its associated controls should be integrated with interfacing systems. After all subsystems are installed and become functional, a complete system integration should be performed. The final phase of the project should involve a technical demonstration of a complete system prototype. Figure 14 provides a possible schedule for the activities identified. 
APPENDIX A

TECHNOLOGY ASSESSMENT WORKSHEETS 


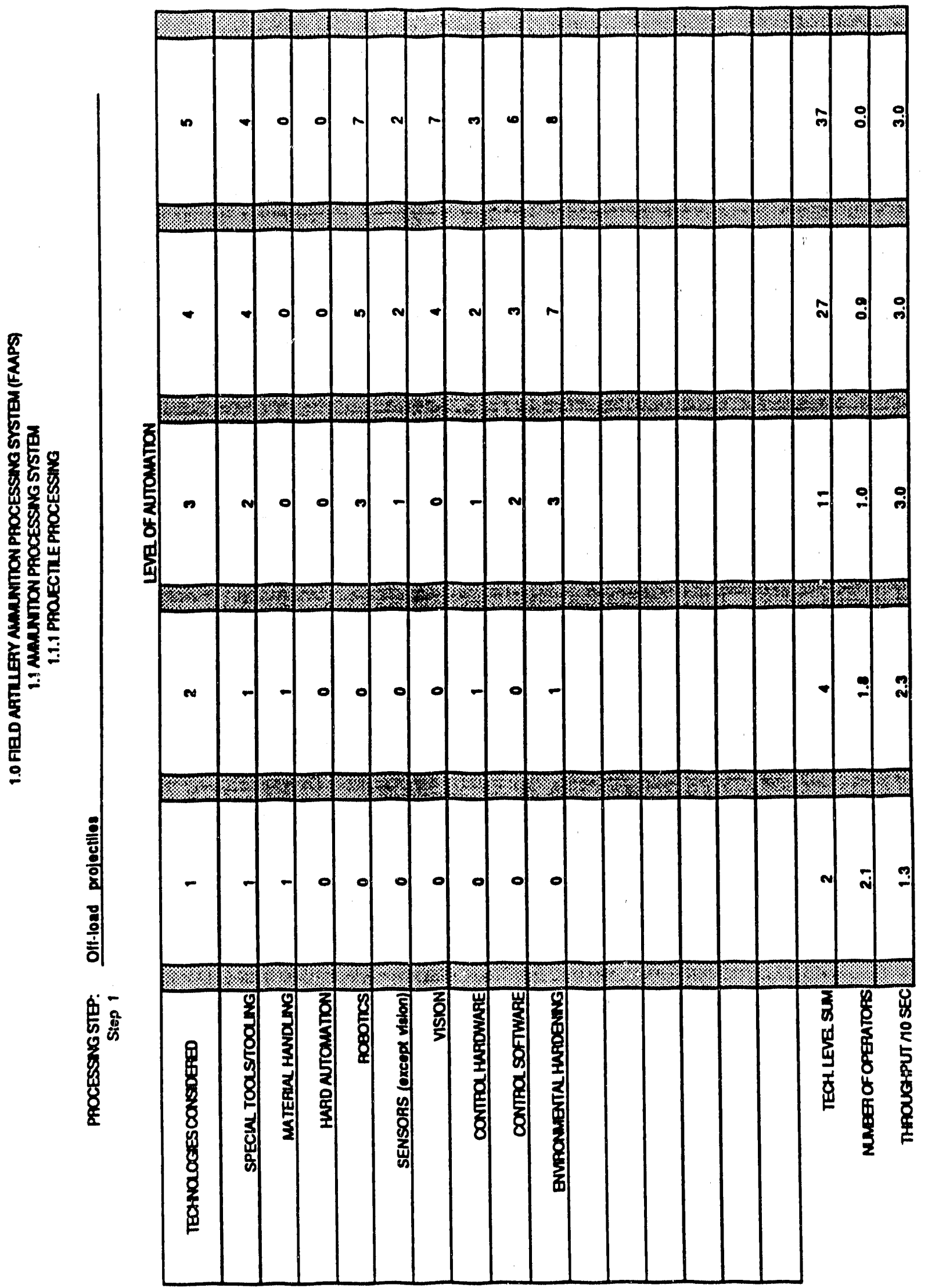




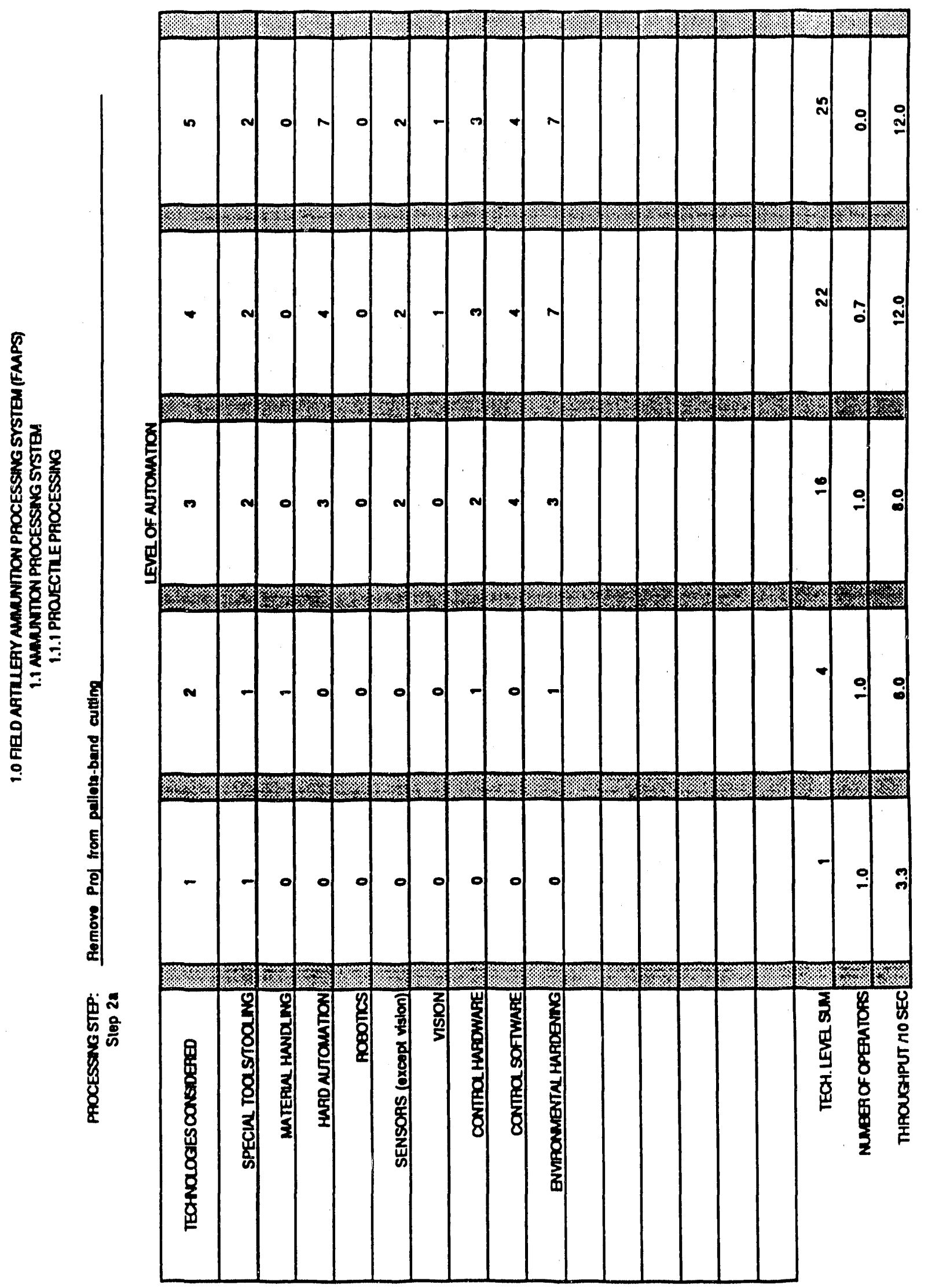




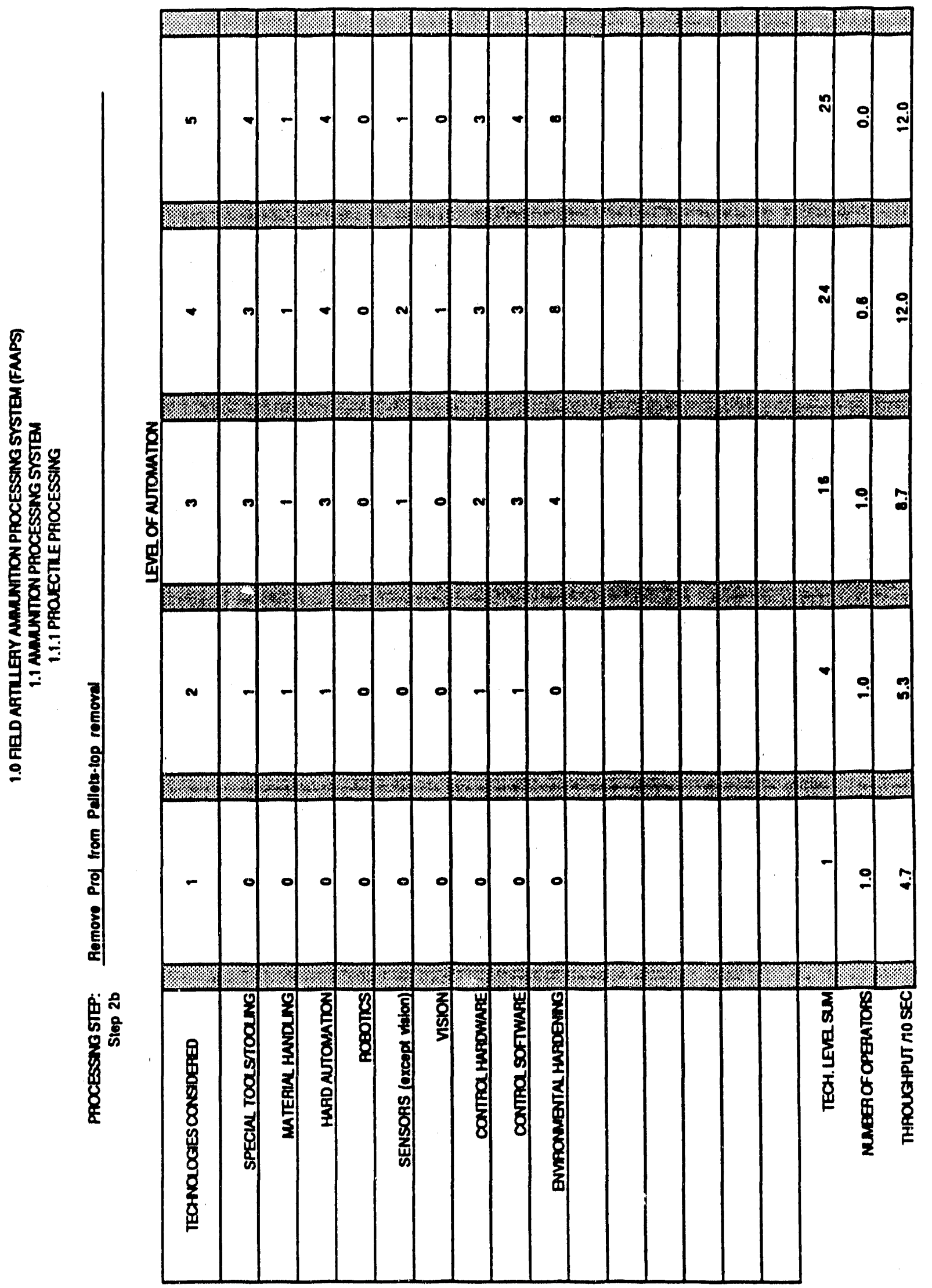




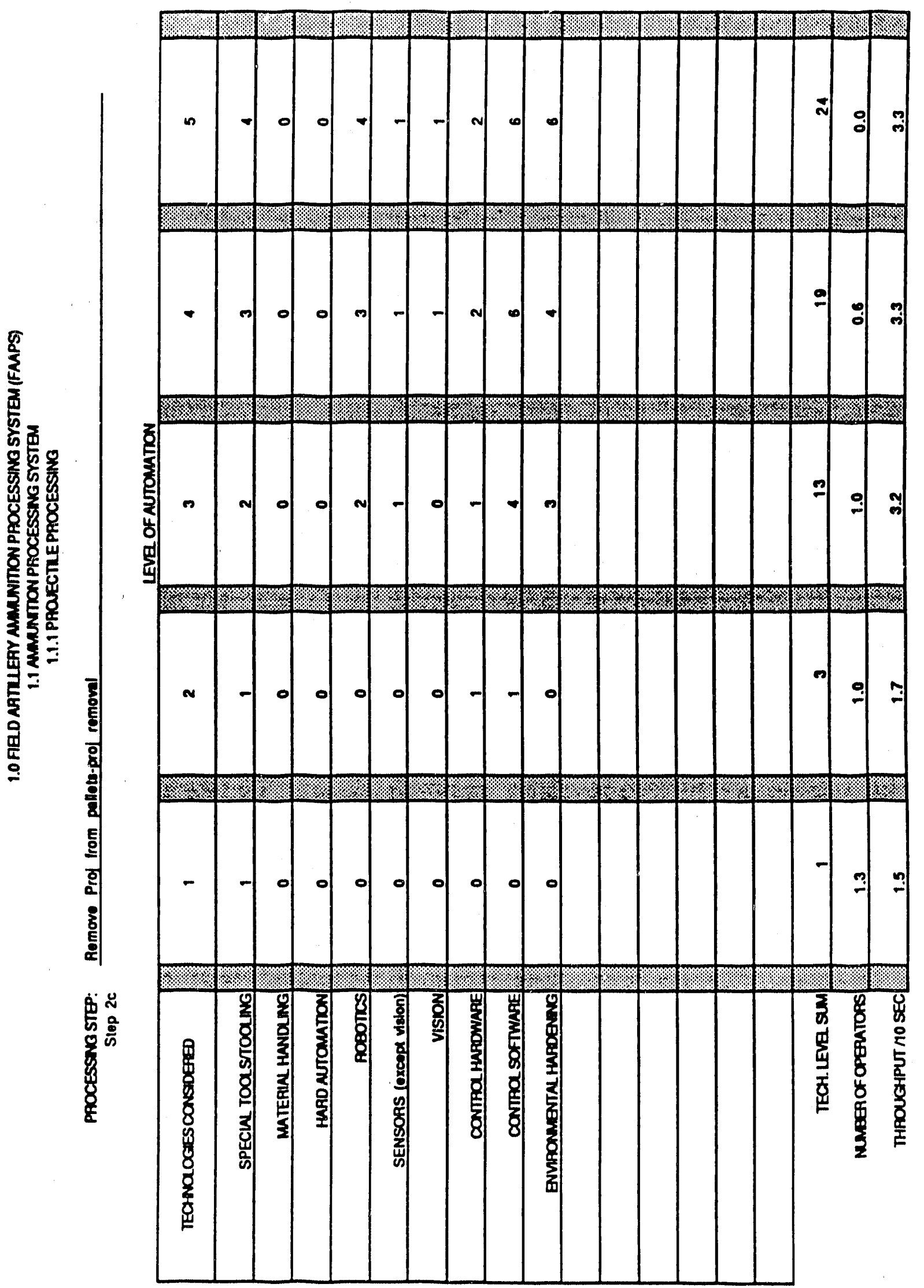




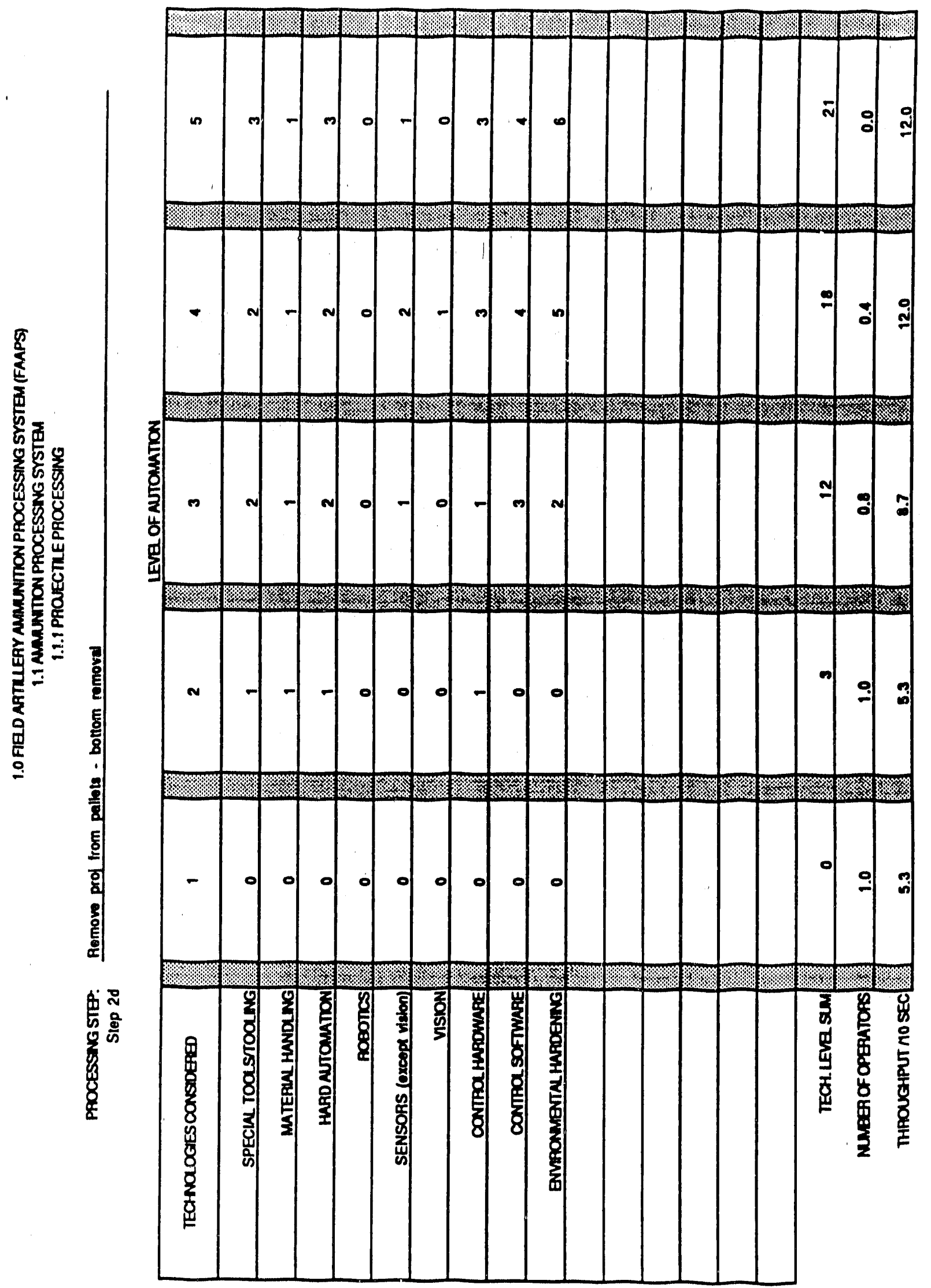




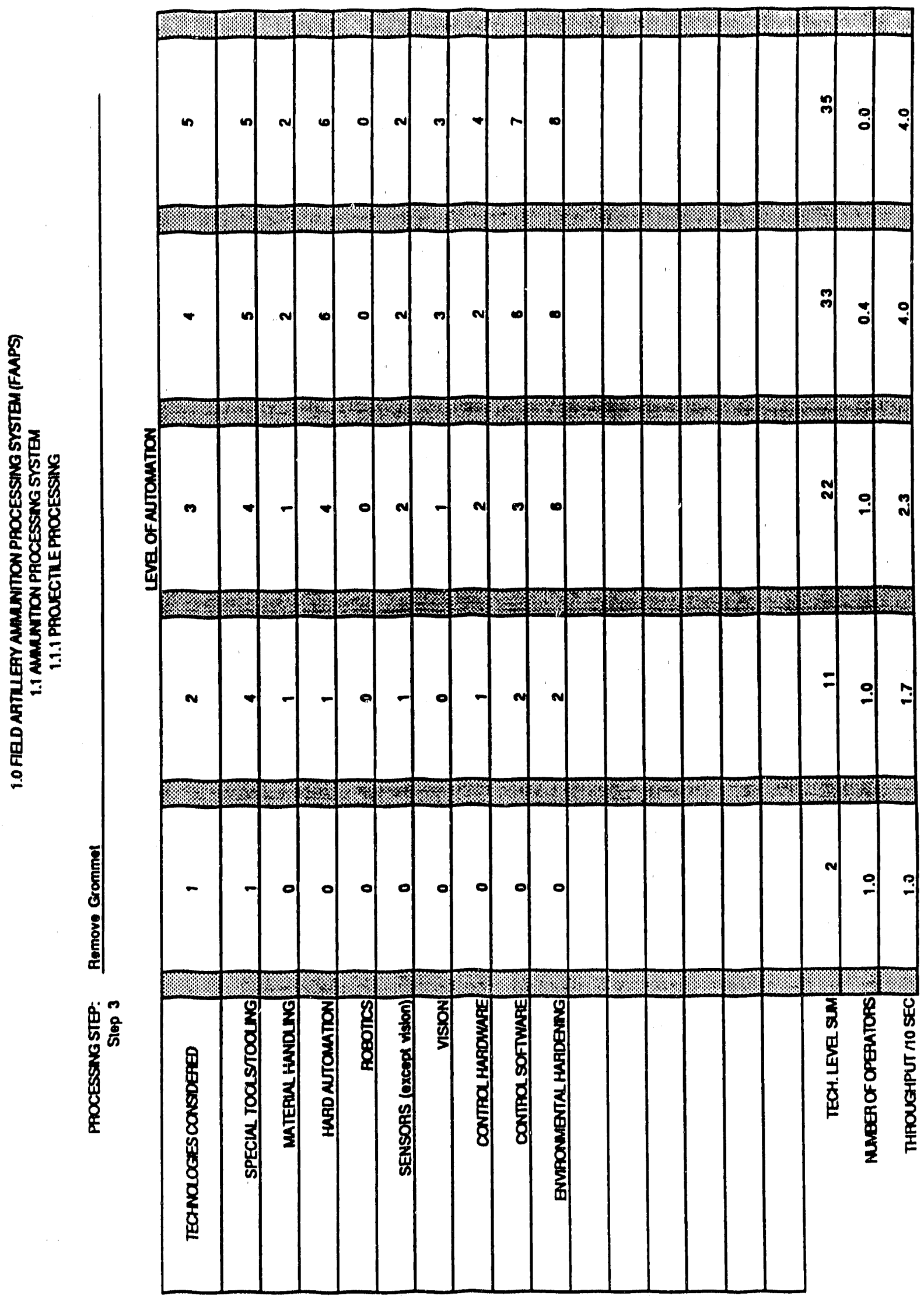




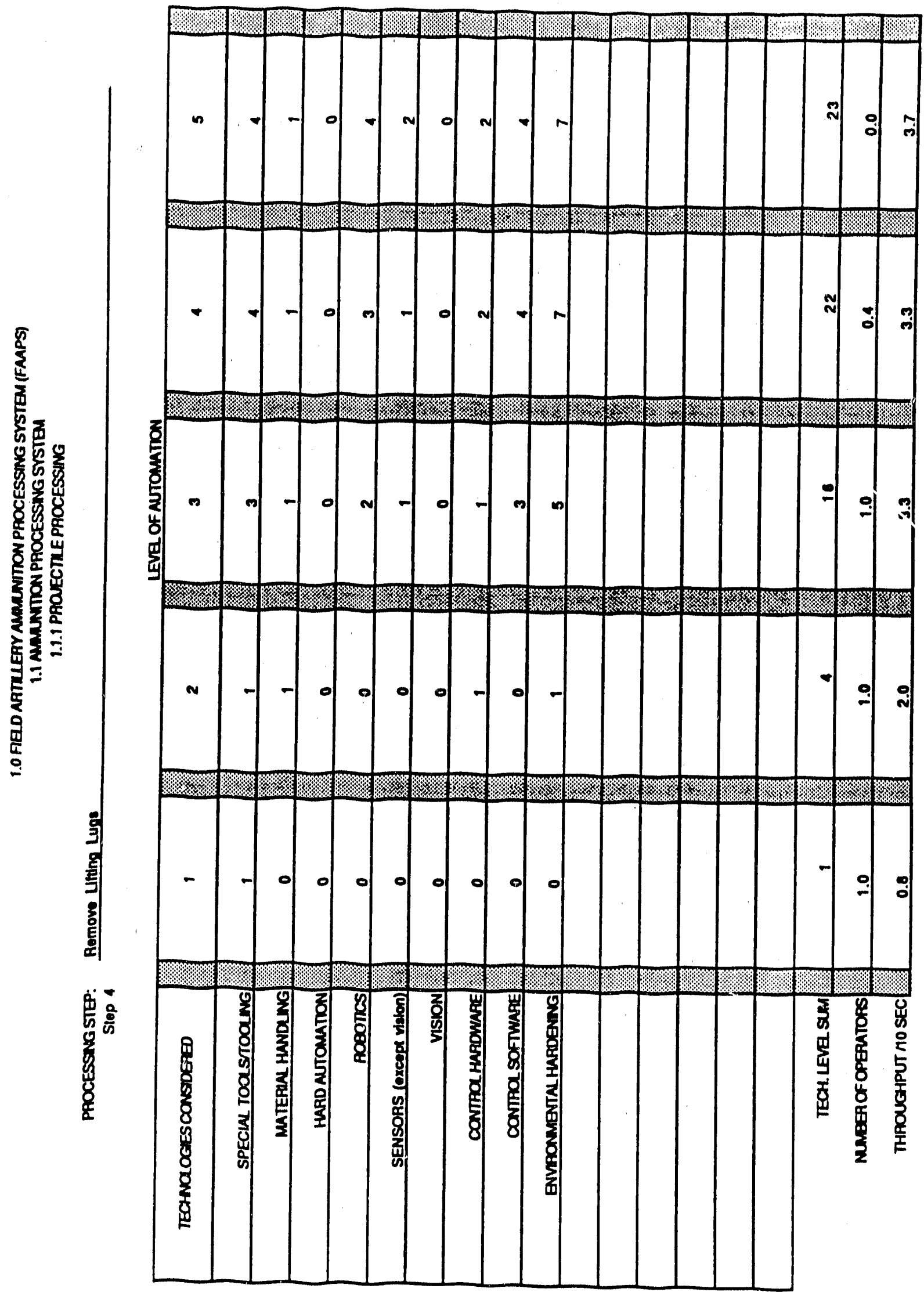




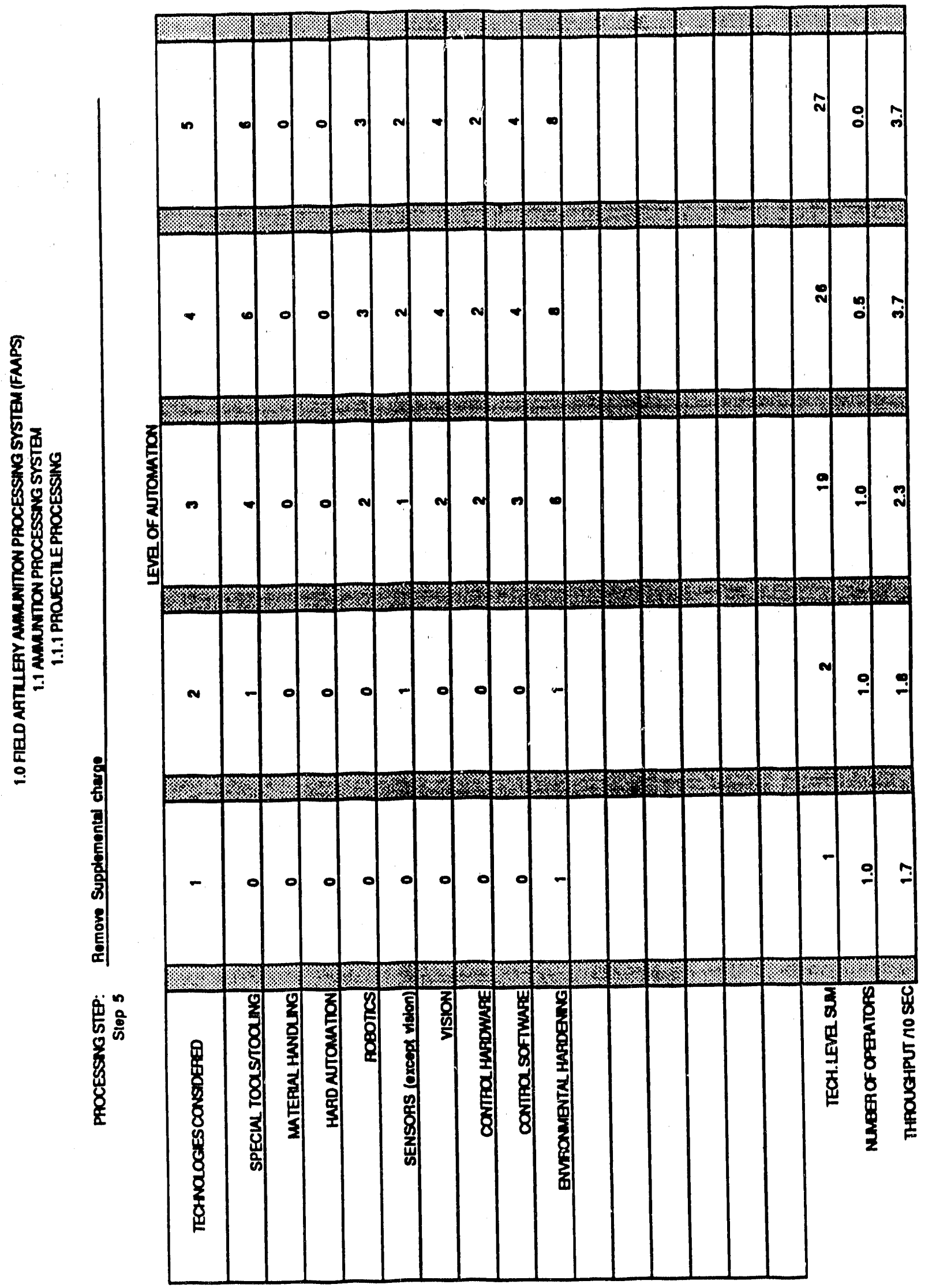




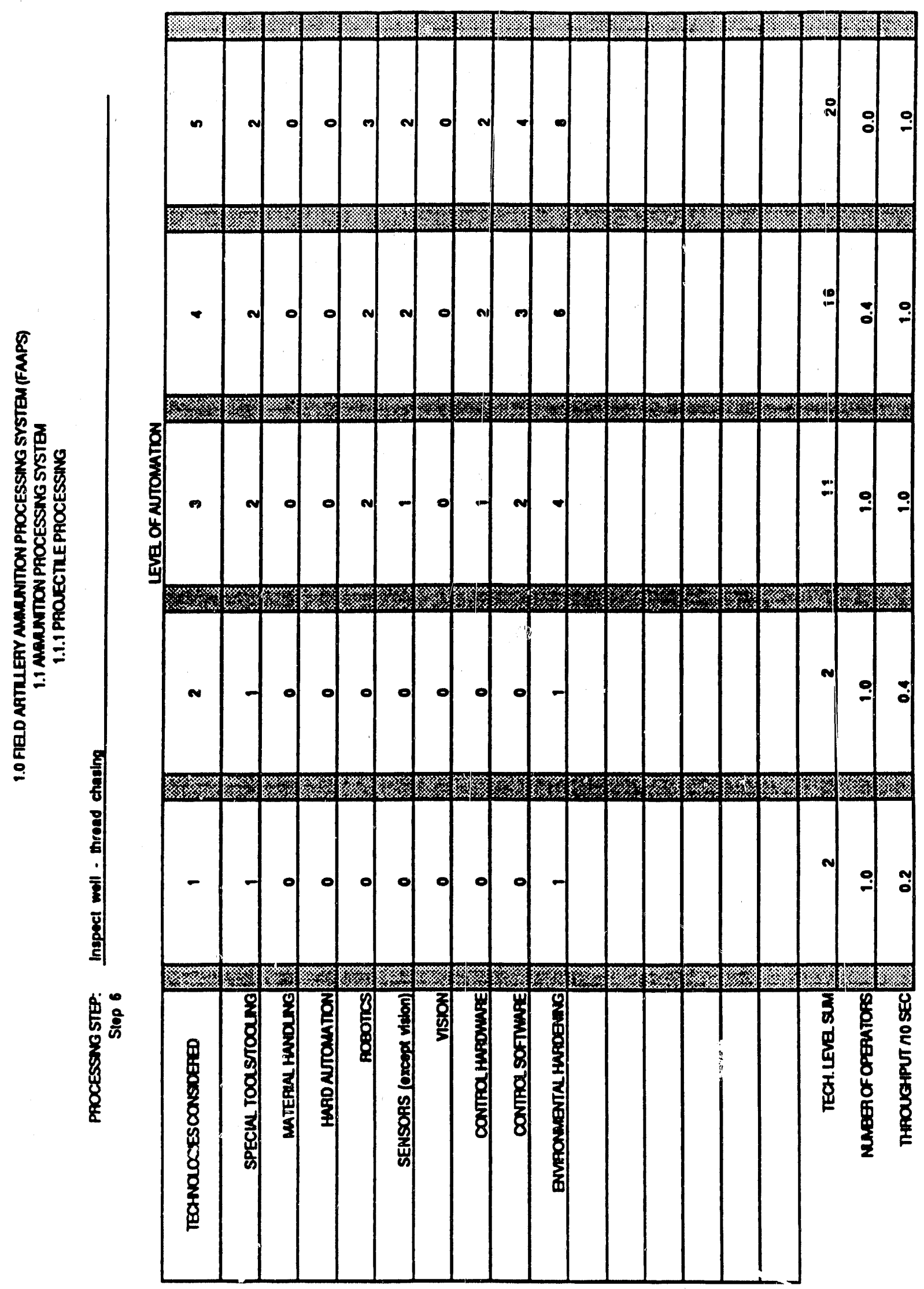




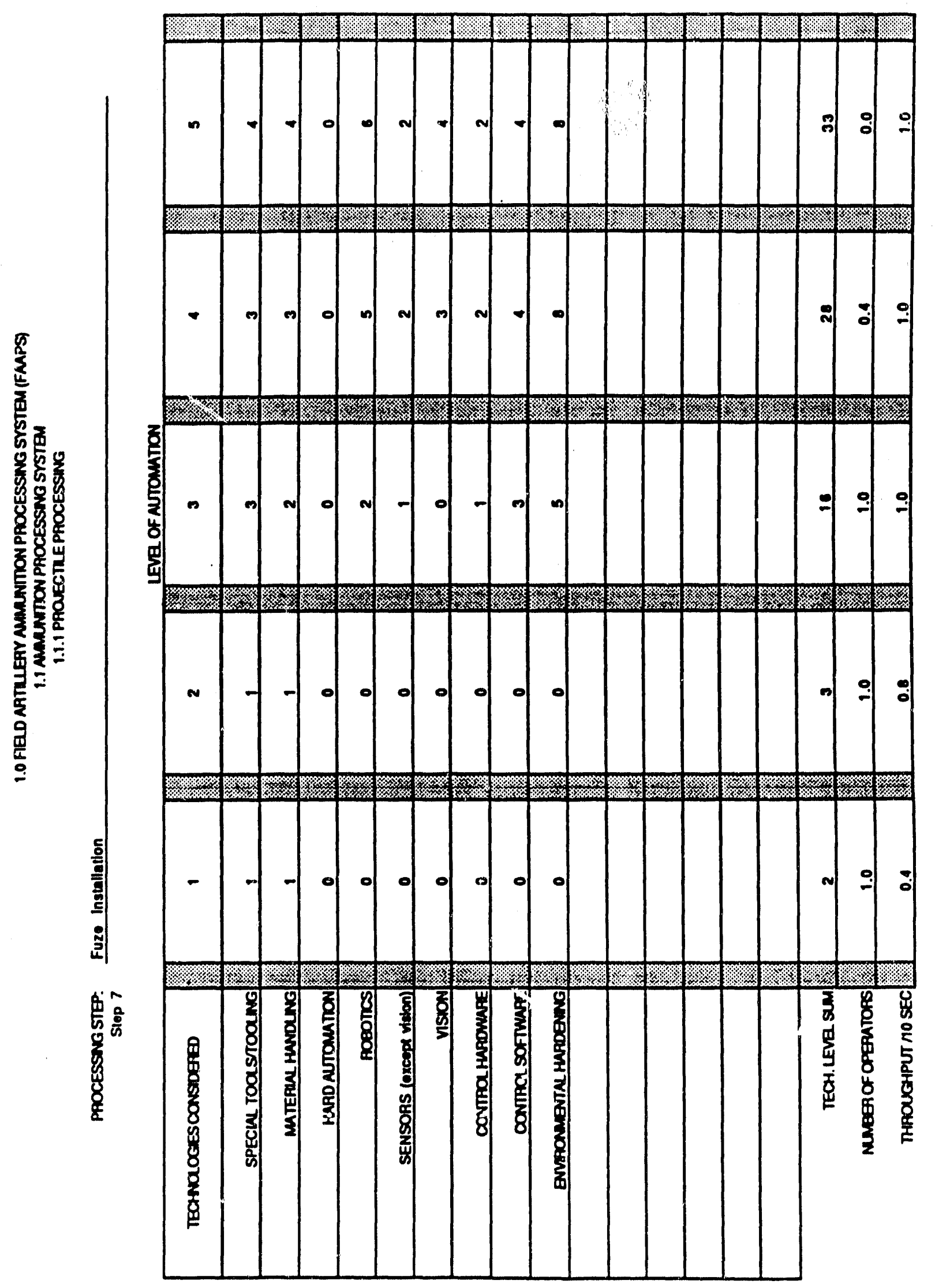




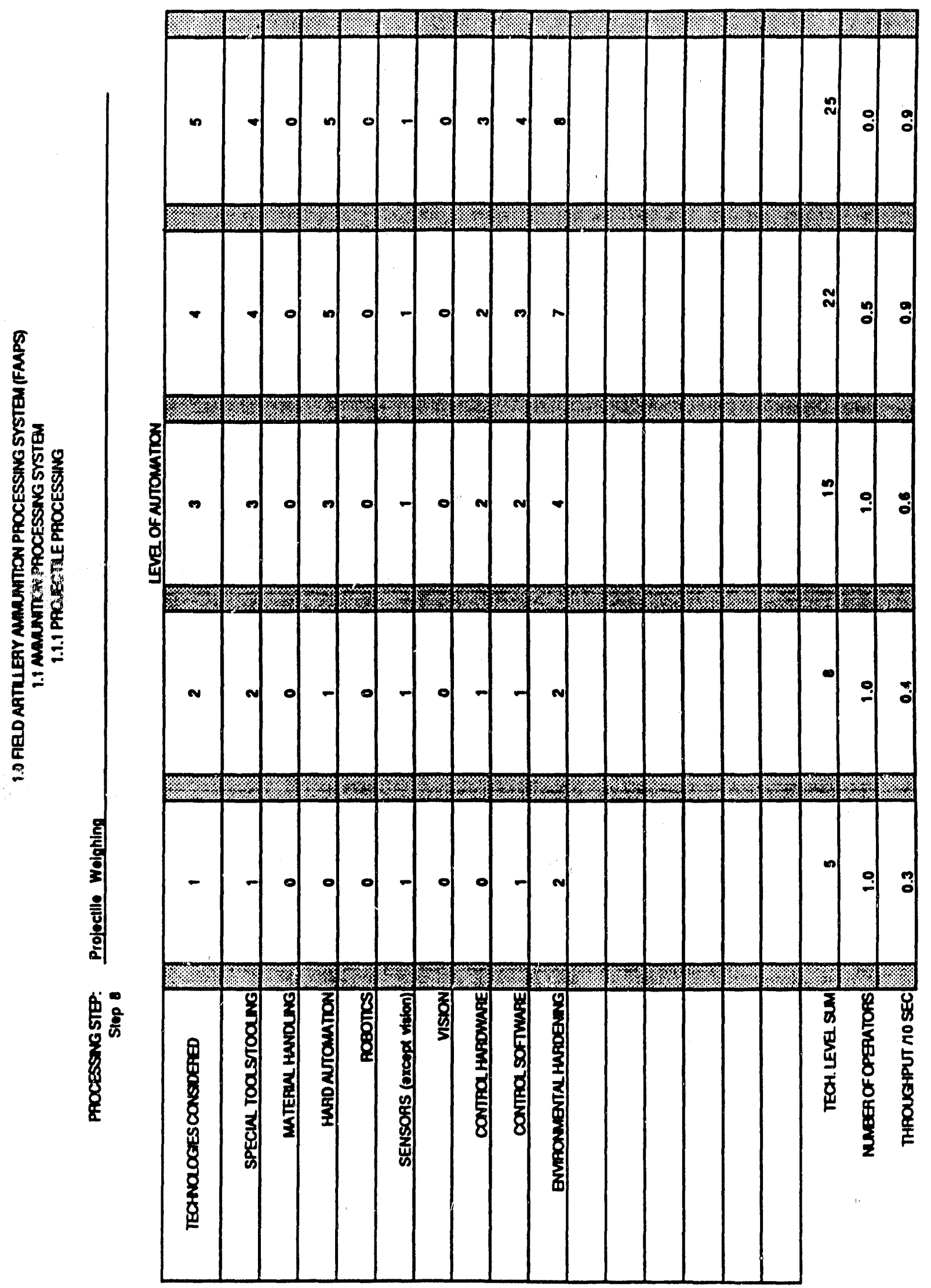




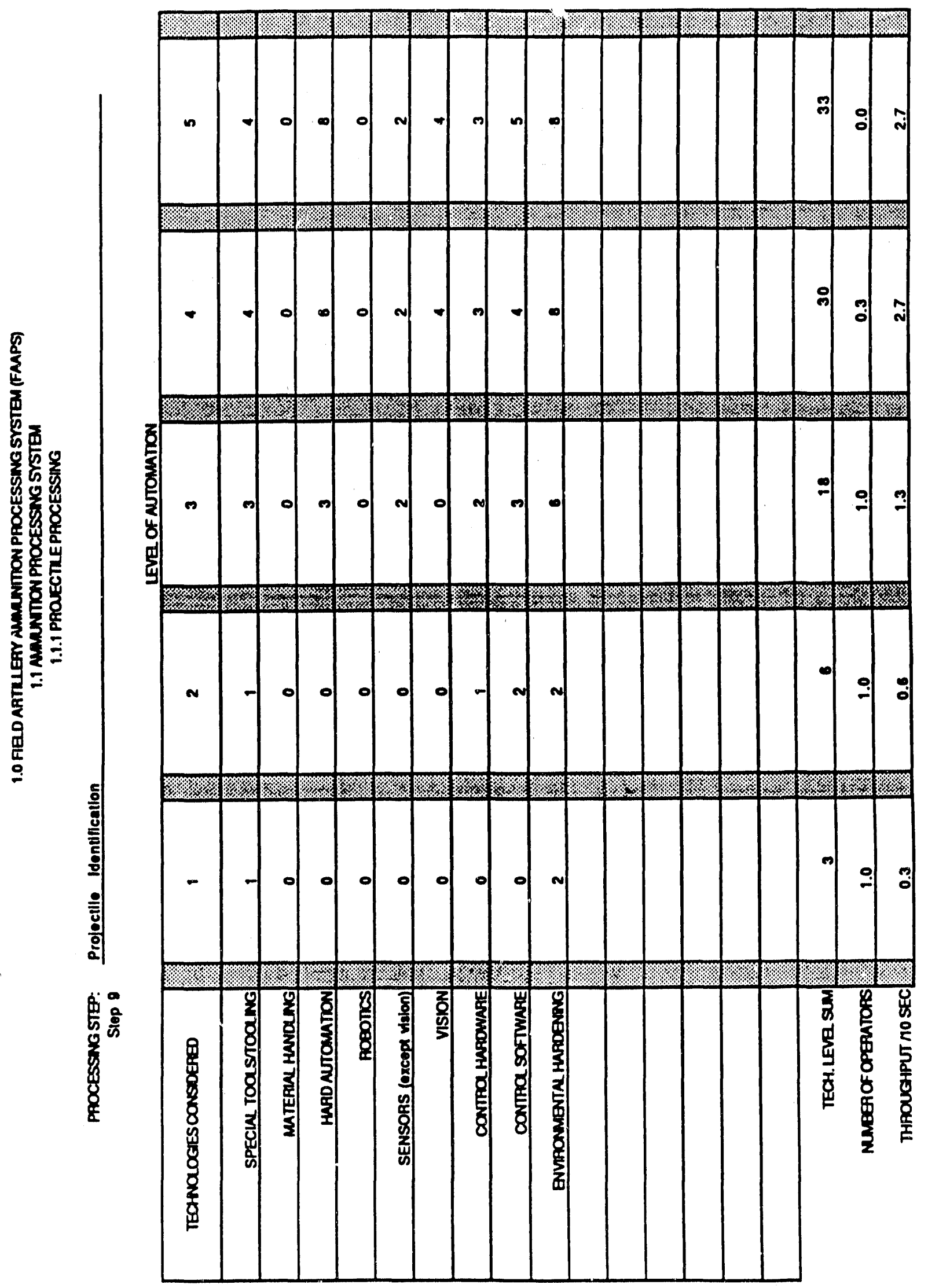




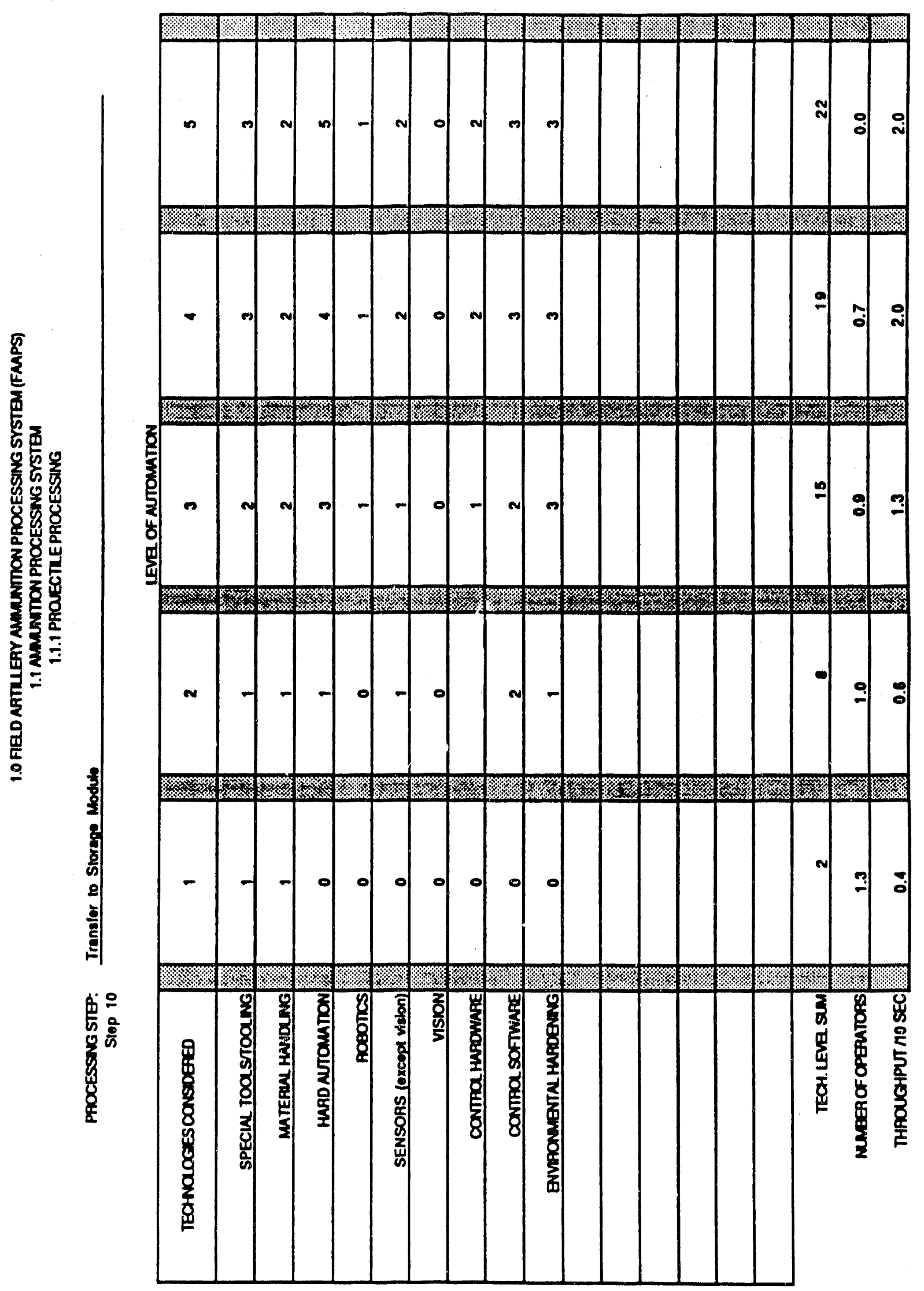




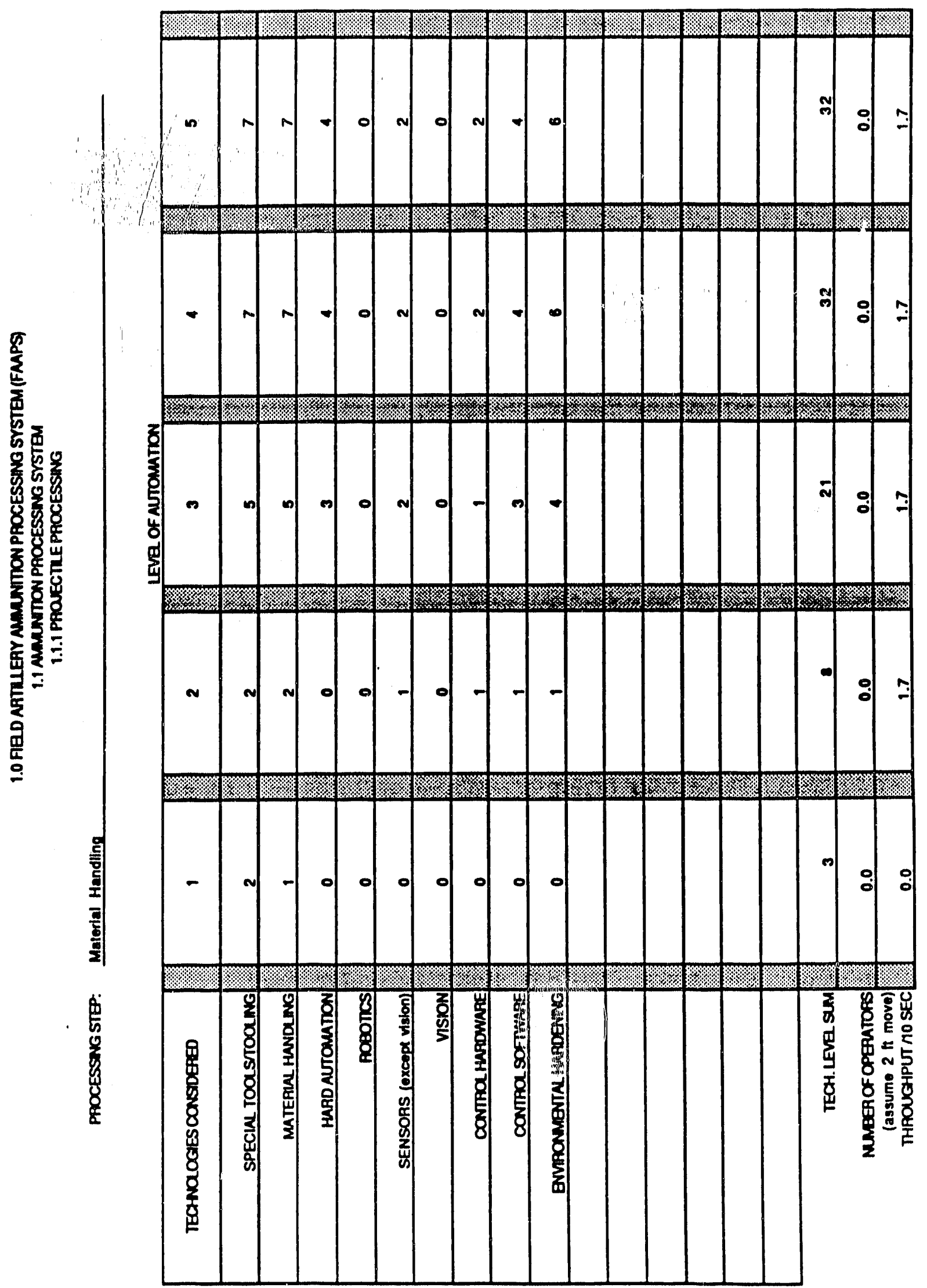




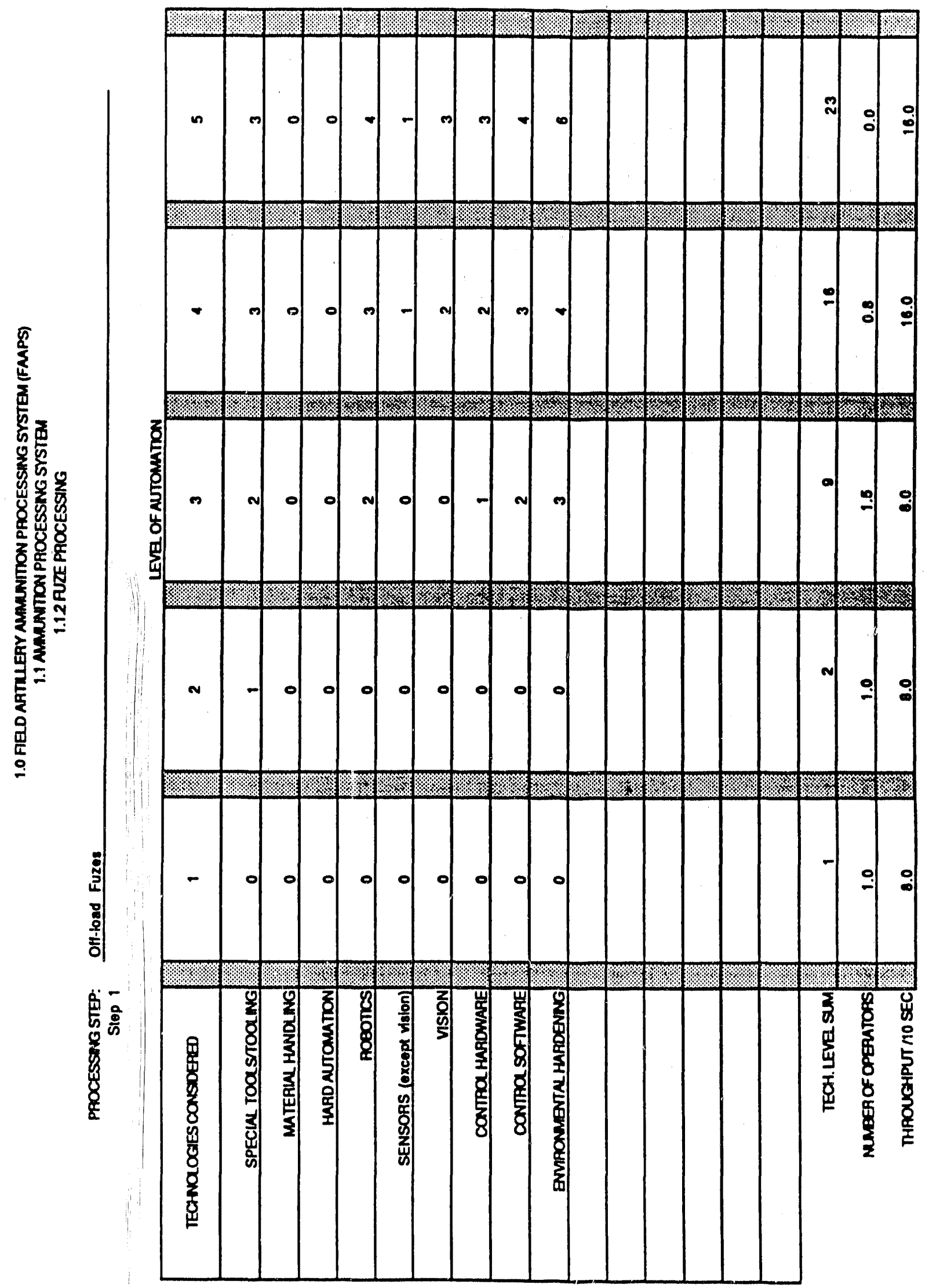




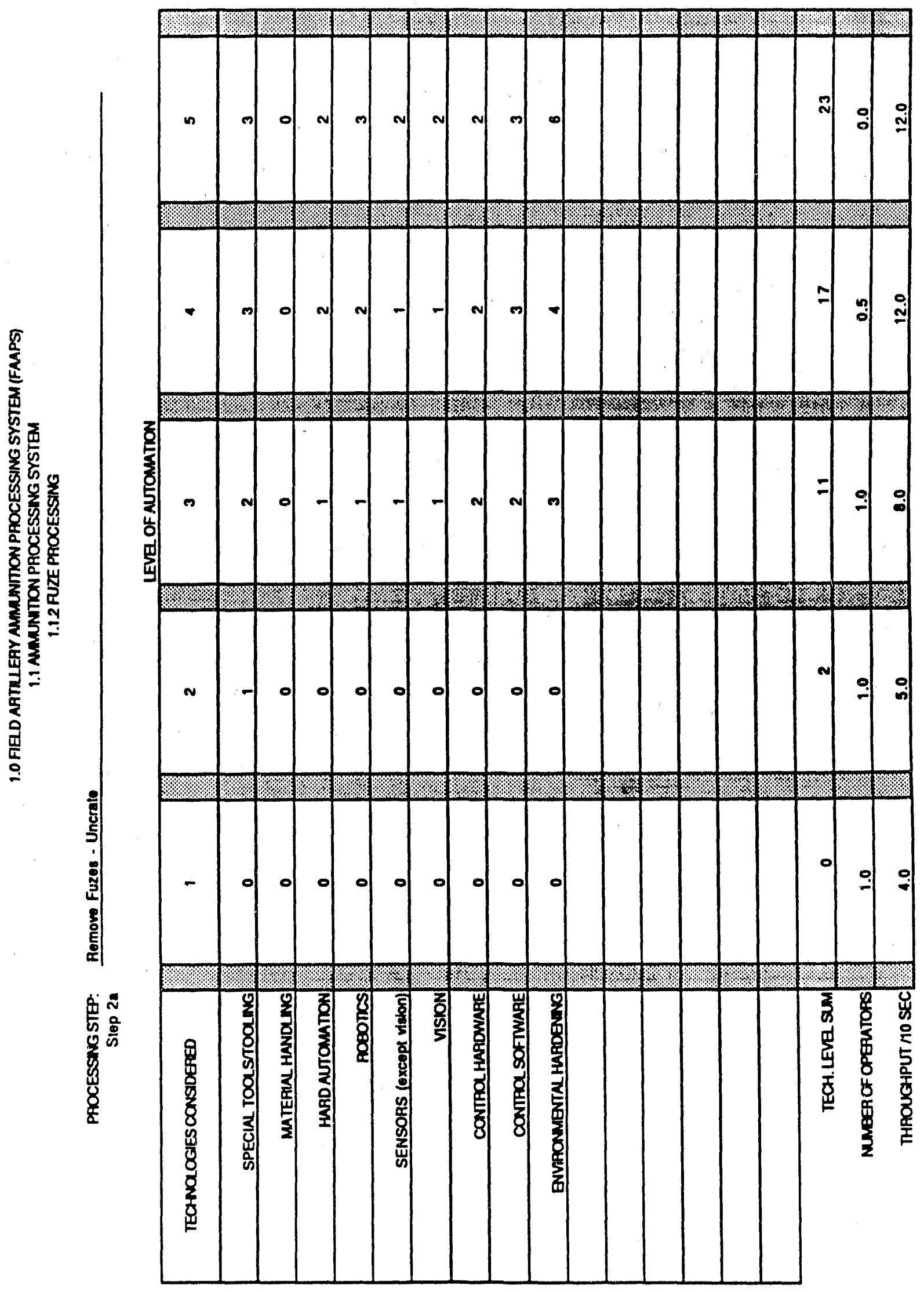




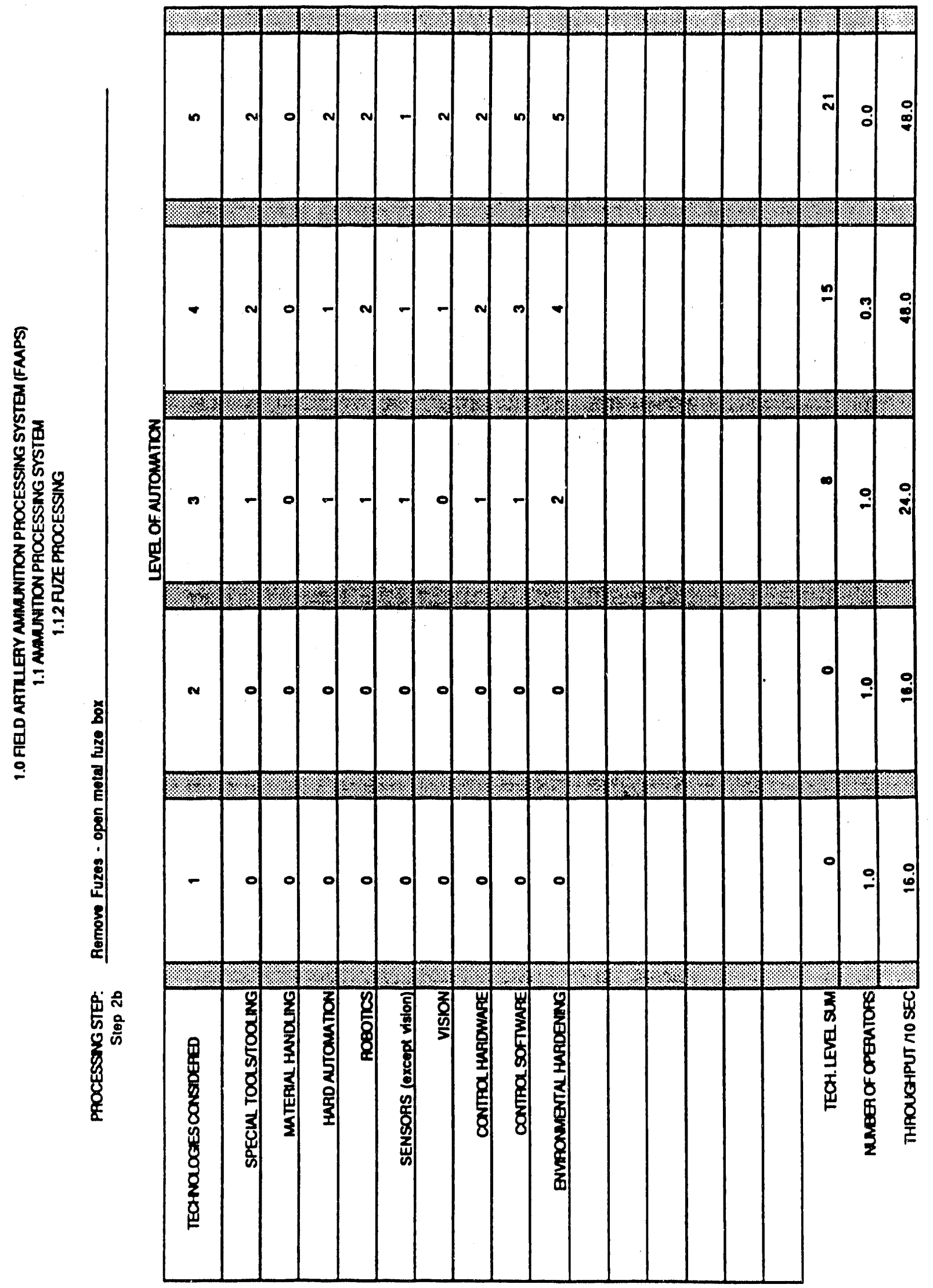




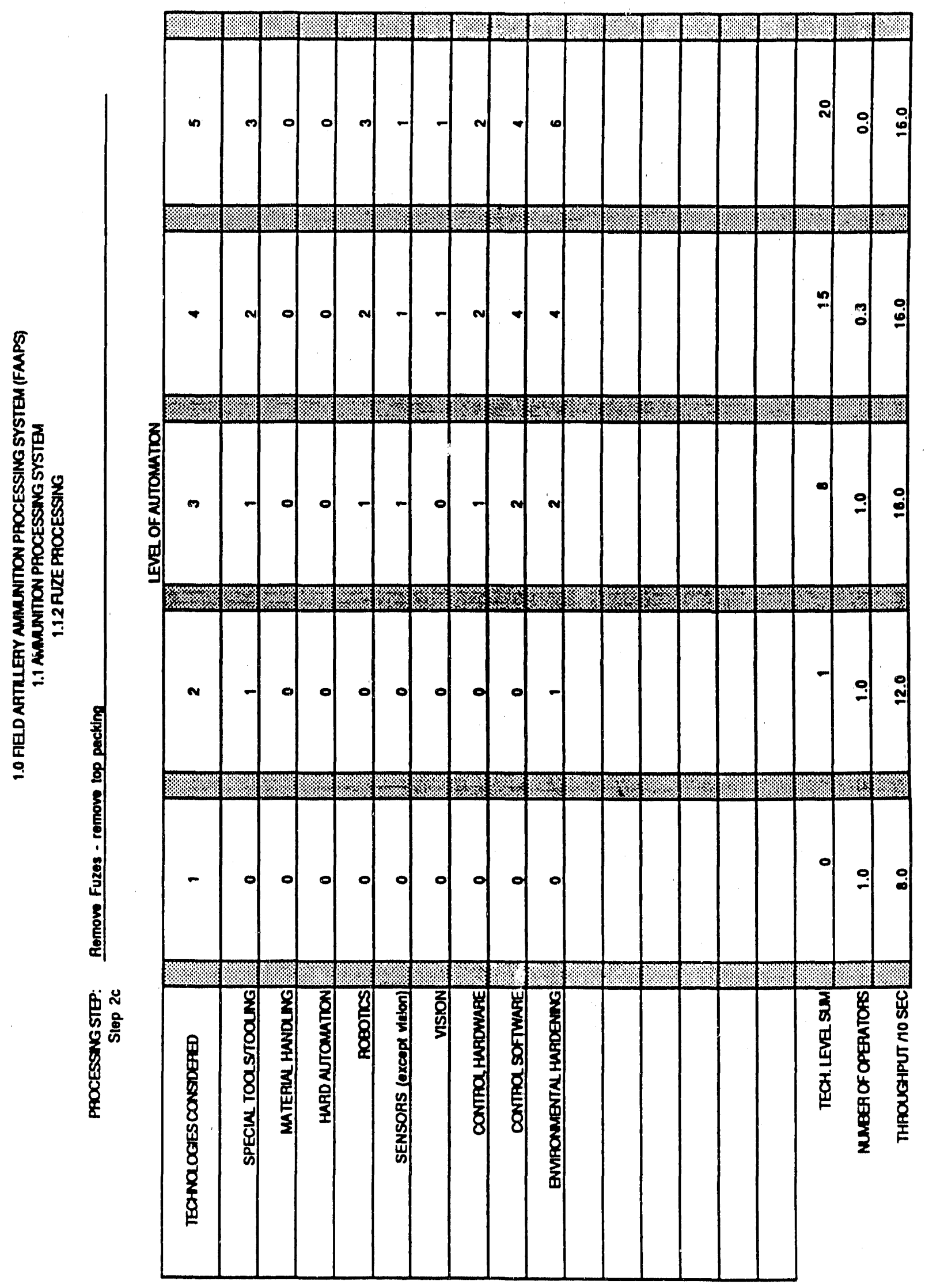




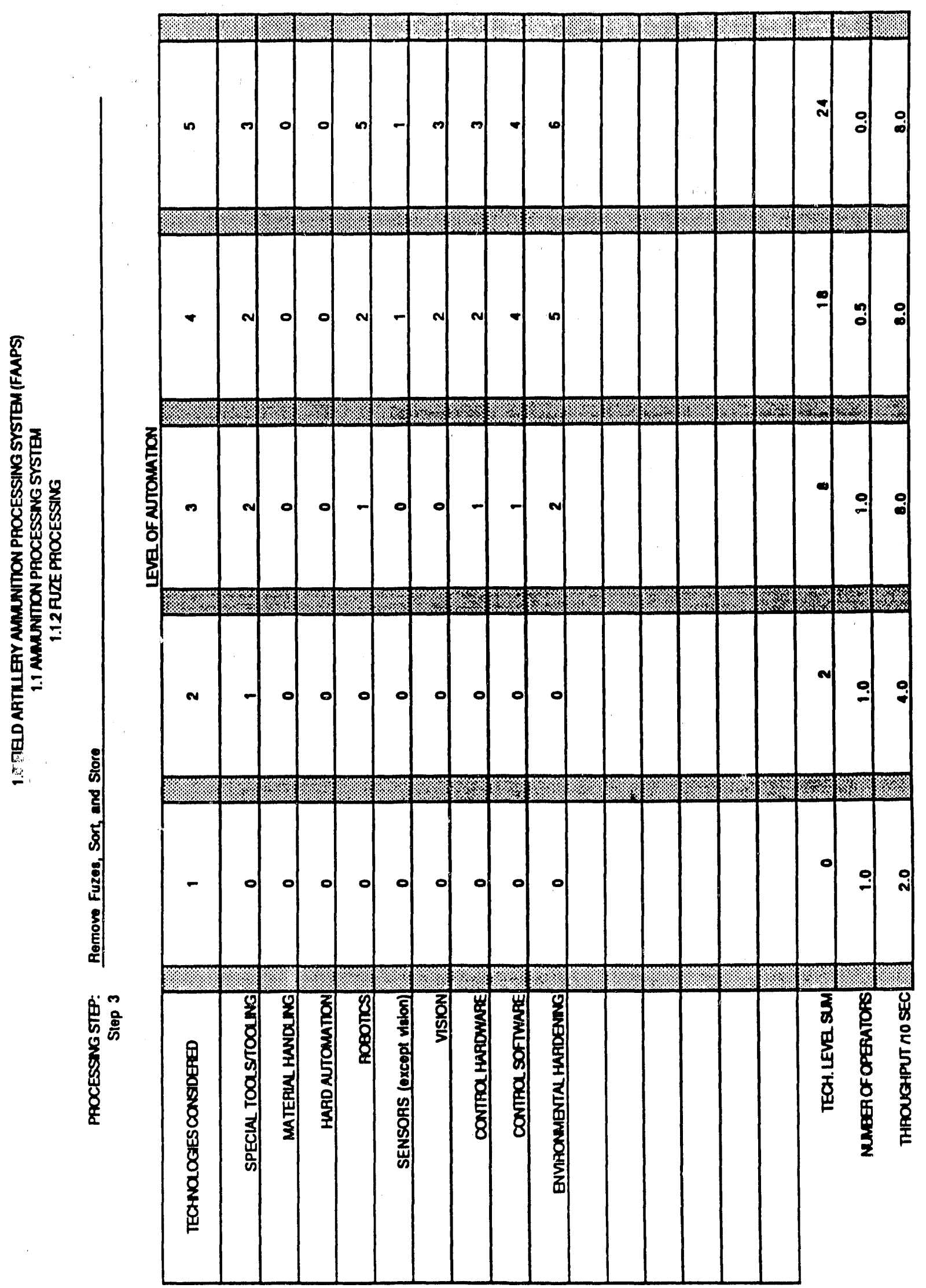




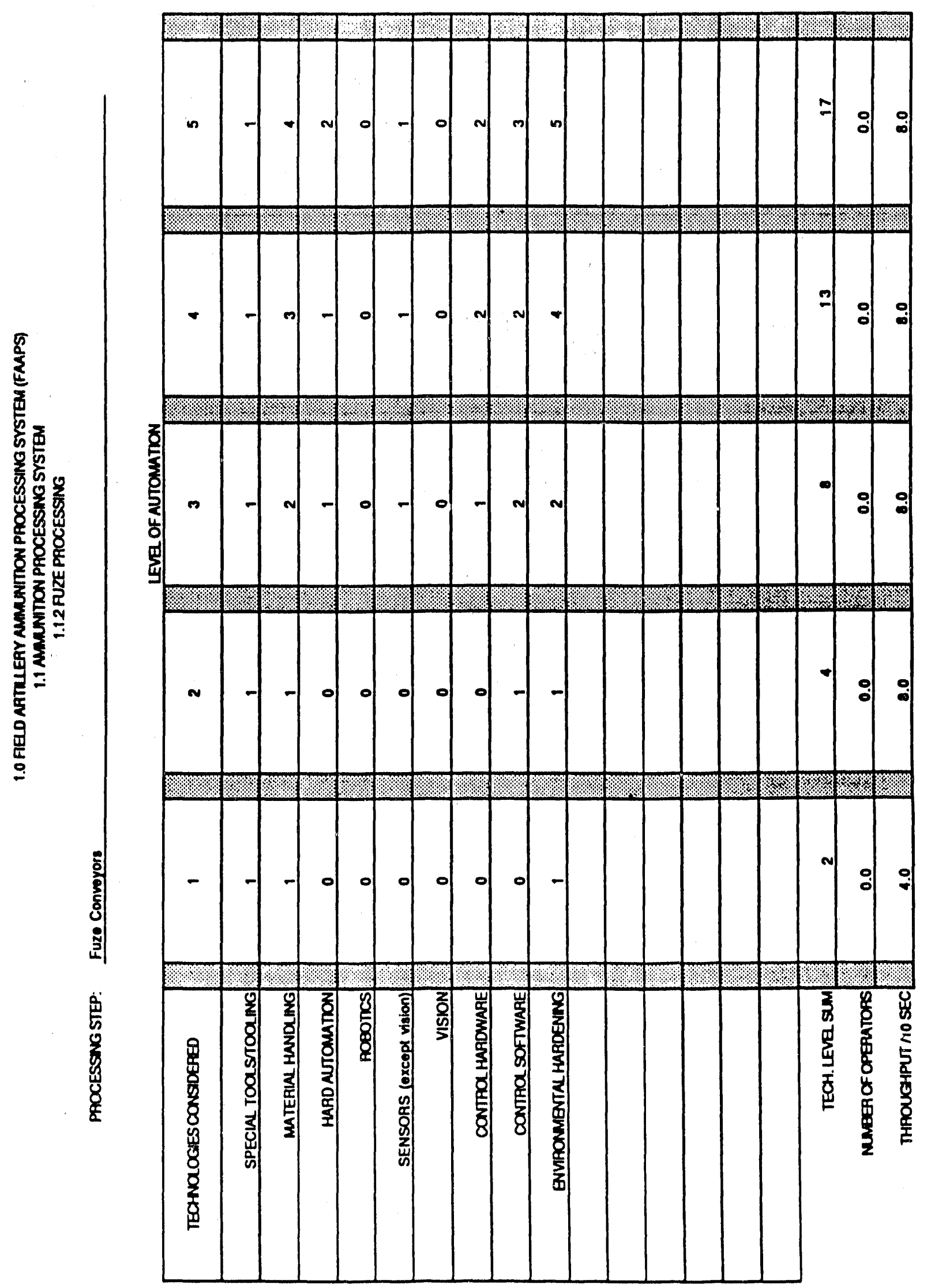




\section{APPENDIX B \\ DETAILS OF POWER REQUIREMENT ESTIMATES}

\begin{tabular}{lccc}
\multicolumn{4}{c}{ Power requirements $(\mathrm{kW})$} \\
\hline Approach & Mechanical/electrical & I\&C & Total \\
\hline Manual & 0 & 2 & 2 \\
Manual/electrical & 6 & 2 & 8 \\
Milan & 11 & 3 & 14 \\
Auto/exist & 31 & 9 & 40 \\
Auto/standard & 24 & 10 & 34 \\
Recommended & 23 & 7 & 30 \\
\hline
\end{tabular}


APPENDIX C

DETAILS OF DEVELOPMENT AND CAPITAL COST ESTIMATES 


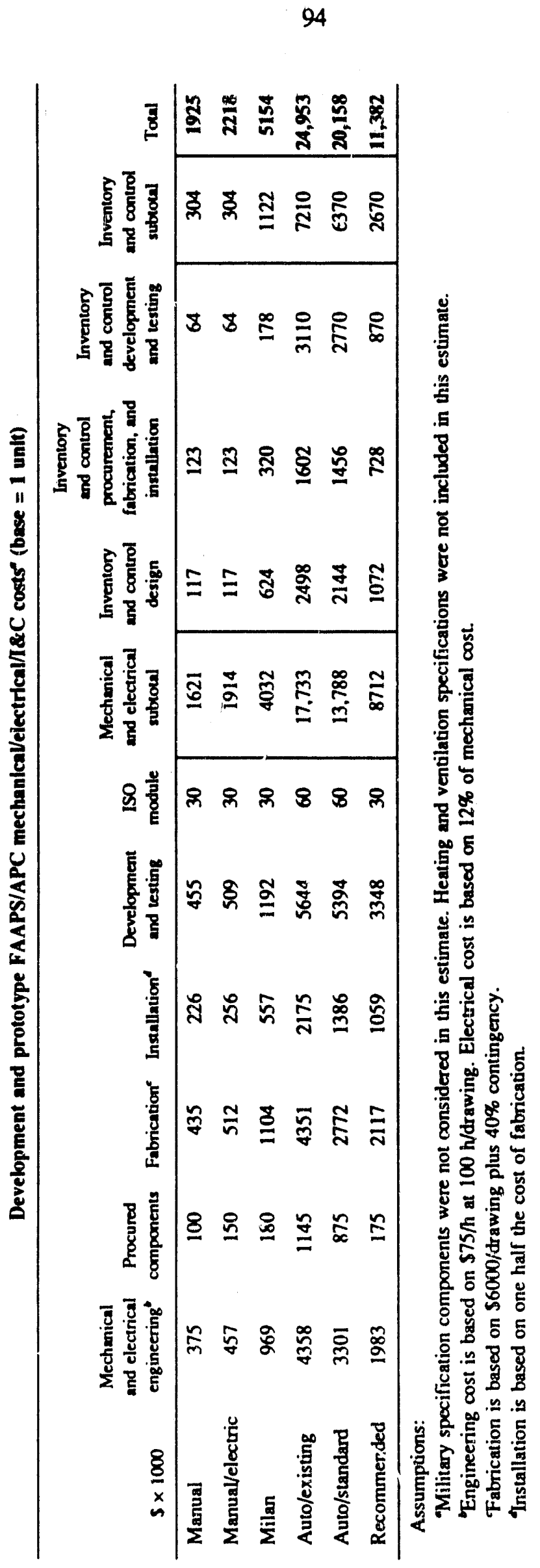




\section{APPEND:X D SPECIAL ISSUES}

Several issues that are of importance to the overall concept evaluation but are not covered elsewhere in the report will be discussed in this appendix. These issues include standardized packaging for all ammunition components and prefuzing of projectiles.

\section{D.1 STANDARDIZED PACKAGING}

The standardization of packaging for projectiles, fuzes, and propellent is an important issue in the selection of a concept. Having to accommodate a multitude of configurations, none of which were designed to be handled by an automated system, while not impossible, certainly makes the system far more complex than otherwise required. Standardization of the projectile pallets, the projectile grommets, and the packing of fuzes could account for a significant reduction in the amount of hardware necessary to automate these steps or the amount of labor required if partially automated or completed manually. The reduction of equipment is illustrated in the fully automated approach that was identified for standardized packaging in Sect. 7. In other concepts presented, the decision to automate versus not to automate certain processes was, in many cases, based on the complexity which resulted from having to deal with multiple configurations. Any standardization that can be acc smplished will result in efficiencies in the overall process as well as improved reliability. This should be identified early in the development of the system to avoid the expenditure of time and money.

\section{D.2 PREFUZING PROJECTILES}

Prefuzing of projectiles will have a significant impact on the complexity of and perhaps even the necessity for FAAPS. In evaluating each of the process steps identified in Sect. 5, prefuzing eliminates all operations associated with the projectile and fuze processing except the following: (1) off-loading of ammunition, (2) removal of projectiles from pallets, and (3) removal of grommets. This assumes the prefuzed projectile has already been weighed and labeled. Numerous scenarios could be considered as a result of prefuzing (several approaches are described below).

One option could greatly reduce the design complexity of FAAPS. It requires the redesign of a standardized pallet (redesign of the pallet is necessary anyway to protect the fuze) to serve a dual function: to contain and protect the fuzed-projectiles and to provide protection for the gas sealing ring thus eliminating the need for a grommet. Essentially all of the projectile processing operations still need to be performed but they can be accomplished under more normal conditions similar to a manufacturing environment, not under batuefield conditions with the associated environmental extremes. The new pallet design could allow easy operation by the soldier, requiring only simple tasks to break down the pallet. 
A second approach could be to automate these steps, as shown in some of the previous concepts. An automated concept dealing with prefuzed projectiles is presented in the following paragraph.

To process fuzed projectiles, it is assumed that a standardized pallet will be used and that the following steps in processing unfuzed projectiles would be unnecessary: (1) any fuze handling or identifying, (2) supplemental charge removal or thread inspection, and (3) weighing and labeling. This concept is shown in Fig. 15. It incorporates two processing lines for greater capacity. A custom-designed jib crane (hoist) with three articulating arms similar to a "Conco" articulated crane or industrial manipulator will be used to off-load the pallets from the supply vehicle to the APC by an operato: outside the module. This 3000-1b capacity jib crane, which is pendant-operated, will be used to off-load pallet from the supply vehicle to the belt conveyor on the APC. Each pallet will be conveyed to the depalletizing mechanism by a powered belt or roller conveyor, then the top will automatically be removed and discarded as dunnage. A bridge-mounted manipulator with $\mathrm{X}-\mathrm{Y}-\mathrm{Z}$ motion and a rotating wrist will convey the projectile from the pallet base by grabbing the projectile at approximately the center of gravity and passes it to the grommet removal station (automatically). It then will rotate the projectile to a horizontal position on a powered roller conveyor which will transfer the projectile to the SM or FARV-A. 


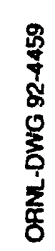
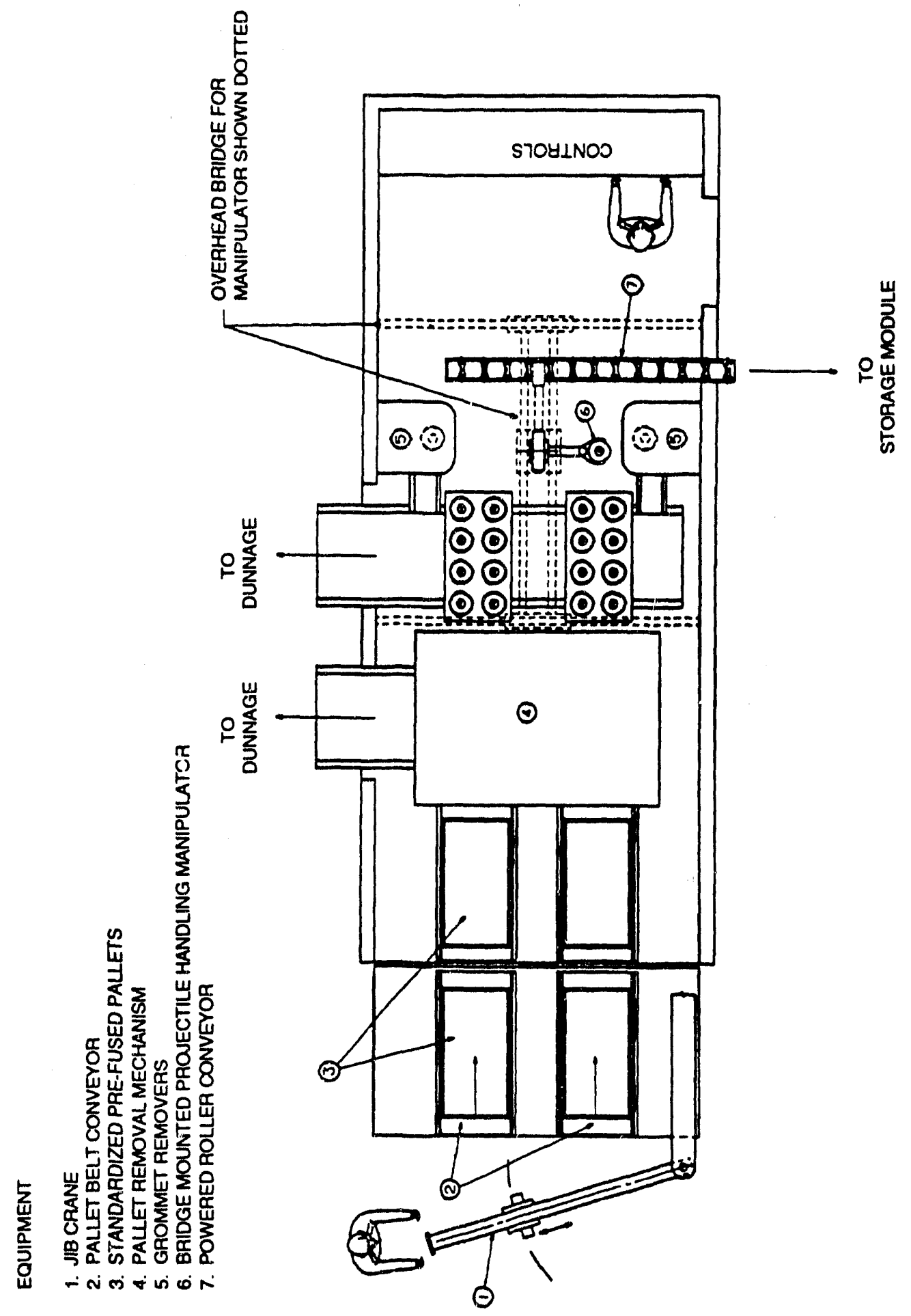

苍 


\section{INTERNAL DISTRIBUTION}

1-5. S. M. Babcock

6. J. B. Chesser

7. J. E. Dunn, Jr.

8. M. J. Haire

9. J. H. Hannah

10. R. T. Jubin

11. T. S. Kress

12-16. C. T. Kring

17. E. H. Krieg, Jr.

18. R. C. Mann

19-21. S. A. Meacham

22. C. F. Metz III

23-25. R. P. Oliver

26. R. E. Norman
27. K. E. Plummer

28. S. L. Schrock

29. B. H. Singletary

30. B. B. Spencer

31. J. C. Walls

32-34. D. C. Watkin

35. B. S. Weil

36-37. Laboratory Records

38. Laboratory Records ORNL-RC

39-40. RPSD Publications Office

41. ORNL Patent Section

42. Central Research Library

43. Document Reference Section

\section{EXTERNAL DISTRIBUTION}

44. Clinton Bastin, Manager, LMR Reprocessing Projects, Division of Fuels and Reprocessing, Office of Facilities, Fuel Cycle, and Test Programs, NE-471, Department of Energy, Washington, DC 20545.

45. L. F. Blankner, Fusion and Nuclear Technology Branch, Energy Programs Division, Department of Energy, X-10 Site, P.O. Box 2008, Oak Ridge, Tennessee 37831-6269.

46. G. Kent, PM-AMMOLOG, HQ ARDEC, AMCPM-AL Picatinny Arsenal, Dover, New Jersey 07801-5001.

47. R. J. Kuper, Chief, Packaging Division, SMCAR-AEP, Picatinny Arsenal, New Jersey 07806 5000 .

48. J. Miemis, Office of the Project Manager for Ammunition Logistics, AMCPM-AL Building 455, Picatinny Arsenal, New Jersey 07806-5000.

49-53. D. S. Scarborough, PM-AMMOLOG, HQ ARDEC, AMCPM-AL Picatinny Arsenal, Dover, New Jersey 07801-5001.

54. Col. T. Tobin, PM-AMMOLOG, HQ ARDEC, AMCPM-AL Picatinny Arsenal, Dover, New Jersey 07801-5001.

55. Office of Assistant Manager for Energy Research and Development, Oak Ridge Operations Office, Department of Energy, P.O. Box 2008, Oak Ridge, Tennessee 37831-6269.

56-57. Office of Scientific and Technical Information, P.O. Box 62, Oak Ridge, Tennessee 37831. 

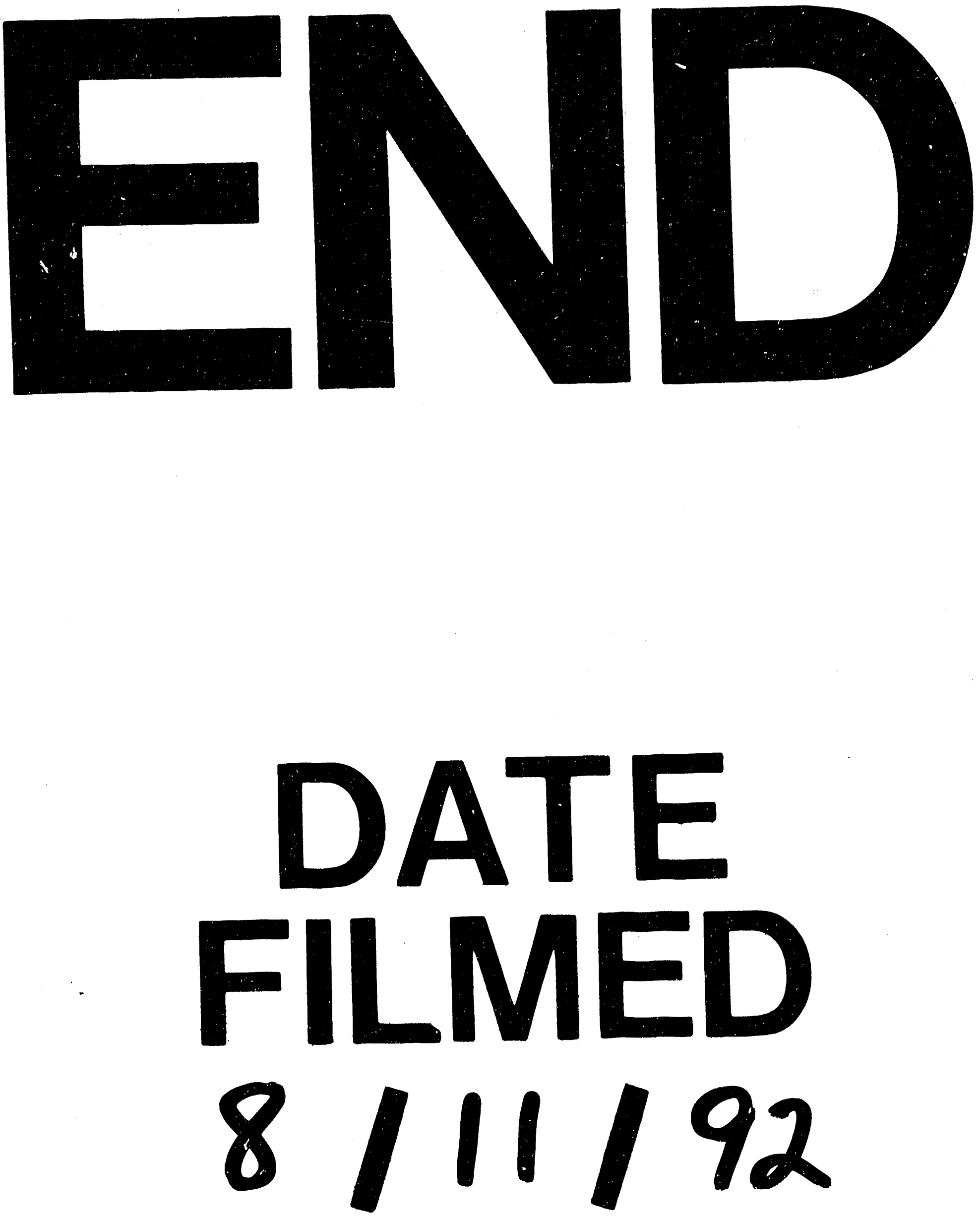
